University of Rhode Island

DigitalCommons@URI

Open Access Dissertations

1989

\title{
THE EFFECTS OF ALBUTEROL AND CHRONIC ANTIDEPRESSANTS ON INTRACRANIAL SELF-STIMULATION REWARD THRESHOLDS
}

Robert Louis Dufresne

University of Rhode Island

Follow this and additional works at: https://digitalcommons.uri.edu/oa_diss

\section{Recommended Citation}

Dufresne, Robert Louis, "THE EFFECTS OF ALBUTEROL AND CHRONIC ANTIDEPRESSANTS ON

INTRACRANIAL SELF-STIMULATION REWARD THRESHOLDS" (1989). Open Access Dissertations. Paper 146.

https://digitalcommons.uri.edu/oa_diss/146

This Dissertation is brought to you for free and open access by DigitalCommons@URI. It has been accepted for inclusion in Open Access Dissertations by an authorized administrator of DigitalCommons@URI. For more information, please contact digitalcommons-group@uri.edu. 
THE EFFECTS OF ALBUTEROL AND CHRONIC ANTIDEPRESSANTS ON INTRACRANIAL SELF-STIMULATION REWARD THRESHOLDS

\author{
BY \\ ROBERT LOUIS DUFRESNE
}

A DISSERTATION SUBMITTED IN PARTIAL FULFILLMENT OF THE REQUIREMENTS FOR THE DEGREE OF DOCTOR OF PHILOSOPHY

IN

PHARMACOLOGY AND TOXICOLOGY

\author{
UNIVERSITY OF RHODE ISLAND
}

1989 


\section{DOCTOR OF PHILOSOPHY DISSERTATION OF ROBERT LOUIS DUFRESNE}

Approved:

Dissertation Committee

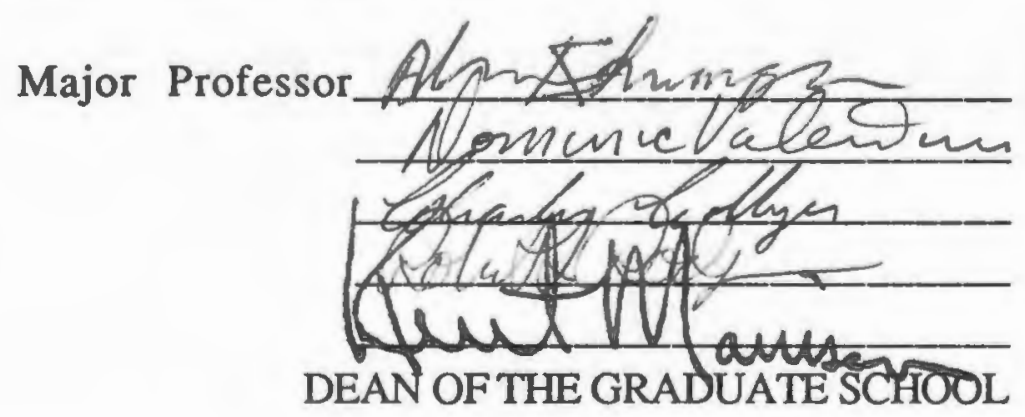

UNIVERSITY OF RHODE ISLAND 1989 


\begin{abstract}
Male Sprague Dawley rats implanted with bipolar stainless steel electrodes aimed at the medial forebrain bundle at the level of the hypothalamus were trained to self administer a rewarding current on a 20:10 DRP operant schedule. A procedure based on the psychophysical method of limits was used to determine the threshold of self administration for this stimulus. The effects of the $B_{2}$-agonist albuterol (salbutamol) on threshold, rearing, and motor activity were examined prior to and after a 19 day period of daily administration of either desipramine $10 \mathrm{mg} / \mathrm{kg}$, fluoxetine $10 \mathrm{mg} / \mathrm{kg}$, or saline.

Acute administration of albuterol $10 \mathrm{mg} / \mathrm{kg}$ caused a significant increase in thresholds and decrease in motor activity and rearing when compared to the three saline days prior to and post administration. Rats tested after 19 days of receiving desipramine daily or saline showed a similar increase in threshold when dosed with the albuterol $10 \mathrm{mg} / \mathrm{kg}$ while the group treated with fluoxetine $10 \mathrm{mg} / \mathrm{kg}$ daily did not. The albuterol caused a pronounced drop in motor activity and rearing regardless of prior chronic drug treatment. These results are consistent with a down regulation of B2-receptors by chronic administration of fluoxetine but not by desipramine or saline.

Acute administration of desipramine, fluoxetine, or saline did not cause any change in self stimulation threshold, though decreases in horizontal motor activity were seen with the antidepressants but not saline. Chronic daily administration of these antidepressants for
\end{abstract}


19 days resulted in a decrease in motor activity over time as compared to the saline treated animals. However, thresholds for rewarding stimulation were not affected by chronic treatment with antidepressant. 


\section{Acknowledgement}

There are many who have made this work possible. I would like to thank my major professor Al Swençer for his aid in helping me navigate through graduate school and for his assistance in helping me design and perfect the write-up of these studies. I would like to thank Charles Collyer and Bob Rogers, who have served on my committee and provided me with valuable feedback on my work. I would like to thank Wayne Velicer for the training in statistics he has provided me through several courses and informal meetings, which has been invaluable in all my professional work. I would also like to thank Drs. Chichester, Weber, Smith, Babson, and Willis who have, at various times, agreed to sit through my oral and dissertation defenses. I would like to thank Tony Riccitelli for efforts in the laboratory, which helped make possible this and other projects.

A special degree of gratitude I reserve for Dom Valentino, who has supervised my research in the laboratory. His influence on my professional development not only includes the present work, but extends throughout much of my past research and my training. I thank him for his excitement concerning the scientific process, his willingness to teach and share his knowledge, his concern for his students, his belief in excellence, his patience, his integrity, his inexhaustible effort in our projects together, and perhaps most of all, his sense of humor which greatly aided in my being able to finish this project. 
Most importantly, I must thank my wife Gina, who has not only tolerated the $\mathrm{m}$. iy hours that my graduate work has taken from our time together, but has encouraged me and done everything in her power to make the journey we are on a pleasant one. 


\section{Preface}

The study descibed was undertaken in order to examine the effects of acute and chronic administration of antidepressants on reward capacity and motor activity in rats. Additionally, the effects of the $B_{2}$-adrenergic agonist albuterol was examined in order to determine its effect on reward capacity and on motor activity. Finally, the potency of the $B_{2}$-adrenergic agonist albuterol in changing thresholds and motor activity after chronic treatment with antidepressants was studied in order to see if $B_{2}$-adrenergic receptor down-regulation caused by the antidepressants fluoxetine and desipramine was evident in lessened response to the $B_{2}$-adrenergic agonist. 


\section{Table of Contents}

INTRODUCTION

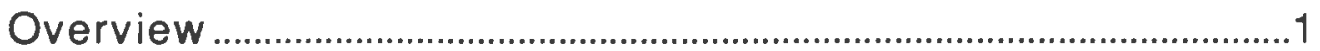

Theories of the Mechanism of Antidepressant Action................3

Catecholamine Hypothesis ........................................................3

Adrenergic Receptor Subsensitivity Hypothesis...............4

Approaches to Identifying Antidepressant Compounds................5

Techniques Based on Neurochemical Activity......................6

Animal Models Based on Behavioral Theories of

Depression ....................................................................................8

A Neurobehavioral Approach Using Self-Stimulation

Techniques.....................................................................................

ICSS techniques: Understanding the neurophysiology

of reward and depression .............................................................11

Depression as a Reward Deficit Syndrome ...............11

Early Attempts to Measure Reward Using Rate

Techniques.........................................................................12

Rate Independent Techniques.........................................14

The ICSS Threshold Procedure as an Animal Model of Depression ...............................................................................16

Prior studies of Antidepressant Activity using ICSS

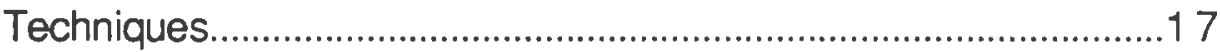

The Experiments of this Dissertation..................................19

METHODS

Summary of the Hypothesis of this Study..........................20

Apparatus

Implantation of Electrodes...........................................................23

Procedure for Determining Thresholds.........................................2 3

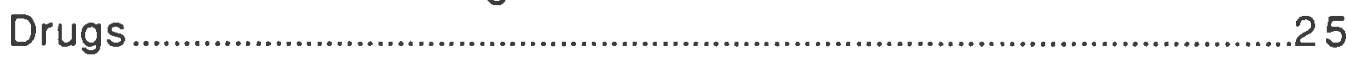

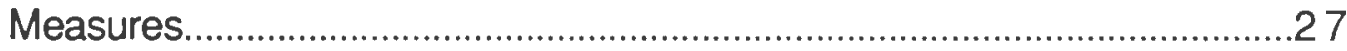

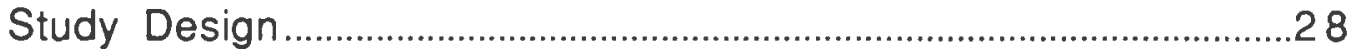

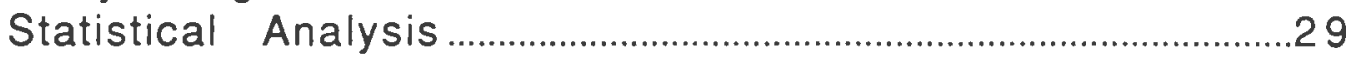

RESULTS

Tests of Albuterol effects prior to chronic antidepressant treatment ..................................................................31

Tests of Albuterol effects after chronic antidepressant treatment.

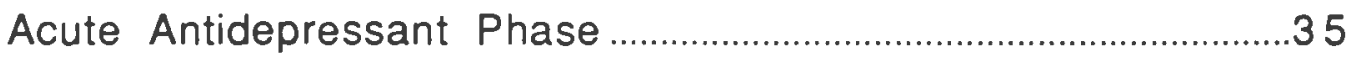

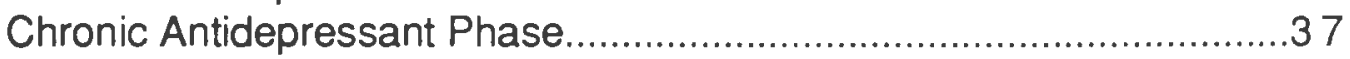


DISCUSSION

Effects of Antidepressants on Self-Stimulation

Thresholds

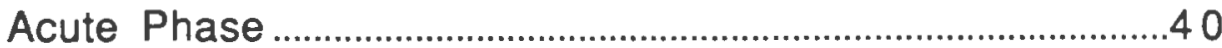

Chronic phase

Effects of Antidepressants on Activity.............................................

Acute effects........................................................................ 51

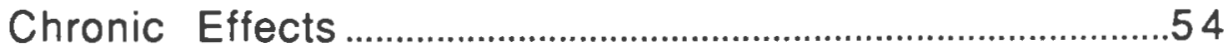

Effects of Albuterol Prior to Antidepressant................................55

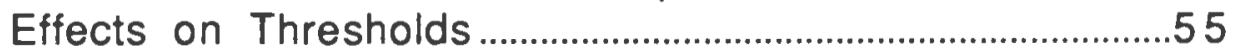

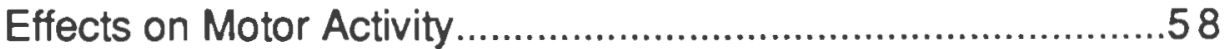

Effects of Albuterol After Chronic Administration of

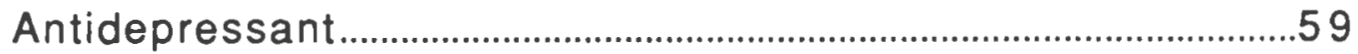

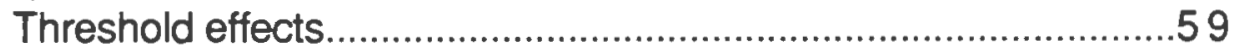

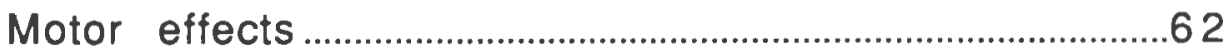

Effects of Antidepressants Given Chronically on Weight..........63

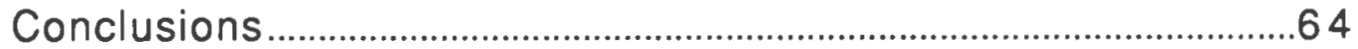

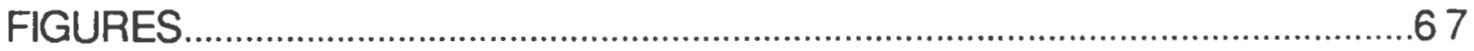

REFERENCES

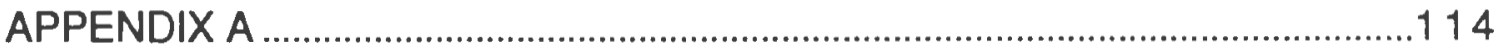

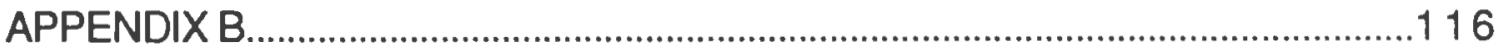

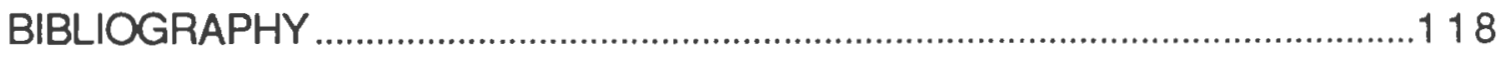




\section{List of Figures}

Figure 1. The effects of albuterol on mean thresholds in the pre-antidepressant period.

Figure 2. The effects of albuterol on descending and ascending thresholds in the pre-antidepressant phase....

Figure 3 to 6 . The effects of albuterol on lateral and rearing movement.

Figure 7. The effects of albuterol on mean thresholds in the post antidepressant phase

Figure 8. The effects of albuterol on descending

thresholds in the post antidepressant phase.

Figure 9. The effects of albuterol on ascending thresholds

in the post antidepressant phase.

Figure 10. The effects of albuterol on weight in the post

antidepressant phase

Figure 11 to 14 . The effects of albuterol on lateral and rearing movement in the post antidepressant phase....

Figure 15. The effects of acute administration of antidepressants versus saline on mean thresholds

Figure 16. The effects of acute administration of antidepressants versus saline on descending thresholds.

Figure 17. The effects of acute administration of antidepressants versus saline on ascending thresholds

Figure 18. The effects of acute administration of antidepressants versus saline on weight 
Figure 19 to 22 . The effects of acute administration of antidepressants versus saline on motor activity...........................8 5 Figure 23. The effects of chronic administration of antidepressants versus saline on mean thresholds......................8 9 Figure 24. The effects of chronic administration of antidepressants versus saline on descending thresholds...........90 Figure 25. The effects of chronic administration of antidepressants versus saline on ascending thresholds.............91 Figure 26. The effects of chronic administration of antidepressants versus saline on weight..........................................99 Figure 27 to 30 . The effects of chronic administration of antidepressants versus saline on motor activity..........................93 Figure 31. The effects of acute administration of Morphine Sulfate on mean thresholds...............................................97 


\section{INTRODUCTION}

\section{Overview}

The fortuitous discovery that the antitubercular compound iproniazid was an effective antidepressant led to the widespread application of congeners in treating individuals with major depressive disorders. These compounds all possessed the ability to block the enzyme monoamine oxidase, which resulted in a buildup in nerve synapses of dopamine, norepinephrine, and serotonin. Due to the high potential for serious side effects with antidepressants of the monamine oxidase inhibitor type, a search began to find an equally effective antidepressant compound that did not possess the side effect profile of the monoamine oxidase inhibitors. This resulted in the discovery that compounds which inhibit presynaptic reuptake of norepinephrine (NE), dopamine (DA), and 5-Hydroxytryptamine (5HT) and thus effectively increase concentrations of these neurochemicals in the synapse were also therapeutically effective antidepressants. Many such compounds were synthesized and marketed, with minor modifications yielding compounds with modestly different side effect profiles. These events led to a general acceptance that increase in synaptic levels of NE, DA, and 5-HT was necessary for antidepressant activity. Since some drugs which were similar in neurochemical profile to established antidepressants were also effective, compounds were routinely screened for such activity as a prerequisite for further testing. 
Also useful in the quest for safer and more effective antidepressants are animal models, many based on behavioral foundations unrelated to theoretical underpinnings of proposed neurochemical mechanisms of action. The success of some of these techniques in developing pharmacologically unique compounds raises important questions as to what physiological effects are key to antidepressant activity. Assumptions as to the mechanism of action of antidepressant drugs were made because those studying the effects of these compounds on behavior could not identify what physiological changes were responsible for the behavioral effects. Attempts to do so related the effects of these drugs on such nonspecific brain areas as "whole cortex" to a grossly observable behavioral change, such as rat immobility, that can only be linked by a tenuous theoretical net to human depressive disorder. Missing from investigations in the area is the concept of a neurobehavioral network; that is, a physiological model that links neurochemical events to change in discrete brain regions associated with predictable changes in behavior.

The need for a technique that tests the effects of drugs on a neurobehavioral network is behind our laboratory's exami: ation of the intracranial self-stimulation (ICSS) model as a possible tool for understanding the mechanism of action of antidepressant drugs. The basic building blocks of animal and human behavior, reward and aversive stimuli, can be studied in relation to physiology in an in vivo preparation. The relationship between a drug's effect on a neurobehavioral network and the relationship of that effect to other behavioral and neurochemical changes can be examined. 


\section{Theories of the Mechanism of Antidepressant Action}

\section{Catecholamine Hypothesis}

Theories for the mechanism of action of antidepressants are based on what neurochemical activities are common to most effective antidepressant drugs. One such activity is the ability of these medications to increase the amount of catecholamines available to the post synaptic cleft by inhibiting reuptake mechanisms. In contrast, medications which deplete presynaptic stores of catecholamines (eg. reserpine) can induce major depression in a substantial proportion of individuals. These two facts led to the development of the first theory of the biochemical basis of depression, the catecholamine hypothesis. Simply, a decrement in the amount of available catechoamines such as norepinephrine or dopamine or the indolamine 5-hydroxytryptamine in the synaptic cleft of brain regions, especially those linked to mood or motor activity, is associated with the development of depressive symptoms. Drugs which cause a reversal of this situation, such as the tricyclic antidepressants or monoamine oxidase inhibitors, are therapeutic (Cooper et al., 1986).

Unfortunately, the catecholamine hypothesis is not consistent with other key properties of antidepressants. For example, it fails to account for the discrepancy between the immediate increase in synaptic catecholamine levels and the one to three weeks of treatment required for these medications to show clinical effects. 
Also, some medications which also increase the availability of these transmitters, such as D-amphetamine or L-dopa, are acutely euphorogenic but are not useful in treating depression (Cooper et al., 1986). Finally, the discovery of agents that do not cause an increase in synaptic catecholamines but are effective antidepressants (Shopsin et al., 1981) led to even more doubt as to the validity of the catecholamine theory of depression.

\section{Adrenergic Receptor Subsensitivity Hypothesis}

A number of theories of the biochemical basis of depression evolved to explain these inconsistencies. One that appeared quite valid for a time was based on the finding that presynaptic alpha receptors, or $\alpha_{2}$-receptors, became desensitized after several days of tricyclic antidepressant (TCA) or monoamine oxidase inhibitor (MAOI) administration (Crews and Smith, 1978). It was thought that this was the critical mechanism underlying response to antidepressant drugs. This theory has the advantage of a temporal association between the neurochemical and the therapeutic changes induced by antidepressants. Also, the alpha adrenergic receptor blocker yohimbine abolished the chronic effects of the tricyclic antidepressants imipramine and nortriptyline in the Porsolt forced swim test (Zebrowska-Lupina, 1980). The discovery and clinical utility of effective antidepressants that do not have this pharmacological effect has caused this theory to fall into disfavor (Sellinger-Barnette, 1980). 
The most plausible remaining theory of antidepressant activity is that it is the down regulation of $B$-adrenergic receptors in the neocortex that is critical to antidepressant activity. SellingerBarnette (1980) demonstrated that a broad range of compounds that were effective antidepressants all caused the down regulation of beta adrenergic receptors in neocortex, whereas compounds which had some pharmacological similarities to these compounds but which were not effective failed to down regulate beta receptors. Gandolfi et al. replicated this (1983) experiment and found similar results, along with a decrease in the amount of cyclic AMP, the second messenger for many neurotransmiters. This effect occurs at fourteen days, which is the time when clinically effective antidepressants begin to work. Direct beta agonists such as albuterol (salbutamol) and clenbuterol have been found to be promising new agents in the treatment of depression, and would directly cause down regulation of these receptors (Simon et al., 1984).

\section{Approaches to Identifying Antidepressant Compounds}

Techniques useful in discovering new antidepressant drugs are employed to measure either behavioral or neurochemical effects of the compound. That is, a compound will be tested to see if inhibits MAO or blocks reuptake of catecholamines using biochemical assays, or it will be tested to see if an animal will perform a certain way in animal paradigm. The predictive validity is critical to the utility of the test; that is, the greater the association of effect in the model and 
clinical utility, the better the test. Assumptions as to how the neurochemical or behavioral change relates to what may occur in human depression are generally speculative and not as critical to an industrial pharmacologist trying to identify useful antidepressants as to their predicative validity.

\section{Techniques Based on Neurochemical Activity}

Many animal models used for predicting the efficacy of potential antidepressant compounds are derived from the ability of the compound to enhance catecholamine functioning in the manner of the MAO inhibitors and tricyclic antidepressants. One of the first animal models of depression useful in developing antidepressants is based on the ability of antidepressant drugs to prevent the autonomic and behavioral effects of tetrabenazine or reserpine (Costa et al., 1960). Pretreatment with antidepressants prevent the reduced locomotor activity, ptosis, hypothermia, and catalepsy caused by reserpine or tetrabenazine. These agents induce depression in up to one-quarter of those receiving them for treatment of hypertension (Quetsch, R.M., et al., 1959), though others put this figure at five percent (Goodwin et al., 1972). It is thought that their ability to deplete synaptic stores of catecholamines is responsible for this effect. Thus, these compounds created the proposed neurochemical disorder as well as the clinical syndrome in many receiving the drug. In accordance with these premises the model has excellent face validity. 
The reserpine or tetrabenazine antagonism model has some difficulties in terms of predictive validity. Some second generation antidepressants such as mianserin, trazadone, and bupropion are not active in this model though they are effective antidepressants (Cooper et al., 1983). Methylphenidate and d-amphetamine are active whether they are given before or after the reserpine or tetrabenazine (Howard et al., 1981). Also, L-dopa, alpha-adrenergic agonists, beta-adrenergic blockers, and antihistamines are active in this model (Wilner, 1984). Therefore, the model does not exclusively detect antidepressant compounds even though it is based on the catecholamine hypothesis, and fails to predict the usefulness of the newer and safer generation of antidepressants.

Other tests based on the catecholamine hypothesis are the Ldopa potentiation test and the $\mathrm{D}$-amphetamine potentiation test. They share the drawbacks of the reserpine-tetrabenazine antagonism model and suffer even greater problems with face validity (Wilner, 1984). For example, pharmacokinetic effects result in the ability of antidepressants to potentiate amphetamine, with impairment of metabolism of amphetamine by the liver being the likely reason for the effect (Sulser et al., 1966). In short, these models yield many false positives and have failed to predict the efficacy of many novel antidepressants. 


\section{Animal Models Based on Behavioral Theories of Depression}

Animals models of depression are critical to the development of safe and efficacious drugs for the treatment of human depressive disorders (Cooper et al., 1983). The mechanism of action of antidepressant compounds is still unknown, and we are still quite dependent on these models for the development of new antidepressant compounds. In the case of some novel "second generation" compounds, animal models based on behavioral theories have been useful for developing medications that are clinically effective, pharmacologically unique, but which lack many of the shortcomings of established medications (Shopsin et al., 1981).

For example, the Porsolt technique for screening antidepressant compounds (Porsolt et al., 1978) is based on the theory of learned helplessness (Miller et al., 1977; Abramson et al., 1978); this theory links the exposure of an animal to inescapable aversive situations with depressive behavior. Porsolt's technique has rats placed in beakers of water, the level of which just higher than their ability to comfortably stand; the rats eventually cease struggling and become immobile. Later tests in the same animals show a drastically decreased amount of struggling than when they were first exposed to this situation. However, rats that were treated with effective antidepressant compounds would struggle for much greater periods when exposed to this situation than control animals. This simple technique requiring little equipment has been very successful in identifying effective antidepressants; some of these antidepressants, 
such as bupropion, share none of the biochemical activities and little of the side effect profile of traditional antidepressants (Shopsin et al., 1981; Dufresne et al., 1984). Other methods based on the learned helplessness paradigm are affected similarly by antidepressants (Leshner et al., 1979).

\section{A Neurobehavioral Approach Using Self-Stimulation Techniques}

As we have seen, a drug can be shown to have a certain effect neurochemically in vitro, or on observed behaviors in animals and humans. All functional tests of these drugs are in some way affected by an end stage behavioral translation of the neurophysiological activity. However, there has been little effort towards understanding the activity of these drugs on isolated tissue systems. We have knowledge of functions of many brain areas, what their neurochemical systems are, and what happens if we destroy a neurochemical tract or lesion the tissue. However, we are not as sure as to how various psychoactive drugs affect different brain regions and how they may remedy psychiatric illness. A system for evaluating the in vivo processes of brain functioning and how this affects behavior would greatly aid researchers out of a "black box" approach to understanding how antidepressants physiologically act in treating depressive symptoms.

The intracranial self stimulation model is an important first tool in that the effects of altering a neurotransmitter in a discrete brain 
region or path can be studied. Furthermore, it offers a mechanism of looking at the relationship between the neurochemical changes, the neurological event, and behavioral change. The interrelationships between brain systems that affect mood, appetite, and motor activity, for example, can be elucidated so that more specific, less toxic drugs can be developed to treat depression and perhaps other diseases of brain and behavior. Finally, the end effect of drugs, such as the down regulation of beta receptors in neocortex, can be examined to see if they are responsible or coincidental to the therapeutic activity of the medication.

The threshold method of the ICSS technique is a potentially useful tool for examining the neurobehavioral effects of psychoactive medications, and has already been very useful in understanding the mechanisms of action of drugs of abuse (Marcus and Kornetsky, 1974; Kornetsky and Bain, 1982; Unterwald and Kornetsky, 1986; Izenwasser and Kornetsky, 1987). Kornetsy has demonstrated repeatedly that the administration of drugs of abuse to rats causes a lowering of the pleasure threshold. That is, a drug such as morphine or amphetamine will cause an animal to work for a smaller amount of electrical stimulation than prior to receiving the drug (Kornetsy and Bain 1982; Hubner et al., 1987). Drugs that are self administered by humans in combination tend to potentiate each others euphorogenic effects (Unterwald and Kornetsky, 1986; Hubner et al., 1987). 


\section{ICSS techniques: Understanding the neurophysiology of reward and depression}

\section{Depression as a Reward Deficit Syndrome}

Stein (1962) advanced the theory that depression occurred as the result of insufficient positive reinforcement. According to his theory, while most of us exhibit some depressive symptoms during periods of low positive reinforcement, depressives tend towards despair even when their environment is sufficiently rewarding. He noticed in his work in stimulation of reward areas of the midbrain tegmentum that the drugs that were psychostimulants reduced the amount of current the rats would work for, whereas the dopamine depleting drug reserpine and haloperidol, a postsynaptic blocker of DA, increased the amount of current necessary for self stimulation response or even completely interfered with responding. The animals receiving the antidopaminergic agents did not show motor impairment. Imipramine did not lower ICSS thresholds on its own but did potentiate the effects of amphetamine on responding.

Olds, the originator of the self-stimulation technique, believed that the brain was organized along hedonistic principles. He asserted that not only interneurons but specialized cell groups were part of a reward pathway which related to basic drives such as drinking, feeding, and mating, and that these systems were critical in reinforcing behavior necessary for survival (Olds and Fobes, 1981). 
Current thinking is that the principle reward pathway is the neural tract which originates in the dopaminergic neurons of the ventral tegmental area (A10) and projects to the limbic forebrain region via the mesocorticolimbic system (Fallon, 1988; Fibiger and Phillips, 1988). Interestingly, major depressive syndrome involves not only anhedonia, but also the so called vegetative symptoms such as psychomotor retardation, decreased appetite, insomnia, and diminished sex drive. Anhedonia, the decreased capacity to experience pleasure, can be understood as due to hypoactivity of the central reward pathways. The vegetative symptoms can be attributed to the resulting decrease in basic drives.

\section{Early Attempts to Measure Reward Using Rate Techniques}

The ICSS procedure involves an animal self administering small amount of electrical current to discrete brain regions through implanted bipolar electrodes. The pioneering work on this procedure was done by Olds (1962). He demonstrated that rats would perform tasks, such as pressing a lever, to receive minute amounts of electric current applied to neurons in the lateral hypothalamus. Later work has examined the effects that psychoactive drugs have on rates of responding to different levels of brain stimulation via implanted electrodes in both reinforcing brain regions such as the lateral hypothalamus, ventromedial tegmentum, substantia nigra, and medial forebrain bundle (Kokkindis and Zacharko, 1980; Leibman, 1983), and in areas where rats work to avoid the stimulation such as 
certain reticular areas (Carr and Coons, 1981). The location of these sites associated with reinforcing electrical stimulation were along those nerve tracts associated with dopamine (DA) and rorepinephrine (NE) neurotransmission.

A principal area of interest was how drugs would affect reward or aversion. Investigators would test to see if various psychoactive substances would increase or decrease rate of response to receive rewarding stimuli (positive reinforcement) or to avoid aversive stimuli (negative reinforcement). The use of these techniques often resulted in interesting findings. For example, Olds and Olds (1964) tested the effects of chlorpromazine, amphetamine, mebrobamate, and LSD-25 on rate of response to rewarding stimulation of the lateral hypothalamus and avoidance of aversive stimulation of the tegmentum. They found that chlorpromazine depressed rates for positive reinforcement in doses that spared negative reinforcement, while the reverse was true for mebrobamate. Thus, these agents had specific effects on reward and aversion capacity unrelated to the decrease in motor activity caused by these medications. However, often conflicting results would appear for many other medications.

For example, studies of the effects of morphine on rate of responding for rewarding stimuli would often be contradictory. In fact, some investigators found variable effects depending on dose and time after administration (Lorens, 1972 and 1976; Adams et al., 1972). Lorens found a suppressive effect on rate of responding for rewarding stimulation of the lateral hypothalamus and the medial frontal cortex one hour after administration, variable effect at 3 hours, and increased responding at 5 and 7 hours after morphine 
given at $3.75,7.5$, and $15 \mathrm{mg} / \mathrm{kg}$ doses via I.P. route. Pert and Hulsebus (1975) found only an increase in rate with morphine sulfate $10 \mathrm{mg} / \mathrm{kg}$ given 3 hours prior to self-stimulation testing. However, consistent results appear in the literature when threshold techniques which are less affected by morphine's motor effects are used. For example, Kornetsky and associates have found repeated lowering of self stimulation thresholds with morphine at between 4 and $16 \mathrm{mg} / \mathrm{kg}$ I.P. in the rat (Marcus et al., 1974; Esposito and Kornetsky, 1977; Kornetsky et al., 1979; Hubner et al., 1986; Izenwasser and Kornetsky, 1987). Unlike the rate techniques, the threshold method seems less confounded by the motor effects of psychotropic medications.

\section{Rate Independent Techniques}

Investigators who used rate of responding per unit ampere or volt as their dependent variable often found their results were confounded by the sedative property of many drugs which are self administered. For example, barbiturates, narcotics, and benzodiazepines tend to cause motor slowing although the amount of current the animals will work for is decreased. Drugs which increase motor activity such as amphetamine also were difficult to assess accurately using rate techniques because of the difficulty in discriminating whether an increase in rate was due to the general stimulant effects of the drug or an increase in the reward value of the electrical stumuli. Thus, the results of studies based on rate of response per unit current of ten conflicted with each other (Olds J., 
and Travis R.P.; 1959, others) as well as with studies which attempted to control for the motor effects of the drugs being tested.

Stein (1962) made one of the first attempts to study drug effects free of the performance confound. He used a two lever setup in which the animals could self regulate their current intensities. The animals would self administer current using one lever. The current would be gradually stepped down. The second, reset lever would be hit by the animal when the current level was judged by the animal to be insufficiently rewarding. Thus, this technique can be seen as a optimal current for reinforcement technique. The optimal current level at which the animal will still work is theoretically independent of the animals level of motor activity.

Another technique designed to improve on the rate only methods is the rate-intensity function method (Fibiger and Phillips, 1981; Leith and Barrett, 1981). In this method current levels are gradually stepped down until the animal stops responding and then increased until the animal once again is at the starting intensity. Rate of response is measured for each equal time interval and a rateintensity curve is plotted with intensity of current (or voltage) on the $\mathrm{X}$-axis and rate of responding on the $\mathrm{Y}$-axis. This method has the advantage of enabling the experimenter to examine the response over all current intensities. However, it is difficult to analyze responses using group statistics since the animals perform over such a wide range of current levels. Fibiger and Phillips (1981) got around this problem by looking at current levels at half maximal rate of performance as the dependent variable and using these values to perform group statistics. This is an effective current for 50 percent 
response analogous to the ED 50 concept in a dose response curve. However interesting this technique may be, it still uses rate of response as a dependent variable and should be affected by motor effects of drugs.

Key to research by Kornetsky and associates is the use of the psychophysical method of limits, which yields results that differ from techniques based on rate of response. This technique measures the minimum current level at which an animal will reliably work. This current level is known as the threshold for response. The threshold obtained using this method is not significantly correlated with rate of response (Kornetsky, 1985). This differs from the rateintensity methods and the two lever method in that the dependent variable is a minimum intensity of current for which the animal will work and not an optimal level. Kornetsky and associates use a stepwise procedure in which current descends and ascends twice; the mean of these values is considered the threshold. It is not reported how the descending and ascending values relate to each other.

\section{The ICSS Threshold Procedure as an Animal Model of Depression}

In a comparison of the relative predictive, face, and construct validity of animal models of depression, the ICSS paradigm is considered to be a useful model of depression (Willner, 1984). Using microelectrode implantation in the A-10 region, drugs such as the antidepressant desipramine have been shown to increase lever pressing per current level in rats treated with agent for fourteen 
days previous to testing (Fibiger, 1981). Willner (1984) emphasized how the inability to experience reward in the ICSS model has face validity in light of the inability of depressives to experience pleasure and reinforcement. The increase in somatic complaints in depressives could also be perceived as an increase in perception of aversive stimulation. The fact that ICSS rates can be controlled by many of the factors which control responding for natural rewards such as food, sex hormones, or water (Olds, 1958; Hoebel and Teitelbaum, 1962) reinforce the view that this model may indeed be examining the neurological basis of reward.

\section{Prior studies of Antidepressant Activity using ICSS Techniques}

Prior work in our laboratory is suggestive that the the ICSS threshold technique is sensitive to behavioral and pharmacological procedures that should lead to changes in hedonic tone. The Porsolt technique of behavioral despair has been used successfully to induce prolonged increases in ICSS reward thresholds in rats (Valentino and Dufresne, 1989; Manuscript in preparation); desipramine $10 \mathrm{mg} / \mathrm{kg}$ P.O. caused moderate but significant drops in reward threshold at day 6 to day 9 as compared to saline controls and rats treated with 5 $\mathrm{mg}$ per $\mathrm{kg}$ of desipramine (Riccitelli et al., 1989). Lastly, we replicated in our laboratory the pronounced reduction in reward thresholds by morphine dosed at $6 \mathrm{mg} / \mathrm{kg}$ I.P. (Wilcoxon signed rank test, $\mathrm{p}<.05$ ) previously demonstrated by Kornetsky's laboratory (Marcus and Kornetsky, 1974). 
Prior investigations into the effects of antidepressant compounds on self stimulation models suffered from two key methodological flaws. Many investigators who tested the acute effects of antidepresiants on intracranial self stimulation ignored the fact that these drugs never demonstrate their therapeutic effects acutely. Not surprisingly, these studies do not reveal an effect for tricyclic and monoamine oxidase inhibitor antidepressants (Binks et al., 1979; Stein, 1962). Another problem was the use of a rate dependent measure that could be confounded by motor stimulant or slowing properties unrelated to effects on reward systems. Fibinger (1981) found an effect of increasing rate of response per microamp associated with chronic but not acute desipramine $(10 \mathrm{mg} / \mathrm{kg} / \mathrm{day}$ over fourteen days) in animals implanted in the A-10 region dopaminergic cells of the ventromedial tegmentum. This effect occurred while current levels ascended but not in the descending segments. It is difficult to interpret this study in light of the conflicting results on the ascending and descending phases; it is even more difficult to say what effect any motor effects of the drug or fatigue had on his results. The psychophysical method of limits that we have adopted from Kornetsky is not contaminated by motor effects, since the threshold is determined by the lowest current level an animal will work for greater than half the time. What is important is whether an animal will respond 5 of ten times the stimulus is presented at a certain intensity; extra responses do not figure into the dependent measure. Since the animal must only make one response every thirty seconds, changes in rate of response or in coordination are not critical to the performance of the task. 


\section{The Experiments of this Dissertation}

The intent of these series of experiments is to examine the effect two antidepressants medications have on thresholds for selfstimulation in the medial forebrain bundle at the level of the hypothalamus, and to examine the consistency of these effects with the beta receptor down regulation theory of antidepressant activity. Desipramine is representative of the noradrenergic reuptake inhibitors while fluoxetine is representative of the serotonergic reuptake inhibitors. Manipulations will be performed to see if the effect on beta receptors is key or coincidental to the effects observed on any thresholds changes for intracranial self-stimulation of the medial forebrain bundle at the level of the hypothalamus. The mean, descending, and ascending thresholds measured in volts are used as the dependent variables rather than the rate of response since this method is theoretically less affected by drug induced alteration in motor performance (Liebman, 1983). Other methods used to evaluate the effects of antidepressants in the past have used techniques in which the overall motor activity of the animal could cause the change in the dependent variable since they were rate dependent (Fibiger, 1981). While overall motor rate may be related in some way to the therapeutic effect of antidepressants, we believe the increased ability to be reinforced by pleasurable stimuli to be an integral part of these medications ability to reverse depressive states. Overall motor rate will be assessed on open field photochamber for horizontal activity and rearing. An initial 15 minute 
exploration period as well as a second 15 minute period which reflects solely motor behavior are examined. The relationship of the motor response rate to threshold are examined.

The first component of this study is an attempt to determine if change in intracranial self stimulation (ICSS) thresholds for reward in the rat occurs with chronic treatment with antidepressants. The second component attempts to explore if such a phenomenon is consistent with subsensitivity of beta adrenergic receptors. My predictions were twofold. The first is that effective antidepressants, no matter what their neurochemical effects, will have in common the ability to lower intracranial self-stimulation thresholds after one to three weeks of administration in rats. Secondly, the administration of a beta agonist compound after three weeks of antidepressant treatment will counteract the effect of down regulation of beta receptors in animals with lowered thresholds; if a beta adrenergic effect is responsible directly for this lowering of ICSS thresholds, the animals treated with antidepressant will have a decreased response to beta agonist in comparison with the control group.

\section{Summary of the Hypothesis of this Study}

The hypothesis of this study are as follows:

(1) Antidepressants alleviate depression by increasing reward capacity. An increase in reward capacity would be reflected in lower ICSS thresholds. Unlike euphorogenic drugs which work immediately (i.e. morphine), antidepressants take a minimum of 7 to 14 days to 
have their effect; therefore, it would take take that long for the thresholds to be lowered.

(2) Effective antidepressants cause a decrease in beta receptor binding sites that is temporally associated with their clinical effect in humans (Cooper et al., 1986). Thus, B-adrenergic agonists should have the opposite effect and raise thresholds for intracranial selfstimulation. If $B$-adrenergic subsensitivity is associated with lowered reward thresholds, then it is likely that $B$-adrenergic supersensitivity is associated with increased reward thresholds. Thus, the $\beta$-agonist albuterol given $10 \mathrm{mg} / \mathrm{kg}$ via lavage should raise thresholds for self-stimulation.

(3) Chronic treatment with the antidepressants desipramine and fluoxetine causes $B$-adrenergic receptor subsensitivity. Since the threshold raising effect of albuterol is likely due to its $B$-adrenergic agonist activity, then B-adrenergic receptor down-regulation should decrease its effect on thresholds. Since chronic administration of antidef sants causes a decrease in B-adrenergic receptor sensitivity, then such treatment should lessen the threshold raising effect of the $B$-adrenergic agonist albuterol when compared to those animals treated chronically with saline prior to the albuterol administration.

(4) The threshold method that we have adapted from Kornetsky and associates is less sensitive to the performance confound than the rate technique for measuring reward capacity. Therefore, it should be possible to show a decrease in motor activity and either no change in or an increase in reward capacity (a lowered threshold). Also, it should be possible to show a change in threshold 
without a change in activity. Finally, an increase in motor activity should not always be associated with a lowered threshold.

\section{METHODS}

\section{Animals}

Male Sprague Dawley Charles River bred rats, weighing from 250 to 350 grams at the time of surgery, were used. Sufficient animals were prepared until 24 rats were evenly divided into the three treatment groups over the full course on antidepressant or saline treatment. They were housed in gang cages prior to and separately after their surgery. They were given free access to food and water, and their living quarters were on an 18 hours of light, 6 hours of dark cycle. They were allowed one week to recover from surgery before training.

\section{Apparatus}

Initial training of the animals took place in identical operant chambers with dimensions of $23 \mathrm{~cm}$ by $21 \mathrm{~cm}$ by $20 \mathrm{~cm}$ and equipped with a $5.0 \mathrm{~cm}$ lever. Stimulation was a monophasic square wave (60 C.P.S., 4 millisecond pulses for 0.5 seconds) delivered by a Grass S48 or S9 Stimulator. Assessment of the actual voltage delivered was monitored using an oscilloscope. After the animals 
had begun to adhere to the desired fixed interval schedule they were trained in identical operant chambers controlled by an Apple II computer running a stimulator manufactured by Coulburn Instrumenis, Inc.. This automated system insures uniform and accurate trials. The electrical stimulus was a 500 millisecond train of 60 C.P.S., 4 millisecond biphasic square waves of intensities of $100 \mathrm{uA}$ per volt. Electrodes were bipolar stainless steel electrodes fully insulated except at the tip. The open field tests were done in a Columbus instruments opto-varimax and opto-vertimax photocell chamber.

\section{Implantation of Electrodes}

The rats were anesthetized prior to surgery with pentobarbital dosed at $50 \mathrm{mg} / \mathrm{kg}$ body weight. Bipolar electrodes were aimed at the medial forebrain bundle at the level of the lateral hypothalamus using stereotaxic instrument. The coordinates used to implant the electrodes, with the top of the skull level, were $2.5 \mathrm{~mm}$ posterior to bregma, $1.8 \mathrm{~mm}$ lateral from the midline suture, and $8.5 \mathrm{~mm}$ ventral from the skull surface.

\section{Procedure for Determining Thresholds}

The animals were first trained to self administer the electrical stimulation. Voltage was set at a reliable setting for the individual animal to continue self stimulation. Initially, a $1: 1$ fixed ratio schedule was used. When animals reliably lever pressed 20 times a 
minute for at least fifteen minutes, they were switched to a fixed interval training schedule in which an initial stimulation preceded a ten second period in which lever pressing yielded a stimulation. After the lever press or ten seconds, whichaver occurred first, the animal entered a 20 second period in which stimulation was not available. A lever press during this period caused the twenty second cycle to begin again. This operant schedule is referred to as a differential reinforcement of a particular schedule (DRP). The method of successive approximation is used to shape animals to this reinforcement schedule.

After animals were trained to the aforementioned fixed interval schedule, their initial thresholds were determined using the Grass S48 stimulator. They were then transferred to a similar operant chamber that was controlled via a computer program which regulated the voltage and kept track of lever presses.

The psychophysical method of limits was used to determine thresholds. In order for a level of voltage to be considered capable of maintaining self stimulation, an animal must have lever pressed for at least five of the ten times the stimulation was available. This would have resulted in a positive segment. Initially, the animal received a level of voltage known in the past to support the self stimulation. Then, voltage descended in 0.2 volt amounts every time an animal lever pressed at least five of ten times to receive the stimulus. Eventually, the animal reached a point where the voltage level was so weak that it was not sufficiently pleasurable to be reinforcing. When the animal did not lever press for at least five of ten times for the voltage level that was available, a negative segment 
was said to occur. When this happened three consecutive times, the animal was said to have reached its descending threshold. At this point, voltage levels began to increase .2 volts at a time. When an animal lever pressed again five of the ten times the stimulus was available, then the ascending threshold had been reached. Two positive segments in a row were required for the ascending threshold to be reached. The mean of the descending and the ascending threshold was said to be the mean threshold of the animal.

Animals prepared to respond on the DRP schedule were tested on the automated apparatus until their thresholds were stable. Stability was determined as variation in voltage level of less than or equal to .6 volts between three successive descending and ascending thresholds and less than or equal to .4 volts between three successive mean thresholds.

\section{Drugs}

Prior to entering the chronic treatment phase, the response of the animals to an acute dose of $10 \mathrm{mg} / \mathrm{kg}$ albuterol on threshold was measured. Animals were then randomly assigned to three treatment groups of at least eight animals per group. These animals received $1.0 \mathrm{cc} / \mathrm{kg}$ of isotonic saline vehicle administered daily via gastric lavage for one week prior to randomization to experimental treatment. Both the desipramine group and the fluoxetine group receive $10 \mathrm{mg} / \mathrm{kg}(1 \mathrm{mg} / .1 \mathrm{cc}$ vehicle) for the next three weeks of the study. 
Desipramine was chosen for this study since it selectively blocks reuptake of norepinephrine into presynaptic cells (Cooper, Roth and Bloom, 1986). Fluoxetine was chosen as the alternative antidepressant due to its very specific effect of inhibiting the reuptake of serotonin into presynaptic cells (Fuller, 1987). Desipramine does not have active metabolites. The principal metabolite of fluoxetine, norfluoxetine, is also a serotonin reuptake inhibitor. Both compounds show very little antihistaminic, anticholinergic, and sedative properties as compared with other antidepressants. Desipramine has been shown to down regulate $B$ adrenergic receptors (Minneman et al., 1979; Sellinger-Barnette et al., 1980; Enna et al., 1981; Stahl et al., 1987,). Fluoxetine has also been found to down regulate beta-adrenergic receptors in several different brain regions and does so in both subtypes of beta receptors (Wamsley, 1987). However, other investigators have failed to observe this effect ( Mishra et al., 1979; Mobley and Sulser, 1981). The dose of desipramine is based on that found to be most effective in lowering thresholds using this procedure in a pilot study (Riccitelli et al, 1989). The dose of fluoxetine is based on those previously found most effective in several animal models of depression (Stark et al., 1985)

Albuterol was chosen for this study since it as well as clenbuterol had previously been shown to possess antidepressant properties in human trials (Simon et al., 1984; Lecubier et al., 1980). Both drugs are beta agonists that are relatively selective for $B_{2}$-adrenergic receptors. It is reasonable to assume that beta agonists found to be effective antidepressants should affect the same receptor population 
as other antidepressants. The dose of albuterol was chosen based on the results of Leibman's study (1984) of B2-adrenoceptor agonists.

\section{Measures}

The dependent variables for all phases of this study were the mean threshold, descending threshold, ascending threshold, and open field activity measures. Weight in grams was measured during the antidepressant test phase. The open field activity measures consisted of horizontal (lateral) movement and rearing (vertical) movement. These measures can be independent; DA agonists tend to increase rearing selectively where DA antagonists tend to decrease rearing. General central nervous system stimulants tend to increase horizontal motion, and the converse in also true with general sedatives. The motoric variables are assessed immediately after the threshold procedure. The first fifteen minutes of activity reflects behavior of an exploratory nature, whereas later activity such as during the second fifteen minute period in this study reflect a less confounded measure of general activity levels. For this reason, the two periods of measured activity will be viewed as reflecting predominantly exploratory or motor activity respectively. 


\section{Study Design}

The first segment of this study examined the effects of the beta agonist albuterol on thresholds prior to and after the chronic antidepressant test period. The response of the animals to a single $10 \mathrm{mg} / \mathrm{kg}$ dose of albuterol was measured prior to and after the antidepressant treatment phase. The pre-antidepressant beta period was designed as follows. The rats received saline via gastric lavage daily for each test period until three consecutive stable thresholds occur. The rats then received $10 \mathrm{mg} / \mathrm{kg}$ of albuterol via gastric lavage. Thresholds were then recorded for three test days after the albuterol treatment.

The second segment of the study was the antidepressant phase. At least one week after receiving albuterol and following at least three consecutive stable baselines, the rats were randomly assigned to receive either desipramine $10 \mathrm{mg} / \mathrm{kg}$, fluoxetine $10 \mathrm{mg} / \mathrm{kg}$, or saline. The rats were tested three times weekly. On the twenty first day the animals received albuterol for the post treatment betaagonist challenge. The rats received the antidepressant or control doses after testing in the early evening; however, the initial dose of antidepressant or saline was given 30 minutes before threshold testing so that the effect of an acute dose antidepressant could be compared with results from other studies and with chronic effects. Since the first test day of the chronic period differs from the others, it was tested independently of the chronic treatments. The acute and 
chronic effects of antidepressants versus control was considered as a second larger experiment

The final part of this study occurs after three weeks of antidepressant treatment. Forty-eight hcurs after the last dose of antidepressant or saline animals were administered the beta- 2 selective agonist albuterol via gastric lavage at a $10 \mathrm{mg} / \mathrm{kg}$ dose and tested for threshold and motor rate one again. If lowering of ICSS thresholds is a direct result of beta receptor down regulation, then the acute administration of the beta agonist should reverse the effect of the antidepressants. The change in threshold due to beta agonist challenge should be less than that observed prior to the antidepressant treatment. If the effect is indirect or not at all related to beta adrenergic receptors, then no reversal due to acute albuterol administration should take place.

\section{Statistical Analysis}

Data was analyzed for each of the phases using Multivariate Analysis of Variance (MANOVA) with repeated measures using the within contrast pooled technique (Winer,1971; Davidson and Toporek, 1986). The only variable not analyzed using MANOVA is the mean threshold, which was separately analyzed via repeated measures analysis of variance in order to avoid collinearity with the descending and ascending thresholds. Significant MANOVA's for each phase are followed by separate repeated measure ANOVA for each dependent variable. Significant ANOVA were followed by tests of simple or simple main effects, with significant tests of simple effects 
being followed by contrasts of individual means using techniques consistent with hypothesis tested. 


\section{RESULTS}

\section{Tests of Albuterol Effects Prior to Chronic Antidepressant Treatment}

It was correctly predicted that the acute administration of the $B$-agonist albuterol $(10 \mathrm{mg} / \mathrm{kg})$ would raise thresholds for selfstimulation. One-way repeated measures ANOVA showed a significant change over time for mean threshold $(F=2.64, \mathrm{df}=4,108$, $\mathrm{p}<.05)$. Contrasts show a significant difference between the two saline test periods prior to treatment with albuterol $(\mathrm{F}=4.65, \mathrm{df}=$ $1,27, \mathrm{p}<.05)$ and between albuterol and the two saline test days following such treatment $(F=4.34, \mathrm{df}=1,27, \mathrm{p}<.05)$. The increased mean threshold in response to treatment with albuterol with the subsequent return to baseline can be seen in Fig. 1.

The dependent variables measured and analyzed by a repeated measures one-way MANOVA were thresholds descending and ascending, and open field activity both horizontal and rearing (vertical) over the first and second fifteen minute periods. There was a significant difference over time (Wilks's Lambda $=0.4692, \mathrm{df}=$ $24,304.72, \mathrm{p}<.001)$ for dependent variables measured. Follow-up ANOVA's demonstrate that there were differences over time for ascending threshold $(F=8.05, \mathrm{df}=1,27, \mathrm{p}<.01)$, but not for descending threshold (Fig. 2). Contrasts show a significant difference for ascending thresholds between the two control test days prior to albuterol administration $(\mathrm{F}=5.58, \mathrm{df}=1,23, \mathrm{p}<.05)$ and the two control test days after $(F=6.00, d f=1,23, p<.05)$. 
Follow-up ANOVA's show that horizontal motion changed over time for the first fifteen minute reading $(\mathrm{F}=9.37, \mathrm{df}=4,92, \mathrm{p}<.01)$ and for the second fifteen minute reading $(\mathrm{F}=6.62, \mathrm{df}=4,92, \mathrm{p}<.01)$. Contrasts showed that the albuterol administration day differed from both the previous $(\mathrm{F}=28.19$ and $11.62, \mathrm{df}=1,23, \mathrm{p}<.01)$ and subsequent $(\mathrm{F}=35.92$ and $6.81, \mathrm{df}=1,23, \mathrm{p}<.05)$ control days for both time periods respectively. Rearing activity also differed over time for both the initial fifteen minute period $(\mathrm{F}=3.85, \mathrm{df}=4,92, \mathrm{p}<.01)$ and for the second $(F=5.93, d f=4,92, p<.01)$. The albuterol test day was once again different from the two control days prior $(\mathrm{F}=34.20$ and 36.73, $\mathrm{df}=1,23, \mathrm{p}<.001)$ and post $(\mathrm{F}=32.16$ and $18.19, \mathrm{df}=1,23, \mathrm{p}<$ $.001)$ for the first and second fifteen minute periods. The decrease in all motoric variables for both exploratory and general motor behavior are pronounced but tend to return to baseline following the albuterol test day (Fig. 3 to 6).

The B-agonist albuterol caused increases in mean threshold and a generalized decrease in activity. This is consistent with the hypothesis that $B$-adrenergic receptor supersensitivity is associated with increases in threshold. However, since motor activity decreased along with reward capacity, it is impossible to rule out a decrement in performance as the reason for the increased threshold. 


\section{Tests of Albuterol Effects After Chronic Antidepressant Treatment}

Two separate comparisons are of impurc here. First, does albuterol $10 \mathrm{mg} / \mathrm{kg}$ cause a change on the dependent variables as compared to the last week of antidepressant or saline treatment, and secondly does any change due to albuterol differ from the three saline test days post administration. A decrease in B-adrenergic receptor sensitivity due to chronic treatment with antidepressants would lessen the threshold raising effect of the B-adrenergic agonist albuterol when compared to those animals treated chronically with saline prior to the albuterol administration.

A comparison of the three last test periods of the chronic antidepressant phase and the final albuterol test day yields interesting findings. ANOVA on mean thresholds (Fig. 7) demonstrate a significant increase over time $(\mathrm{F}=8.48, \mathrm{df}=3,63, \mathrm{p}<.01)$ and for drug over time $(\mathrm{F}=2.54, \mathrm{df}=6,63, \mathrm{p}<.05)$. Tests of simple effects show that both desipramine $(F=8.21, \mathrm{df}=3,63, \mathrm{p}<.01)$ and saline $(F=5.01, \mathrm{df}=3,63, \mathrm{p}<.01)$ treated animals show increased thresholds in response to albuterol while the fluoxetine treated animals do not. The albuterol test days was different than all three previous days (protected contrasts, $\mathrm{df}=1,7, \mathrm{p}<.05$ ) for both desipramine and saline.

Repeated measures MANOV $a$ on the remaining variables (Fig. 8 -14) resulted in a significant finding for change over time (Wilkes's Lamda $=.2537, \mathrm{df}=21,164.22, \mathrm{p}<.0001)$ but not for drug by time. 
Follow-up ANOVA's show a similar pattern of change over time $(d f=3,63, p<.01)$ regardless of drug group for descending threshold $(F=4.95)$, ascending threshold $(F=6.37)$, weight $(F=17.49)$, horizontal movement over both fifteen minute periods $(F=7.14$ and 4.91$)$, and for rearing over both periods $(F=7.59$ and 10.74). A significant result for mean thresholds and not for the descending or ascending threshold separately may be related to increased reliability or measurement with a decreased error term when using the average measure of threshold.

Mean thresholds did not differ between the albuterol test day and the three control test days afterwards. MANOVA on the remaining dependent measures show a significant decrease from the albuterol test day to the saline days thereafter (Wilkes's Lamda = $.1173, \mathrm{df}=21,147, \mathrm{p}<.0001)$ regardless of group membership.

Follow-up ANOVA's show no differences for descending or ascending threshold from albuterol test day to the saline control days. The motoric measures differed over time without regard to group. Horizontal activity differed over time for the first $(F=16.61, \mathrm{df}=3,57$, $\mathrm{p}<.01)$ and second $(\mathrm{F}=14.50, \mathrm{df}=3,57, \mathrm{p}<.01)$ fifteen minute periods as did rearing for both periods $(\mathrm{F}=11.13$ and 12.84 , $\mathrm{df}=3,57, \mathrm{p}<.01)$. As the animals previously treated with antidepressants began to regain lost weight the ANOVA demonstrated a significant time $(\mathrm{F}=66.48, \mathrm{df}=3,57, \mathrm{p}<.01)$ and drug by time interaction $(F=6.50, d f=6,57, p<.01)$.

The animals treated for nineteen days with fluoxetine 10 $\mathrm{mg} / \mathrm{kg}$ via gastric lavage did not show an increase in threshold upon administration of albuterol whereas those treated with desipramine 
$10 \mathrm{mg} / \mathrm{kg}$ or equal amounts of saline vehicle ove te same time period did show an increase in mean threshold upon albuterol administration. One possible interpretation is that the serotonergic antidepressant fluoxetine prevented threshold elevation upon administration of albuterol, while the noradrenergic antidepressant desipramine did not. An alternative explanation is that the desipramine and saline treated animals developed increased thresholds due to withdrawal of the daily evening injections. The later explanation would be in accordance with the continued elevation of thresholds after the albuterol test day. However, the lack of threshold elevation in the fluoxetine treated animals during this period is not explained by the alternative interpretation.

\section{Acute Antidepressant Phase}

As acute treatment with antidepressants does not result in therapeutic improvement in patients suffering from major depressive syndrome, it was not expected that thresholds would be altered by acute treatment with desipramine or fluoxetine as compared to saline when given thirty minutes prior to testing. The results of this study phase is consistent with these expectations.

MANOVA on descending and ascending thresholds, motor activity variables, and weight demonstrates that there was a significant change over time (Wilks's Lamda $=.5075, \mathrm{df}=14,72, \mathrm{p}<$ .05 ) and significant change for drug by time (Wilks's Lamda $=.3373$, $\mathrm{df}=14,72, \mathrm{p}<.05)$. There were no significant changes over time or 
for drug by time for mean, descending, or ascending thresholds (Fig. 15 - 17). There was a significant over time interaction for weight ( $F=$ 11.20, $\mathrm{df}=2,42, \mathrm{p}<.01$ ) with all animals gaining weight (Fig. 18) during the control test days as would be expected. Follow-up ANOVA'S show significant differences on some motoric variables (Fig. 19 - 22) for drugs over time. In the first fifteen minute exploratory phase there were significant differences for drug by time for horizontal activity $(\mathrm{F}=3.81, \mathrm{df}=4,42 . \mathrm{p}<.01)$ and for rearing $(\mathrm{F}=2.62$, $\mathrm{df}=4,42, \mathrm{p}<.05)$ activity. A modest decrease in activity independent of drug treatment was also present $(F=5.99$, df $=2,42, p$ $<.01)$. On follow-up tests of simple effects the desipramine treated animals show a pronounced decrement in horizontal motor activity $(F=3.53, \mathrm{df}=2,42, \mathrm{p}<.05)$ and rearing $(\mathrm{F}=6.11, \mathrm{df}=2,42, \mathrm{p}<.01)$ for the first fifteen minute period whereas the fluoxetine treated animals only exhibited a decrease in rearing $(\mathrm{F}=4.89, \mathrm{df}=2,42, \mathrm{p}<$ .05). Curiously, the saline treated animals exhibited a significant $(\mathrm{F}=3.68, \mathrm{df}=2,42, \mathrm{p}<.05)$ increase in horizontal activity during the first fifteen minute test period. Follow-up contrasts $(p<.05)$ demonstrate these significant effects to be a result of differences between the two control test days and the acute antidepressant treatment day.

The results of ANOVA'S on the second fifteen minute period showed a significant drug group over time interaction for horizontal movement $(F=4.19, \mathrm{df}=4,42, \mathrm{p}<.01)$ but not for rearing. Simple effects tests reveal that the desipramine $(\mathrm{F}=4.10, \mathrm{df}=2,42, \mathrm{p}<.05)$ and fluoxetine $(\mathrm{F}=3.80, \mathrm{df}=2,42, \mathrm{p}<.05)$ groups had decreased horizontal motor activity over time whereas the saline group did not. 
Follow-up contrasts show this difference to occur between the control days and the acute antidepressant treatment day (protected contrast, $\mathrm{p}<.05$ ).

The decreases in activity observed on the motoric variables was not associated with a concomitant increases in threshold; this lends support to a lack of confound between motoric and threshold effects. The significantly increased levels of lateral activity in the first fifteen minute period seen with the saline control group did not occur on any other tests of motor activity during the entire study and is thought to be the result of type I error. Simply, it is likely that for every twenty tests of statistical significance at an alpha level of $p<.05$, one will be statistically significant due to chance. A lack of alternative causes for this effect and the fact that opposite changes occurred in the treatment groups lend support to this conclusion.

\section{Chronic Antidepressant Phase}

This study phase was performed to test the hypothesis that antidepressants alleviate depression by increasing reward capacity. An increase in reward capacity would be reflected in lower thresholds for intracranial self-stimulation which would occur at least one week of chronic antidepressant treatment. However, the antidepressants desipramine and fluoxetine given $10 \mathrm{mg} / \mathrm{kg}$ via lavage daily for nineteen days did not lower thresholds as compared with saline. 
For the descending and ascending thresholds, motoric variables, and weight there was a significant change over time (Wilks's Lamda $=0.4422$, df $=63,1036.77, \mathrm{p}<.0001)$ and for drug over time ( Wilks's Lamda $=0.1969, \mathrm{df}=126,1212.07 . \mathrm{p}<.00011$. Follow-up ANOVA's show that there was a significant increase in thresholds over time (Fig. 23 - 25) independent of drug treatment group for mean ( $F=2.96$, $\mathrm{df}=9,189, \mathrm{p}<.01)$, descending $(\mathrm{F}=3.17, \mathrm{df}=9,189, \mathrm{p}<.01)$, and for ascending thresholds $(F=2.02$, df $=9,189, p<.05)$. These findings indicate a gradual increase in thresholds irrespective of drug treatment over the 18 day period.

ANOVA for weight showed a significant decrease in grams over time $(F=3.34, \mathrm{df}=9,189, \mathrm{p}<.01)$ and for drug by time $(F=14.23$, $\mathrm{df}=18,189, \mathrm{p}<.001)$. Tests of simple effects show that weight decreased dramatically in the desipramine $(F=9.23, \mathrm{df}=9,189, \mathrm{p}<$ $.01)$ and fluoxetine $(\mathrm{F}=8.93, \mathrm{df}=9,189, \mathrm{p}<.01)$ groups (Fig. 26) and increased markedly in the saline group $(\mathrm{F}=13.64, \mathrm{df}=9,189, \mathrm{p}<.01)$.

Follow-up ANOVA for the first fifteen minute activity period shows that all groups decreased significantly over time for horizontal activity (Fig. 27) and rearing (Fig. 28). For the second fifteen minute period there was a significant drug by time interaction for horizontal activity $(\mathrm{F}=2.32, \mathrm{df}=18,189, \mathrm{p}<.01)$ and rearing $(\mathrm{F}=2.47, \mathrm{df}=18,189, \mathrm{p}$ $<.01)$ as well as non-specific over time effect for rearing $(F=1.50$, $\mathrm{df}=9,189, \mathrm{p}<.01)$. Tests of simple effects show decreased horizontal activity (Fig. 29) for desipramine $(\mathrm{F}=2.68, \mathrm{df}=9,189, \mathrm{P}<.01)$ and fluoxetine $(\mathrm{F}=2.81, \mathrm{df}=9,189, \mathrm{p}<.01)$, but not for the saline treated animals. Similarly rats administered desipramine $(\mathrm{F}=3.41, \mathrm{df}=9,189$, $\mathrm{p}<.01)$ and fluoxetine $(\mathrm{F}=3.05, \mathrm{df}=9,189, \mathrm{p}<.01)$ showed decreases in 
rearing activity (Fig. 30) while saline did not. Thus, drug induced decreases in motor activity after the exploratory period were pronounced.

The pronounced decreases in lateral and rearing activity were not associated with significant increases in threshold. This result is consistent with a lack of dependence of the threshold measures with decreased motor activity. However, since changes in threshold did not occur without concurrent changes in motor activity of the opposite direction, the dissociation of these measures can not be entirely proven based solely on the result of this study. 


\section{DISCUSSION}

\section{Effects of Antidepressants on Self-Stimulation Thresholds}

\section{Acute Phase}

As hypothesized, there were no effects of an acute dose of desipramine $(10 \mathrm{mg} / \mathrm{kg})$, fluoxetine $(10 \mathrm{mg} / \mathrm{kg})$, or saline on either mean threshold or its component descending and ascending thresholds (Fig. 15-17). This is expected since antidepressants take a minimum of one to three weeks to exert their therapeutic actions clinically (Cooper et al., 1983). However, drugs which increase catecholaminergic activity tend to reduce reward thresholds (Kornetsky et al., 1979; Hubner et al., 1987) while agents such as reserpine (Stein,1962; Leith and Barrett, 1980) raise reward thresholds. This has led others to test for acute activity of antidepressants in intracranial self-stimulation.

Binks (1978) and associates tested the acute effects of varying doses of the tricyclic antidepressants imipramine and protriptyline on rates of self-administration of current on fixed interval schedules ranging from 9:1 to 1:1 ratios of response to reinforcement. The electrode implant was aimed at the medial forebrain bundle of the lateral hypothalamus as in the present study, and the rats were required to demonstrate two consecutive days of stable response baseline prior to receiving each dose of drug. The criteria for stability was not revealed in the report. Imipramine given 
subcutaneously in 3,10 , and $30 \mathrm{mg} / \mathrm{kg}$ dosages and similarly administered protriptyline (10 mg/kg) did not cause significant differences from saline control over all fixed interval schedules. However, D-amphetamine $0.5 \mathrm{mg} / \mathrm{kg}$ given subcutaneously resulted in significantly increased response rates which were most pronounced at the higher fixed interval ratios. These results are consistent with the immediate pronounced mood elevating effects of d-amphetamine not seen with antidepressants.

Stein (1962) tested the effects of catecholaminergic drugs on threshold of self-stimulation to the lateral hypothalamus and midbrain tegmentum. He theorized that clinical depression was the result of insufficient positive reinforcement due to decreased catecholaminergic activity resulting in a hypoactive reward system. Rates of responding to gradually decreasing levels of current were recorded; a second lever was available to the animals which they would press to reset current to the highest level after the ever lowering stimulation level was no longer sufficiently rewarding. Methamphetamine and d-amphetamine caused lowering of reset value and rate, while reserpine and chlorpromazine had no effect on these parameters. Stein also tested an acute dose of imipramine $10 \mathrm{mg} / \mathrm{kg}$ and found no effects on reset value or rate. However, he found that the same dose of imipramine potentiated the effects of $d$ amphetamine on these measures. He found these results to be consistent with his understanding of the relation of catecholamines and the reward systems. He failed to address the lack of effect of imipramine in his paradigm even though it also acutely increased DA and NE levels in the synapse. 
In Fibiger's study (1981) of the activity of desipramine on selfstimulation of the dopaminergic A-10 region of the ventromedial tegmentum, an acute dose of the drug was also given. As in the preicus itudies, there were no acute effects of the antidepressant on rate or on a rate for current intensity curve. One early study did show an increase in response rate by imipramine in cats working for very low current stimulation of the lateral hypothalamus (Horovitz et al. 1962). It is unclear if this finding could be due to the difference in type of test animal. An acute study of the effects of fluoxetine on rate of responding for electical stimulation of the medial forebrain bundle showed a dose dependent decrease in rate with fluoxetine (Katz and Carrol, 1977); however, this effect was not observed in the present study and is likely an artifact of a decrease in motor activity reducing the rate of response without an actual change in reward threshold being present.

\section{Chronic phase}

In the rats given chronic daily doses of desipramine and fluoxetine there were no significant differences in mean, descending, or ascending thresholds as compared with the saline control (Fig. 2325). In fact, the thresholds of the antidepressant treated animals appear to be drifting upward relative to control. These results differ from prior studies of chronic antidepressant effects on selfstimulation.

A previous study performed in our lab did show a small but significant decrease in thresholds in rats given desipramine 10 or 20 
$\mathrm{mg} / \mathrm{kg} /$ day by lavage versus those given a $5 \mathrm{mg} / \mathrm{kg}$ day dose or saline (Riccitelli et al., 1989). The absolute difference was small (.4 volt or 2 steps) when compared with control, especially compared to the pronounced decreases observed with morphine sulfate $6 \mathrm{mg} / \mathrm{kg}$ in our lab (Fig.31). Kornetsky has observed a similar dramatic effect in a threshold procedure with mood altering drugs such as morphine (Izenwasser and Kornetsky, 1987) and amphetamine (Kornetsky, 1985). Also, this difference between desipramine and saline was enhanced by a gradual upward drift in thresholds by the control group over the three week period not observed in the desipramine 10 and $20 \mathrm{mg} / \mathrm{kg}$ groups. Thus, this difference could have been a prevention of upward drift in self stimulation thresholds rather than a real decrease. Furthermore, the effect was very small as compared with the marked threshold lowering effects of euphorogenic drugs and therefore of doubtful value in significantly increasing the capacity for reward.

Another possible explanation for the difference in result between the present and previous study is that the drugs were given one-half hour prior to testing throughout the chronic antidepressant period in the first study. In the present study we administered the antidepressants or saline after the animals had been tested such that it was always twenty-four hours after the last dose when the animals were tested. Since desipramine has a long half-life, takes at least a week of administration to be effective, and is likely dependent on subtle receptor changes for its therapeutic activity, it seems likely that any effect on reward thresholds would be more pronounced when not confounded by acute effects such as sedation. 
However, one cannot rule out that in the study of Riccitelli and associates the rats began to respond to the later doses of antidepressant via some form of sensitization such as reverse tolerance.

Both results differ from that of the most promising study performed examining the effects of chronic antidepressant treatment on self-stimulation. Fibiger and Phillips (1981) demonstrated that, after fourteen days of chronic daily injections with desipramine 10 $\mathrm{mg} / \mathrm{kg}$, rats implanted in the A-10 region of the ventromedial tegmentum had an increased rate of self administration per unit current than controls and rats treated acutely with desipramine. However, this effect occurred only as stimulation intensity was gradually increased and not as it was decreased. The effect was largest at the point of half-maximal responding, with those animals treated chronically with desipramine responding at the same rate for 26.35 percent of the current required at baseline and by the control. However, neither maximal rate of response nor response rate at the lowest current intensities which support self-stimulation were different between treatment groups.

Fibiger and Phillips noted consistently higher rates of responding for the middle current intensities while stimulation intensities were ascending as compared to when they were descending. Koop (1977) previously demonstrated a similar positive contrast effect. An alternative explanation for the effect seen with chronic desipramine treatment on the ascending current intensities is that the antidepressant enhanced this positive contrast effect and not reward (Liebman, 1983). 
An important difference between the study of Fibiger and Phillips and the present study is location of implant. The A-10 region is a dopaminergic nucleus, whereas the medial forebrain bundle also contains noradrenergic and serotonergic fibers. Desipramine, a potent NE reuptake blocker, could have an indirect effect on A-10 via noradrenergic innervation or on DA metabolism. This effect might not be observed in the medial forebrain bundle where there is a more heterogeneous distribution of neurotransmitters and innervation (Cooper et al., 1983).

Another possible explanation for the lack of effect of desipramine and fluoxetine on thresholds in our study is that antidepressants work to prevent or reverse abnormal raising of reward thresholds without having any threshold lowering effects in animals already at normal reward capacity. The analogous situation in humans is that antidepressants work to abolish or prevent depression but have no euphorogenic effects in man. This is consistent with current knowledge of antidepressant therapy; that is, they are effective in reversing depression after two or three weeks in many patients but are not abused for euphorogenic effects. While it is possible thi is because addicts typically lack the patience to abuse a drug with many side effects for two weeks or more to get an effect, a lack of euphorogenic effects is consistent with the frequent lack of compliance seen with antidepressant drugs.

A study in mice that supports this notion is that of Zacharko and associates (1984). They demonstrate that mice given uncontrollable foot shock show a pronounced decrease in rate of selfstimulation of the nucleus accumbens for up to at least one week 
after stress situation. Control mice and thoss treated with desipramine $5 \mathrm{mg} / \mathrm{kg}$ do not show this prolonged reduction in threshold. Interestingly, the desipramine treated animals show the same response to shock as the saline treated animals immediately after the stress situation, but not at 1 and 7 days. Also, a trend for somewhat increased rate of response for both desipramine groups in comparison to saline control is evident between day 1 and day 7 for both shock conditions. However, a comparison of the shocked animals shows a three fold greater response in the desipramine treated animals as compared to saline control. Therefore, it seems possible from this study, and consistent with clinical experience, that antidepressants require that the reward capacity be abnormally low to show a pronounced effect. This is in contrast to drugs such as morphine or d-amphetamine, which cause pronounced decreases in reward threshold even if an animal is already functioning at a normal level of reward capacity. Also, this view is consistent with the ability of antidepressants to prevent relapse of depression in humans.

To treat mood disorders, it is imperative to restore the normal capacity of the reward system without causing instability. Damphetamine increases reward capacity immediately and dramatically, yet it is not "seful therapeutically in affective disorders and causes decreased reward capacity upon withdrawal. Antidepressants share neither of those properties with amphetamine-like drugs. One would expect this. In order to function adaptively, the reward system must be stimulated only by actions and events that increase survival value to the organism or to 
offsprir Thus, a hyperactive reward system would be as detrimenıal to an animal as a hypoactive reward system; one could in fact view the condition of bipolar affective disorder as a cycling between the two extremes with an inability to maintain a proper level of reward capacity. Consistent with this paradigm is the ability of lithium to be effective both as an antidepressant and antimanic agent. One could view the effects of lithium as preventing the reward capacity from being too extreme to effectively modulate the behavior of the animal.

Major reward pathways such as the medial forebrain bundle may not be directly affected by antidepressants. Since antidepressants do not appear to cause dramatic changes in reward capacity in normal animals, it is possible that they modulate the tone of the system in response to behavioral cues. They could do this by actions on pathways which indirectly affect major reward pathways. The affect of amphetamine in mood disorders may be akin to throwing gasoline on a running engine; rather than increasing performance, it is likely to cause an explosion. Likewise, a dramatic increase in catecholaminergic transmission could cause further instability in reward capacity that is detrimental to the animal. However, if a medication's effect on a system which enervated reward systems were to cause the system to function more evenly and to avoid extremes of reward capacity, it could have great therapeutic value.

The ability of antidepressants to down regulate $B$-adrenergic receptors, decrease the sensitivity of $\alpha_{2}$-adrenergic receptors, and increase the sensitivity of $\alpha_{1}$-adrenergic receptors occurs temporally with their therapeutic effects (Kostowski et al., 1986) and may be 
involved in modulating catecholaminergic transmission and thus reward capacity. In order to observe a large effect of these medications on reward threshold in the rat, it may be necessary to disturb the system either by inessapahlc :trass (Zacharko et al., 1984; Valentino and Dufresne, 1989), or by observing the interaction of a medication that directly affects reward systems such as amphetamine or morphine. In light of the proposition that antidepressants reverse or prevent abnormally low reward capacity, effects of these medications on thresholds following catecholaminergic depletion by reserpine, tetrabenazine, or chronic amphetamine administration followed by withdrawal would be quite large, whereas a medication such as lithium might be useful in modifying both the effects of agents that either increase or decrease thresholds.

Similar interaction techniques have been used in conjunction with the ICSS technique to examine the effect of depletion of neurotransmitters in reward. One example is in a study in which catecholamine depletion by alpha-methyl-para-tyrosine reversed morphine sulfate increases in rate of self-stimulation whereas the serotonin depleting agent para-chlorphenylalanine did not (Pert and Hulsebus, 1975). This study demonstrated the relative importance of dopamine and norepinephrine as compared to serotonin for morphine's effect on reward systems. Decreases in escape from aversive stimulation of the mesencephalic reticular formation by morphine were potentiated by the potent indirect catecholaminergic agonist d-amphetamine even though the low dose of d-amphetamine had no effect in this model (Sasson et al., 1986). Such techniques 
used to examine the pharmacological effects of analgesics could be used to understand the nature of antidepressant effects in reward systems.

Another potentially important factor in affective disease is the interplay between reward capacity and aversion capacity. Aversion capacity is the relative sensitivity of the animal to aversive stimuli that enables the animal to avoid detrimental situations. Electrical stimulation of brain areas involved with the aversion system causes the animal to attempt to escape or avoid the noxious stimulation in a similar manner as it would to an environmental punisher (Cooper and Taylor, 1967; Clarke and File, 1982). As reward capacity is critical to positive reinforcement and negative punishment, aversion capacity is necessary for negative reinforcement and positive punishment to occur. The most obvious example is the need of the animal to sense pain and thus avoid tissue damage. The indirect dopamine agonist d-amphetamine is a potent analgesic which does not require central endorphin activity for its effect (Drago et al., 1984). Interestingly, the dopamine antagonist haloperidol as well as nalaxone inhibited the analgesic effects of morphine as well as $d$ amphetamine, whereas nalaxone failed to inhibit d-amphetamine induced analgesia. It appears that dopamine is as critical to pain as it is to reward.

Reward capacity and aversion capacity function in a reciprocal fashion. Rewarding electrical stimulation of the medial forebrain bundle of the lateral hypothalamus has been shown to reduce escape from aversive stimulation of the nucleus reticularis gigantocellularis (Carr and Coons, 1981). Agents which increase reward capacity, such 
as morphine, d-amphetamine, or chlordiazepoxide, also decrease the escape or avoidance of aversive brain stimulation (Marcus and Kornetsky, 1974; Morato de Carvalho et al., 1981; Clarke and File, 1982). In light of the numerous somatic complaints of depressed patients as well as the use of tricyclic antidepressants in chronic pain (Maciewicz and Martin, 1987), clinical evidence also seems to support this inverse relationship between aversion and reward. Also, chronic administration of desipramine has been shown to decrease the density of cortical opiate receptors; this finding supports an indirect effect of antidepressants on opiate systems (O'Neill, 1983).

Decreased reward capacity increases apparent aversion capacity, and lessened aversion capacity seems linked to increased reward capacity. Thus, it may be necessary to monitor both reward and aversion threshold in investigating the mechanism of action of antidepressants and in the detection of future useful agents.

The lack of pronounced effect of chronic treatment with antidepressants in lowering self-stimulation thresholds in the present study calls into question whether the critical effect of antidepressants is raising reward capacity or whether it is in restoring reward capacity to normal. This effect could either be direct or secondary to a decrease in aversion capacity. It is unlikely that the lack of effect of desipramine or fluoxetine on thresholds is due to insufficient dosage, as weight reduction and decreased motor activity is pronounced for these groups as compared with control. Also, the threshold technique we used accurately demonstrated the marked threshold lowering effects of $6 \mathrm{mg} / \mathrm{kg}$ of morphine sulfate (Fig. 31). It now appears more likely that antidepressants show a 
large effect in preventing or reversing elevation of reward thresholds induced by environmental stressors. This theory is supported by the results of the study of Zacharko and associates (1984). As we have demonstrated in our lab, animal models of depression can be used to cause a persistent raising of reward thresholds (Valentino and Dufresne, 1989). The small effect seen with desipramine 10 and $20 \mathrm{mg} / \mathrm{kg}$ in this model may be related to a post surgery induced raising of thresholds due to the stressful nature of the experience. This is likely not a factor in the current study due to the extra three to four weeks required by the initial albuterol testing prior to the chronic antidepressant phase. Also, it cannot be ruled out that the one time administration of albuterol or the difference in antidepressant dosing schedule may have affected response to the antidepressant.

\section{Effects of Antidepressants on Activity}

\section{Acute effects}

Interest in the acute effects of antidepressant drugs on exploratory behavior and locomotor activity can be traced back to the lack of interest and psychomotor retardation predominant in major depressive syndrome. Separating the effects of antidepressants on spontaneous locomotor activity and on exploratory behavior is often difficult (File and Tucker, 1986), and it is unclear whether to do so is unrealistic as the two behaviors are 
highly associated with one another. Some authors argue that the first minutes after being put in an open field an animal's activity mainly reflects exploration. Others argue that the activity of the animials it exploring mazes or tunnels is indicative of exploratory behavior and that this can be measured separately from the locomotor activity. Researchers use different paradigms as well as different time of measurement after entry into the open field or device. Therefore, comparisons among the different studies of antidepressants on locomotor activity and exploratory behavior can be difficult and often contradictory. However, some general conclusions can be drawn.

In the present study the first fifteen minutes of activity in the open field is considered to be a combination of exploratory and motor behavior, whereas the second period reflects predominantly locomotor activity. The desipramine treated animals show a pronounced decrement in ambulation (horizontal motor activity) and rearing for the first fifteen minute period whereas the fluoxetine treated animals only exhibited a decrease in rearing. For the second fifteen minute period the desipramine and fluoxetine groups had decreased ambulation whereas the saline group did not (Fig.19-22). There were no cases in which the antidepressants increased activity. These effects are consistent with the majority of the literature.

Desipramine $(10 \mathrm{mg} / \mathrm{kg})$ and imipramine $(10 \mathrm{mg} / \mathrm{kg})$ but not nortriptyline $(15 \mathrm{mg} / \mathrm{kg})$ were shown to decrease ambulation acutely, while nortriptyline was shown to increase rearing acutely over two minutes in the open field (Kulkarni and Dandiya, 1973). In this study monoamine oxidase inhibitors pargyline and nialamide 
decreased ambulation but had no effect on rearing. Przegalinski and associates (1983) demonstrated decreased ambulation and rearing over three minutes for $10 \mathrm{mg} / \mathrm{kg}$ of imipramine and desipramine, while fluvoxamine $10 \mathrm{mg} / \mathrm{kg}$ reduced only ambulation. Strangely, the sedating antidepressants amitriptyline and citalpram $(10 \mathrm{mg} / \mathrm{kg})$ had no effect on either. These studies looked at only the exploratory period of motor activity. Shillito (1970) saw similar decreases in exploratory behavior using a tunnel entry paradigm on the first day with imipramine $20 \mathrm{mg} / \mathrm{kg}$, though on the second day of treatment an increase in exploratory behavior was observed. The monoamine oxidase inhibitors tranylcypromine and nialamide increased exploratory behavior in mice on both the first and second days of treatment. Interestingly, amphetamine $4 \mathrm{mg} / \mathrm{kg}$ and $8 \mathrm{mg} / \mathrm{kg}$ reduced exploratory activity but caused an increase in locomotion.

In contrast, the second generation antidepressant bupropion given acutely (10 and $30 \mathrm{mg} / \mathrm{kg}$ ) increases locomotor activity in rats in a dose dependent manner (Nielsen et al., 1986; Tucker and FIle 1986). In a review of the effects of antidepressants on motor activity, Tucker and File (1986) observed that with the exception of amineptin, bupropion, and nomefensine all antidepressants tend to depress locomotor activity acutely. Amineptin, bupropion, and nomefensine are all antidepressants in which a dopaminergic mechanism of action has been implicated (Dufresne et al., 1984; Tucker and File, 1986). 


\section{Chronic Effects}

During the first fifteen minute activity period (Fig. 27 - 28) all groups exhibit decreases in ambulation (horizontal activity) and rearing. Thus, exploratory activity does not differ between antidepressant and control groups over the course of the study. However, results for the second fifteen minute period of locomotor activity show decreased ambulation (Fig. 29) for desipramine and fluoxetine, but not for the saline treated animals. Similarly, rats administered desipramine and fluoxetine show decreases in rearing activity during the second fifteen minute period (Fig. 30) as compared to control. These were most pronounced between days four and eleven. Thus, chronic treatment with both desipramine and fluoxetine causes greater decreases in spontaneous locomotor activity than controls over time, but neither antidepressant group shows differences in exploratory activity.

The lack of effect of chronically administered desipramine on exploratory activity as compared with control is dissimilar from the increase in ambulation seen with the agent in the study of Przegalinski and associates (1983) and the decrease after fifteen days of treatment seen by Kulkarni and Dandiya (1973). Long-term treatment with fluvoxamine, an antidepressant similar chemically and pharmacologically to fluoxetine (Mendels, 1987; Doogan, 1980), has been shown to decrease exploratory ambulation and rearing (Przegalinski et al., 1983). The results of a study of the effects of six days of treatment with imipramine or chlorimipramine on exploratory activity in the rat were similar to those of this study in 
that there were no significant differences with control in exploratory ambulation as measured by tunnel entries and for rearing (HarrisonRead and Steinberg, 1980).

The decrease in both ambulation and rearing seen in the present study is consistent with previous studies showing decreased spontaneous motor activity with most antidepressants (Tucker and File, 1985). The decrease in ambulation and rearing as compared with control was most evident between day 11 and day 18 . This result does not fit with a pattern of early sedation, and is apparently a result of chronic treatment with the antidepressants. This could be the result of pharmacodynamic changes due to chronic antidepressant treatment or could partially reflect the five days or more needed to reach peak plasma concentrations of antidepressant. These effects on ambulation and rearing occur during the same time period in which antidepressants first show their clinical effects.

\section{Effects of Albuterol Prior to Antidepressant}

\section{Effects on Thresholds}

Increases in mean and ascending thresholds was observed on administration of the B-agonist albuterol to the naive rats (Fig. 1-2). Thresholds immediately returned to baseline after the test day. The most pronounced effect was on ascending thresholds. The increase in thresholds, and thus the decrease in reward capacity, is consistent with the study of Liebman and associates (1984) in which they used a rate technique to study $B$-agonist effects. They found that the $B_{2}$ - 
agonists clenbuterol, albuterol, and terbutaline decrease rate of response for current levels at the lower end of their animals response curve. They also found that these effects were reversed by the non-selective $B$-antagonist propranolol. However, since these $B$ agonists also caused a pronounced decrement in spontaneous motor activity, it is difficult to separate the effect of reduced motoric performance on lever pressing from the reward capacity of the animal. Since the threshold technique in the present study is theoretically free of performance confound, this is the first study to show unequivocally that the $B_{2}$-agonist albuterol raises reward thresholds in the rat. As there are instances in this study where decreased motor activity is not associated with change in threshold, it is apparent that the threshold technique is free from performance confound in reality as well as in theory.

An interesting finding of the Liebman and associates study (1984) is that the potent $B_{2}$-agonist clenbuterol failed to affect thresholds in animals with high baseline activity. As animals with high baseline activity levels were receiving current well above their thresholds, and the low baseline animals were probably receiving current not far above their thresholds, it is apparent that there is a current level where an animal will respond no matter how the reward system is compromised. This is consistent with the findings of Fibiger and Phillips (1981), who failed to see differences at the extremes of the dose response curve even though there was a pronounced difference between treatment groups at the middle levels of current intensities. 
An important implication of the decrease in reward capacity caused by $B_{2}$-adrenergic agonists is its consistency with the $B$ adrenergic receptor down regulation theory of depression. The $B$ adrenergic agonist effect results in increased activity in these systems as would likely occur due to supersensitivity in these systems in major depression. Since overactivity of B-adrenergic systems is associated with dysphoria, it is understandable that a decrease in B-receptor sensitivity would be therapeutic. In light of the reported selective actions of albuterol on $B_{2}$-adrenoceptors, it is tempting to speculate that these receptors may have an important role in depressive disorders.

Another important finding of the Liebman et al. (1984) study is that the self-stimulation rate lowering effects of clenbuterol $(0.3$ $\mathrm{mg} / \mathrm{kg}$ ) and albuterol ( 1 and $10 \mathrm{mg} / \mathrm{kg}$ ) disappear after 3 days of treatment. This rapid tolerance is not seen with clonidine $(0.3$ $\mathrm{mg} / \mathrm{kg}$ ), which also decreases rate of ICSS responding to 20 percent of controls. The persistent effect of clonidine, an $\alpha_{2}$-agonist at low doses and an $\alpha_{1}$-agonist at higher doses, on reward capacity is interesting in light of the effects of many antidepressants on $\alpha-$ adrenergic receptors. Desipramine has been shown to cause subsensitvity of $\alpha_{2}$-adrenergic receptors in rat brain (Crews and Smith, 1978; McMillen et al., 1980). Yohimbine, an $\alpha$-adrenergic antagonist with some selectivity for $\alpha_{2}$-receptors, has been shown to potentiate the activity of antidepressants in the behavioral despair model (Zebrowska-Lupina, 1980) and many other animal models of depression (Malick, 1981). 


\title{
Effects on Motor Activity
}

\author{
Albuterol caused a pronounced decrease in exploratory and \\ spontaneous ambulation and rearing (Fig. 3-6). For all but \\ exploratory ambulation there was a return to baseline values by two \\ days after albuterol administration. This A-B-A return to baseline \\ design reveals a 60 percent decrement in ambulation for both \\ periods with albuterol and a greater than 35 percent drop in rearing \\ for both periods. This is similar to the large decrease in motor \\ behavior seen by Liebman et al. (1984) for the B2-agonists albuterol, \\ clenbuterol, and terbutaline and also by Mogilnicka (1982) for \\ albuterol. All effects of the $B_{2}$-adrenergic agonists were reversed by \\ propranolol, and tolerance to the motor effects of clenbuterol \\ developed by the end of a four day treatment period (Liebman et al., \\ 1984). Prezegalinski and associates (1983) have observed albuterol \\ induced decreases in exploratory ambulation to as little as only 20 \\ percent of control. \\ Therefore, B2-agonists cause pronounced decreases in both \\ exploratory and spontaneous motor activity. Overactivity of B- \\ adrenergic neurosystems as caused by these $B_{2}$-adrenergic agonists \\ may be analogous to that seen due to supersensitive $B$-adrenergic \\ receptors in depression. This would be consistent with the \\ psychomotor retardation that is a frequent symptom of depressive \\ disorders. Interestingly, the $B$-antagonist propranol given acutely \\ has been shown to reduce rat immobility in the Porsolt behavioral \\ despair model in the same manner as antidepressants; clonidine also
}


showed this property (O'Neill, 1983). Propranol given acutely would cause immediate reversal of overactive $B$-adrenergic systems.

Clonidine causes reduction in immobility in the Porsolt model via an $\alpha$-adrenergic agonistic mechanism; it is unclear whether the activity on $\alpha_{1}$ or $\alpha_{2}$-adrenergic receptors is critical. The $\alpha$ adrenergic antagonist yohimbine, like propranolol, has been shown to reverse albuterol induced hypoactivity in the rat (Mogilnicka, 1982). Thus, the $\alpha$-adrenergic antagonists consistently act as the $B_{2}$-agonists and the $\alpha$-adrenergic agonists act in the manner of the $\beta$-adrenergic antagonist. A functional relationship between these neurotransmitter systems seems likely with regard to motor activity and perhaps reward capacity.

\section{Effects of Albuterol After Chronic Administration of} Antidepressant

\section{Threshold effects}

Both desipramine and saline treated animals show increases in mean threshold in response to albuterol while the fluoxetine treated animals do not (Fig. 7). Thus, chronic treatment with fluoxetine 10 $\mathrm{mg} / \mathrm{kg}$ apparently causes decreases in sensitivity to the $B_{2}$ adrenergic antagonist that differs from the effects of both saline and desipramine $10 \mathrm{mg} / \mathrm{kg}$. As both the fluoxetine and desipramine groups show pronounced weight loss as compared with control over 
the course of the study, the difference is not due to lack of sufficient treatment with desipramine.

A similar trend is evident for the descending and ascending thresholds that fails to reach significance (Fig. 8-9). It is likely that the relatively low power of the between group comparisons in this design decreased the sensitivity of the analysis for the separate indices. However, the mean threshold is a combination of the two indices and is therefore more reliable. The increase in reliability for the mean threshold decreased the error of measurement sufficiently for the similar difference to be statistically significant.

The increase in mean threshold upon albuterol administration for the desipramine and saline treatment groups persists for at least one week; this is dissimilar to the effects of albuterol prior to antidepressant treatment. While it is possible that withdrawal from desipramine could be responsible for this effect, it is unlikely since the saline treated animals also demonstrated a persistent increase in thresholds. The only systematic difference between the postalbuterol saline treatment days prior to and after antidepressant treatment is that the animals were used to receiving the nightly injection of antidepressant or vehicle for the three week period prior to the terminal albuterol challenge. However, the lack of any changes in threshold for the fluoxetine treated animals would argue against this confound. Thus, the best explanation for this phenomena is a differing effect on $B$-adrenergic receptors for desipramine and fluoxetine.

It is reasonable to infer that the selective effects on serotonergic mechanisms by fluoxetine is responsible for the lack of 
reactivity of this group to the albuterol challenge. Fluoxetine is very specific in inhibiting serotonin reuptake and is devoid of affinity for histaminic, muscarinic, 5-HT-1 or 5-HT-2, or either $\alpha_{1}$ or $\alpha_{2}$ adrenergic receptors (Stark et al., 1985). The innervation of B2adrenergic receptors in the cerebral cortex is currently unknown; $B_{1}$ receptors are neuronally innervated by norepinephrine (Minneman et al., 1981). It is tempting to speculate that serotonergic systems innervate the $B_{2}$-adrenergic receptors in cerebral cortex.

There is increasing evidence that antidepressants cause a down-regulation of a linked 5-HT/norepinephrine B-adrenoceptor system, and that impairment of normal functioning of serotonergic neurons prevents this down-regulation even by non-serotonergic antidepressants such as desipramine (Sulser, 1987). Serotonergic mechanisms have been shown to be necessary for B-adrenergic down-regulation by imipramine (Dumbrille-Ross and Wang, 1983). Fluoxetine, which selectively blocks 5-HT reuptake, has been shown to down regulate $B_{2}$-adrenergic receptors in several brain regions (Wamsley et al., 1987).

Noradrenergic and serotonergic neurosystems appears to be interdependent. The $\alpha_{2}$-adrenergic agonist clonidine has been shown to reduce the electrically evoked release of $3 \mathrm{H}-5-\mathrm{HT}$ from rat brain cortical slices (Grob et al., 1987). Also, the B2-adrenergic agonists albuterol and clenbuterol have been shown to potentiate 5HT mediated behaviors induced by the serotonergic agonist quizapine (Cowen et al., 1982; Green et al., 1984), and clenbuterol was demonstrated to increase 5-HT turnover (Green et al., 1984). Interestingly, the clenbuterol induced potentiation of 5-HT mediated 
behaviors and increase in 5-HT turnover was antagonized by the centrally acting $B_{1}$-adrenergic selective antagonist metoprolol and by atenolol but not by the $B_{2}$-adrenergic antagonist butoxamine (Cowen et al., 1982; Green et al., 1984); therefore, it is premature to link this effect on serotonergic systems to either B-adrenergic receptor subpopulation.

\section{Motor effects}

There were no differences in exploratory or spontaneous motor activity between animals chronically treated with desipramine or fluoxetine as compared with controls (Fig. 11-14). This differs from the results of the study of Przegalinki and associates (1983) who found that the antidepressants imipramine, desipramine, amitriptyline, fluvoxamine, and citalopram given orally at $10 \mathrm{mg} / \mathrm{kg}$ twice daily prevented albuterol (10 mg/kg I.P.) induced hypoactivity in rats. Our results may have differed with theirs due to the differences in dose and dosing schedule. Also, their study examined only initial exploratory motor activity over three minutes, and their animals received the antidepressants or 14 days rather than 19 days. However, these differences in the two studies appear small, and it is difficult to understand why the results of the present study fail to replicate their findings.

It is important to note that the difference in mean thresholds upon albuterol challenge between the fluoxetine treated animals and the others is not mirrored in the results of the motoric variables. Similarly, the differences in spontaneous motor activity between 
control and antidepressant group in the chronic antidepressant phase were not mirrored by raises in threshold. This is further evidence that the threshold technique is not confounded by motoric impairment.

\section{Effects of Antidepressants Given Chronically on Weight}

Both fluoxetine and desipramine caused dramatic weight loss as compared to control (Fig. 26). Fluoxetine, a selective reuptake inhibitor of 5-HT, is likely to have caused this through a serotonergic mechanism. The 5-HT reuptake inhibitor and releaser dextrofenfluramine, used clinically in treating obesity and possibly effective in treating seasonal affective disorder (O'Rourke et al., 1987), has been shown to be anorexigenic in rats (Chaouloff et al., 1989). Dextrofenfluramine has also been shown to decrease rate of self stimulation of feeding centers in the lateral hypothalamus in rats (McClelland et al., 1989). The antidepressant zimelidine is, like fluoxetine, a potent serotonergic reuptake inhibitor; it has been shown to decrease eating and drinking behavior in a dose dependent fashion in pigeons while the serotonin antagonist cyproheptadine antagonized this effect (Gonturkun et al., 1989).

The weight loss caused by desipramine could be accounted for by at least two mechanisms. First, the stimulatory effect of norepineprine on feeding behavior is mediated by $\alpha_{2}$-adrenergic receptors located in the medial hypothalamus; $\alpha_{2}$-adrenergic agonists such a clonidine cause hyperphagia in rats, while $\alpha 1$-adrenergic 
blockers such as prazosin do not antagonize the stimulatory effect of norepinephrine on eating behavior (Leibowitz et al., 1988). Weight loss during chronic desipramine treatment in this study is possibly due to a decrease in $\alpha_{2}$-adrenergic receptor sensitivity (Crews and Smith, 1978; Kostowski et al., 1986) which may have led to decreased caloric intake. Another possible contributing mechanism in rats could be an acute increase in interscapular brown adipose tissue activity in rats; $B$-adrenergic receptors are activated by norepinephrine to stimulate metabolism (Carlson, 1986). The increase in norepinephrine in the synapse caused by desipramine could be responsible for the weight loss via an increase in metabolism prior to $\beta$-receptor down-regulation, while $\alpha_{2}$-adrenergic receptor subsensitivity could mediate decreased food intake and weight loss after the first week or drug administration.

\section{Conclusions}

The antidepressants desipramine and fluoxetine given at dosages of $10 \mathrm{mg} / \mathrm{kg}$ via lavage daily for nineteen days did not lower thresholds as compared with saline. The results of this study do not support the hypothesis that antidepressants alleviate depression by increasing reward capacity. There are plausible alternative hypothesis. For example, the rats tested were not originally dysphoric. Humans who are not suffering from depression are not reported to experience euphorogenic effects or even improvements in mood with antidepressants. Animals may have to be in a state of 
abnormally decreased reward capacity for there to be an effect. Furthermore, antidepressants may act to prevent abnormally low levels of reward capacity without affecting normal reward capacity. Also, aversive systems may be involved. An increased tolerance to aversive stimuli may be the principal result of therapy with antidepressant medication.

The hypothesis that B-adrenergic agonists should raise ICSS thresholds was confirmed. The $B$-adrenergic agonist albuterol caused an increase in mean threshold of self-stimulation. However, the hypothesis that chronic administration of the antidepressants desipramine and fluoxetine would decrease $B$-adrenergic receptor sensitivity and cause a diminished response to albuterol was only partially supported. The animals treated for nineteen days with fluoxetine did not show an increase in threshold upon administration of albuterol whereas those treated with desipramine or equal amounts of saline vehicle over the same time period did show an increase in mean threshold upon albuterol administration. Thus, only the fluoxetine treated animals appeared less sensitive to albuterol induced changes in threshold. Also, the persistent elevation of thresholds of up to a week after albuterol challenge for the saline and desipramine treated animals leaves open the possibility that a non-specific effect such as withdrawal of the evening injections resulted in the change. However, the lack of such an occurrence for the fluoxetine treated animals argues against this interpretation.

The last hypothesis stated that the threshold method that we have adapted from Kornetsky and associates is less sensitive to the 
performance confound than the rate technique for measuring reward capacity. While we were able to show a decrease in motor activity without a concomitant increase in reward thresholds during treatment with antidepressants, the only major changes in reward capacity we observed were increases in threshold which occurred concomitantly with substantial decreases in motor activity. Thus, while these experiments demonstrated that motor activity can change without affecting thresholds, we were unable to prove that thresholds could change without a corresponding change in motor activity. The inability to do so is largely due to the lack of a threshold lowering effect of desipramine or fluoxetine. Future studies with drugs likely to lower thresholds for self-stimulation and decrease motor activity or to increase ICSS thresholds while increasing motor activity would be helpful in this regard. 


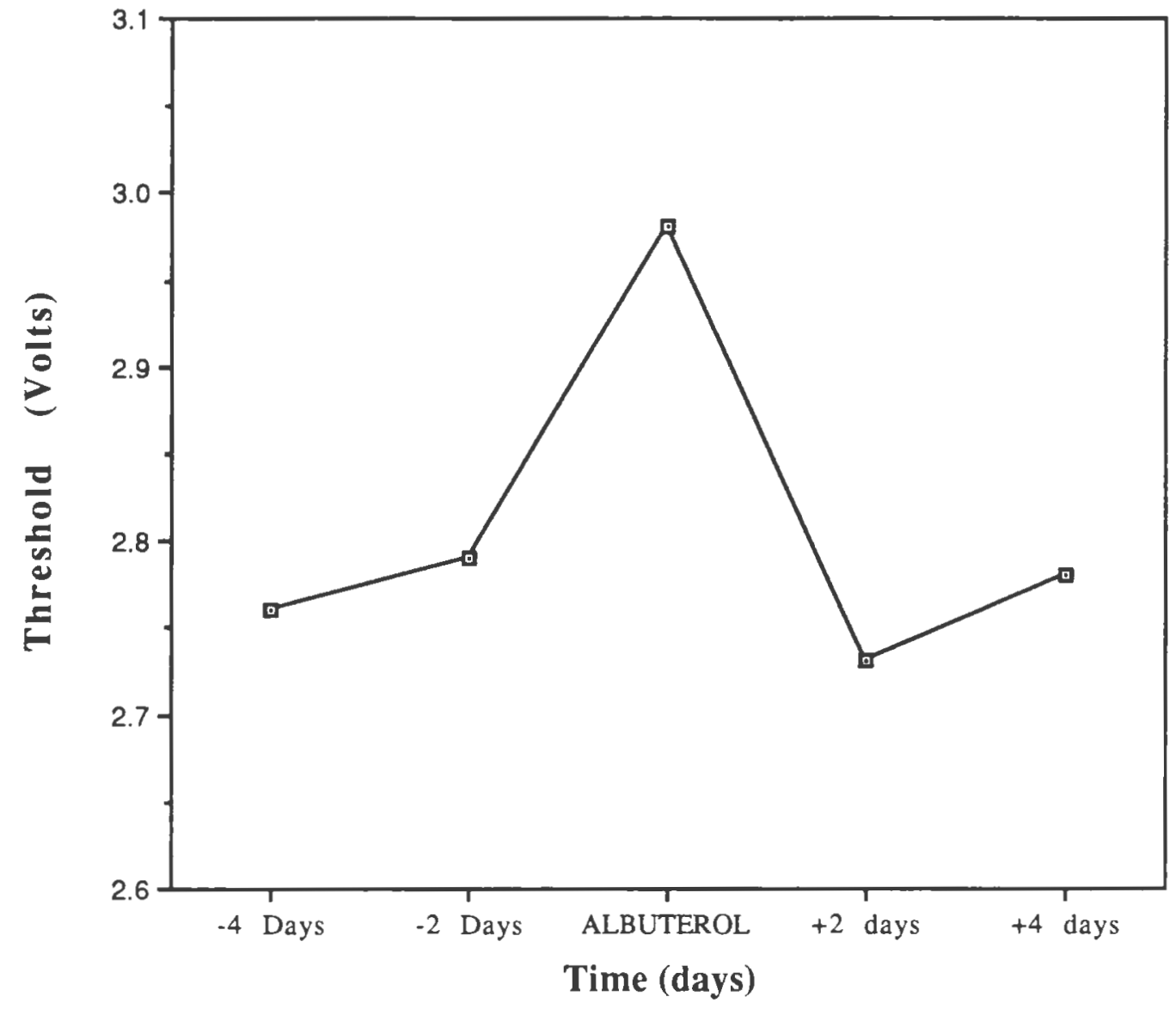

Fig. 1. The effects of albuterol on mean thresholds in the pre-antidepressant period. Albuterol $(10 \mathrm{mg} / \mathrm{kg})$ given by lavage 30 minutes prior to testing at time zero caused a significant $(p<.05)$ increase in mean thresholds. 


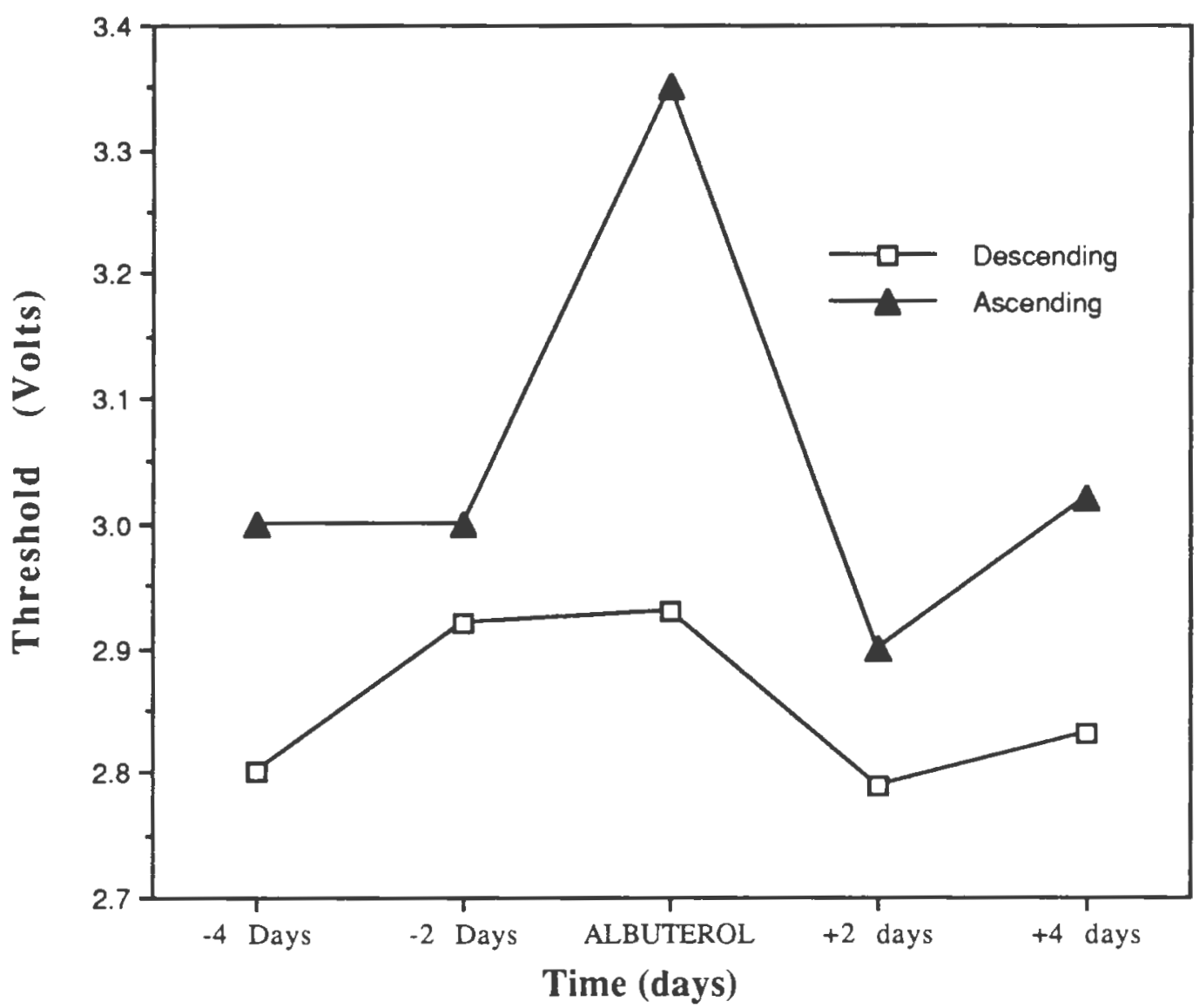

FIG. 2. The effects of albuterol on descending and ascending thresholds in the pre-antidepressant phase. Albuterol (10 mg/kg) given at time zero caused a significant increase in ascending thresholds $(p<.01)$ but did not affect descending thresholds. 


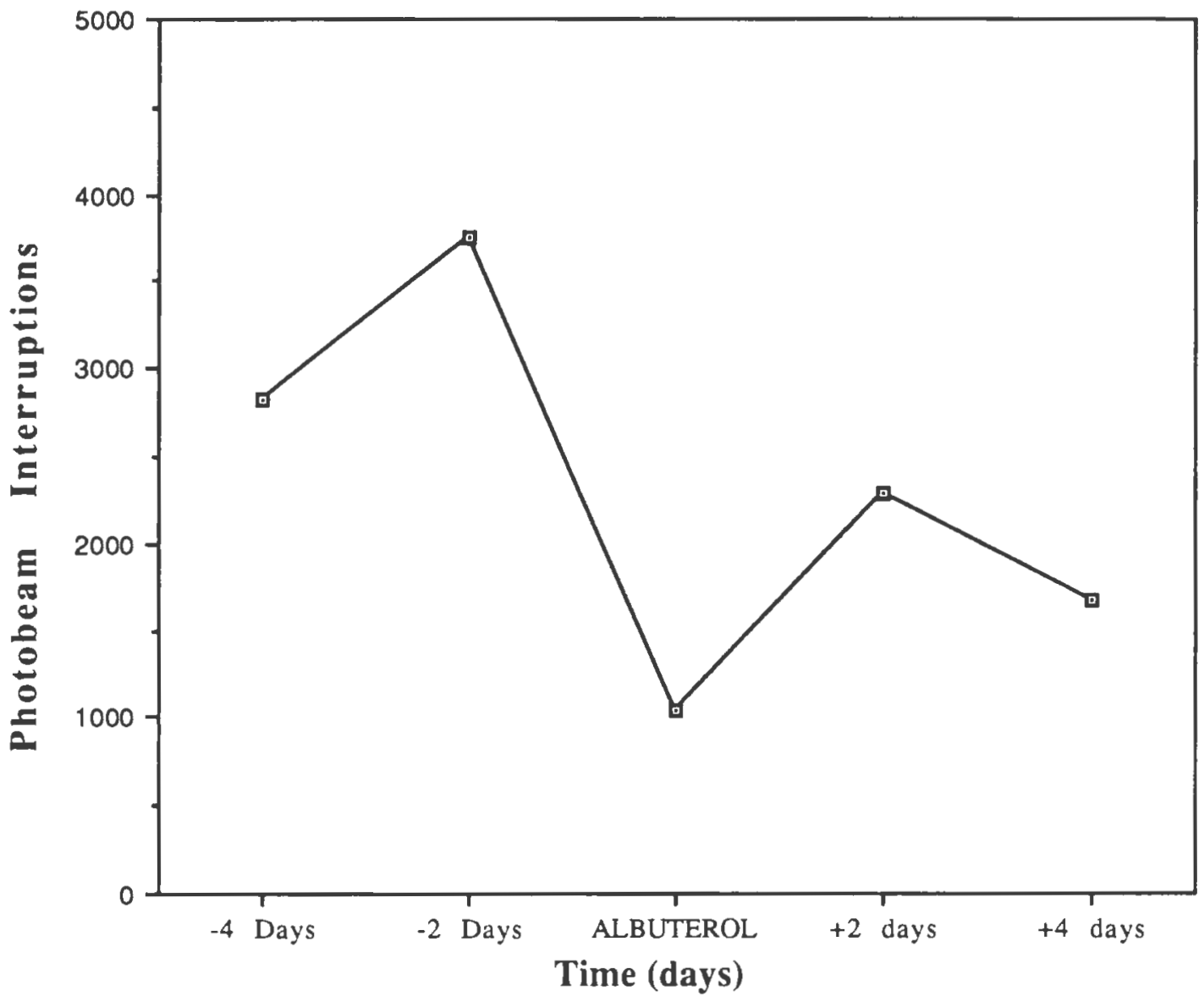

Fig. 3. The effects of albuterol on horizontal movement during the first fifteen minute period for the preantidepressant period. Albuterol $(10 \mathrm{mg} / \mathrm{kg})$ given by lavage at time zero caused a significant $(p<.01)$ decrease in activity. 


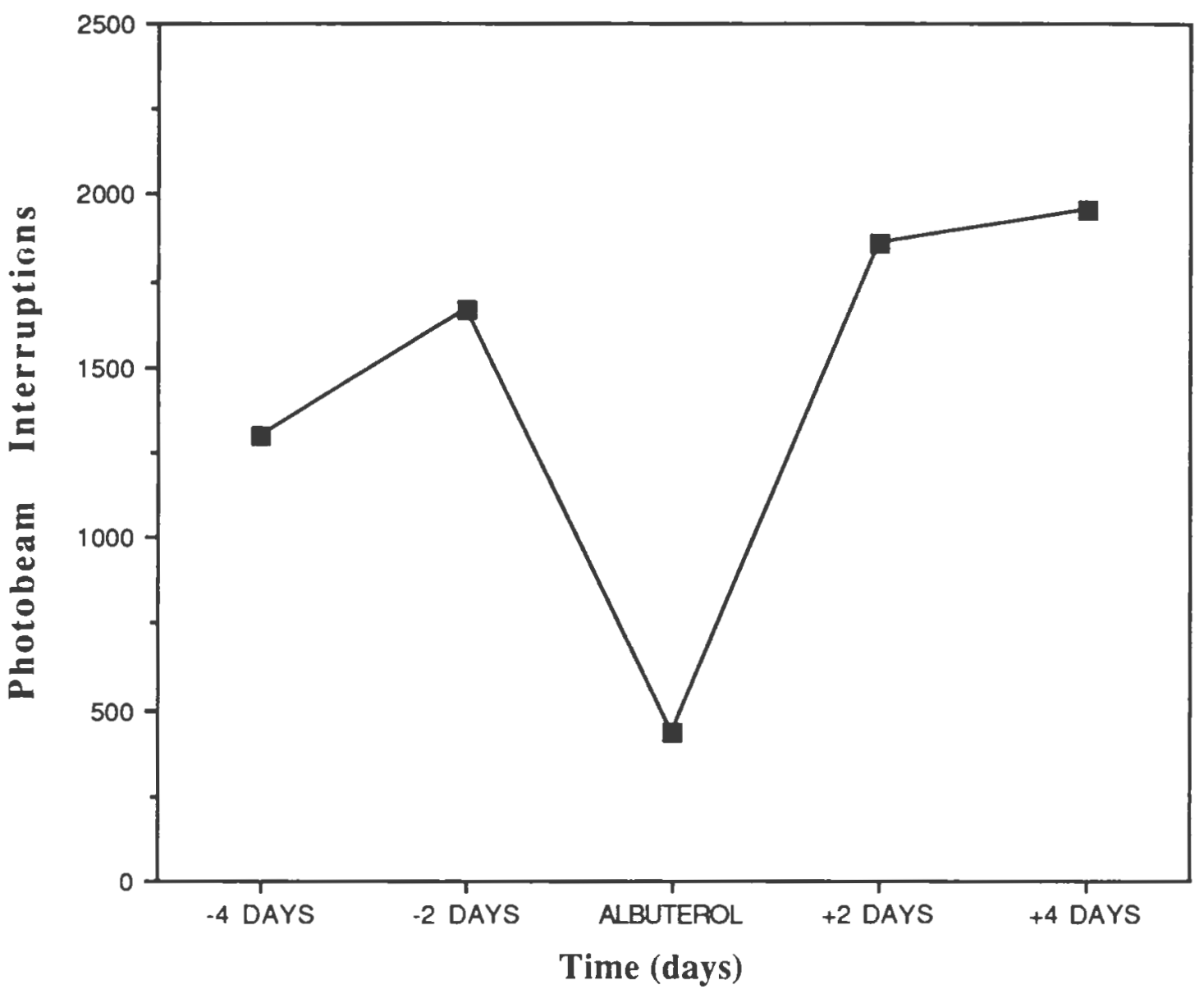

Fig. 4. The effects of albuterol in the pre-antidepressant period on horizontal motor activity during the second fifteen minute period. Albuterol $(10 \mathrm{mg} / \mathrm{kg})$ given at time zero caused a significant decrease $(p<.01)$ in activity. 


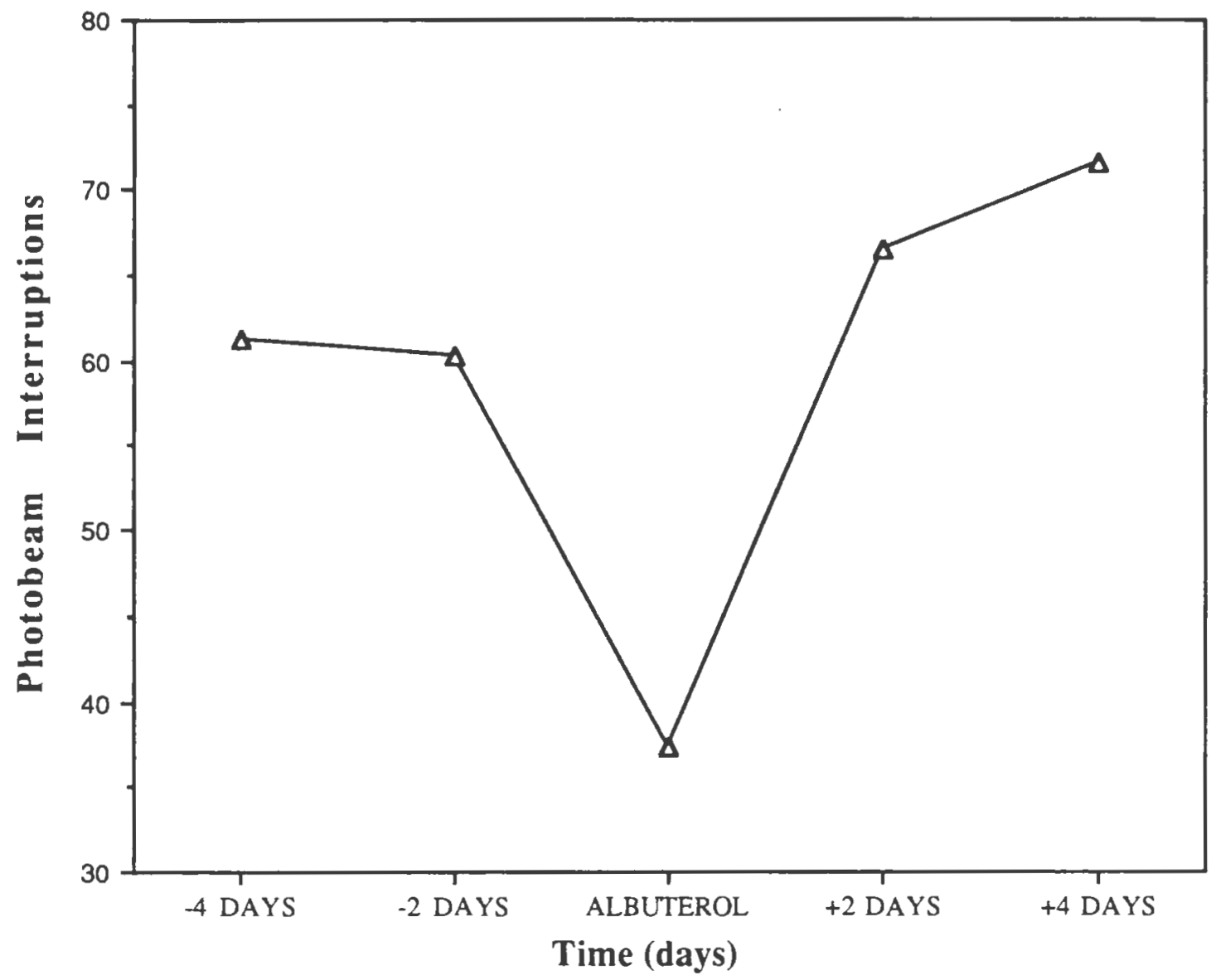

Fig. 5. The effects of albuterol on the first fifteen minutes of rearing in the pre-antidepressant phase. Albuterol $(10 \mathrm{mg} / \mathrm{kg})$ given at time zero caused a significant $(\mathrm{p}<.01)$ decrease in rearing. 


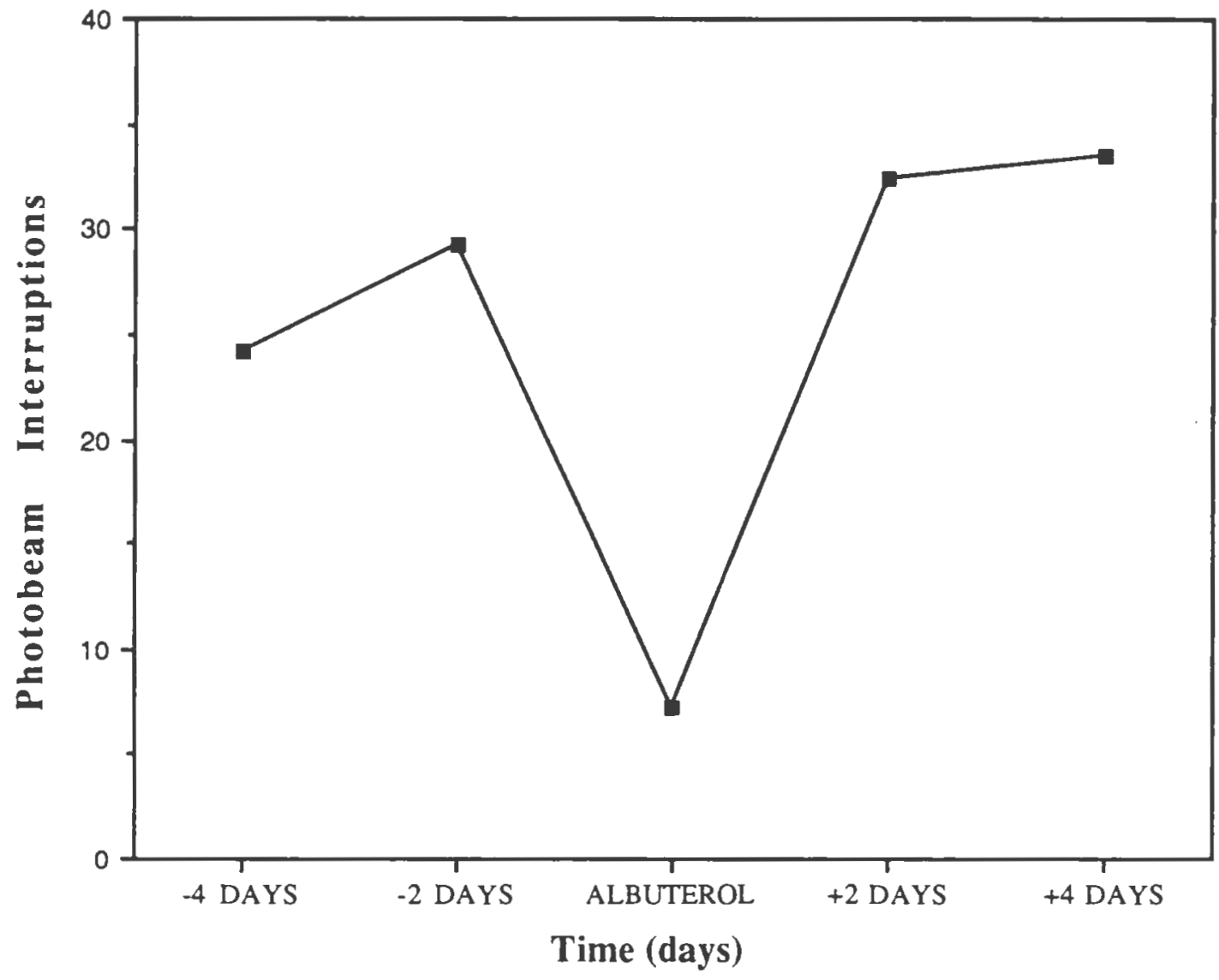

Fig. 6. The effects of albuterol on rearing activity in the second fifteen minutes in the pre-antidepressant period. Albuterol $(10 \mathrm{mg} / \mathrm{kg})$ given at time zero caused a significant $(\mathrm{p}<.01)$ decrease in rearing. 


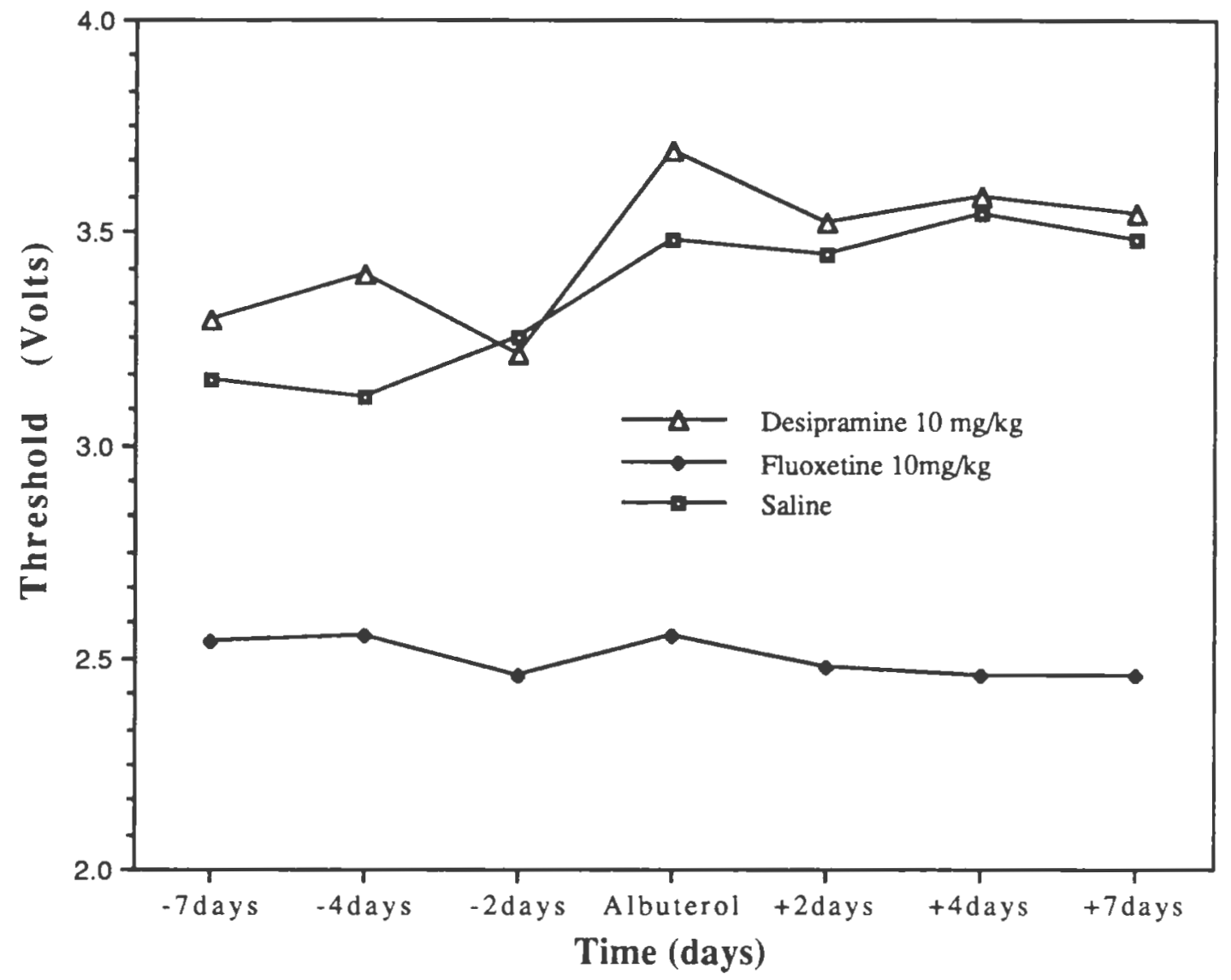

Fig. 7. The effects of albuterol on mean thresholds in the post antidepressant phase. Albuterol given at time zero is associated with a significant $(p<.05)$ increase in thresholds for desipramine and saline but not fluoxetine treated animals. 


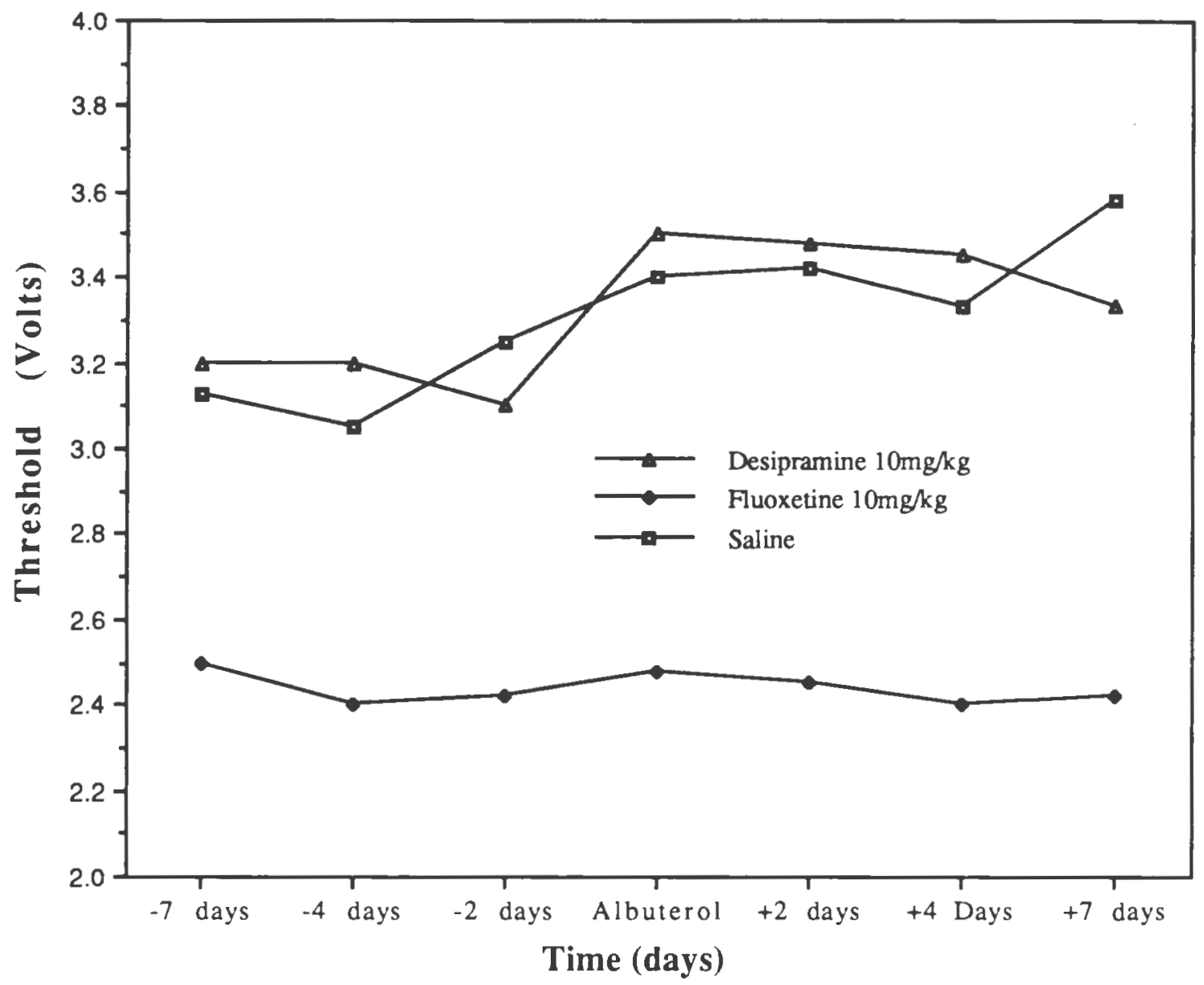

Fig. 8. The effects of albuterol on descending thresholds in the post antidepressant phase. Albuterol ( $10 \mathrm{mg} / \mathrm{kg})$ given at time zero was associated with increased thresholds. Drug group by time differences were not significant. 


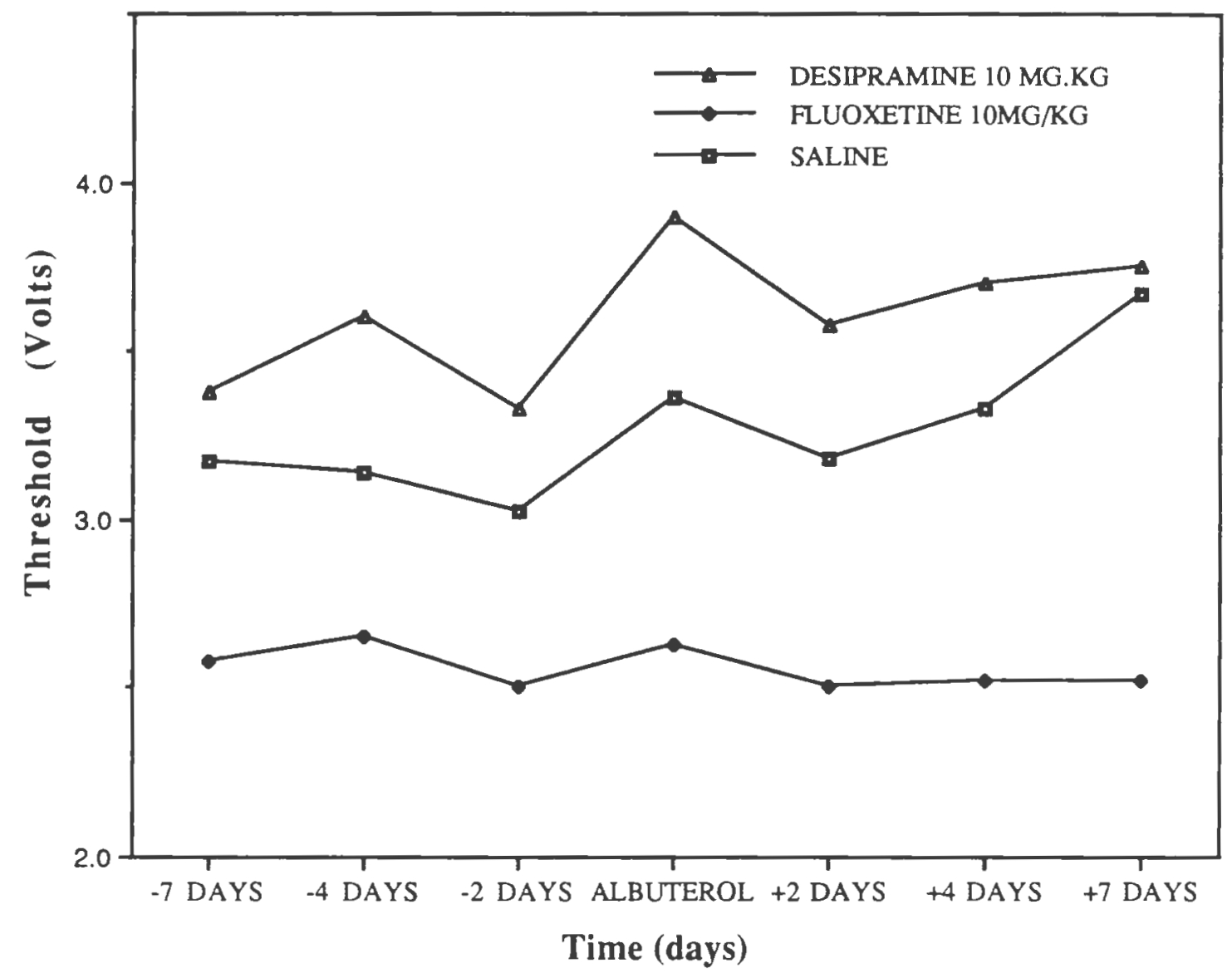

Fig. 9. The effects of albuterol on ascending thresholds in the post antidepressant phase. Albuterol $(10 \mathrm{mg} / \mathrm{kg})$ given at time zero was associated with an increase in threshold that did not differ between drug treatment groups. 


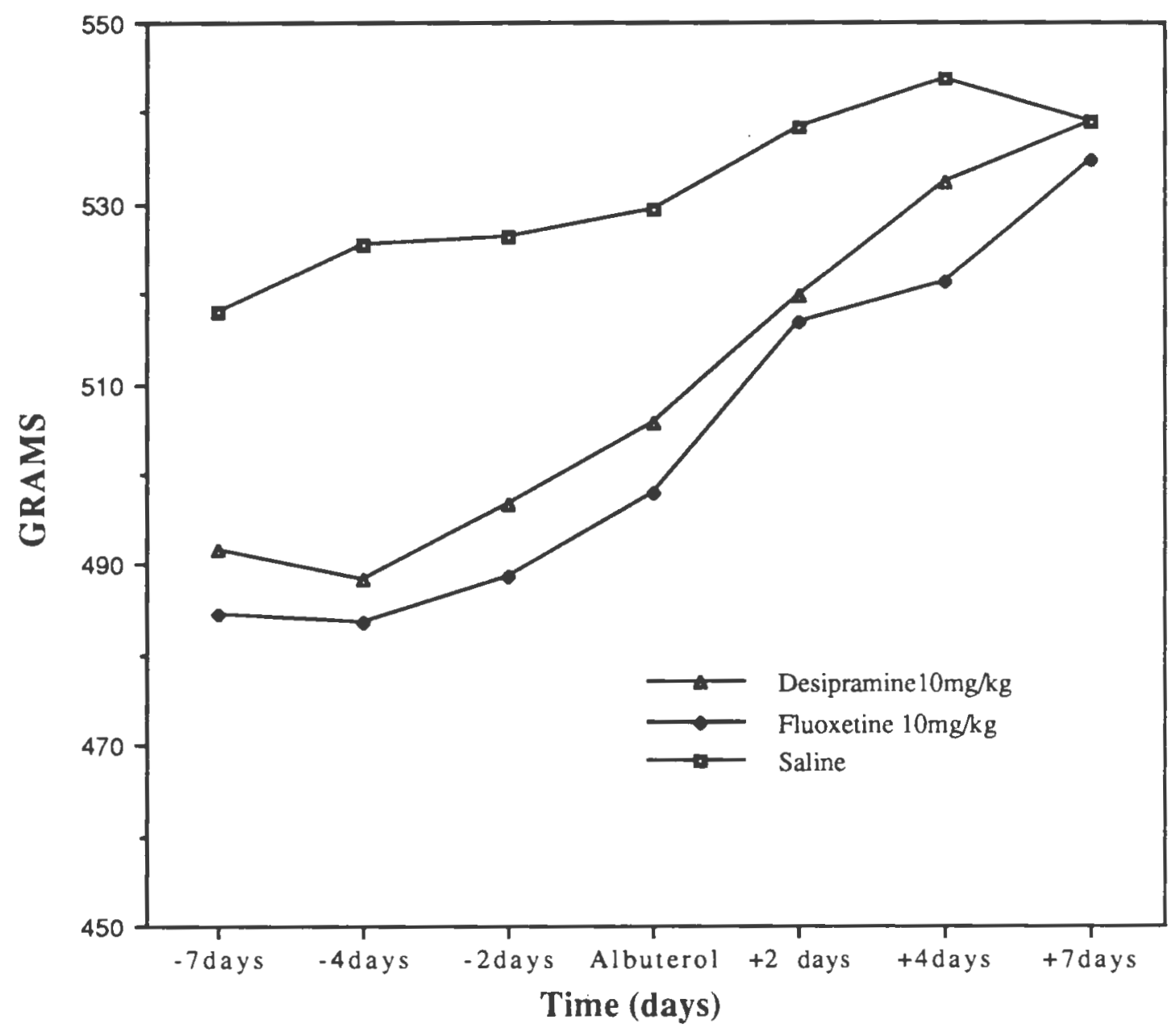

Fig. 10. The effects of albuterol on weight in the post antidepressant phase. A significant increase in weight was observed $(p<.01)$ that was not related to drug treatment group or albuterol adminstration. 


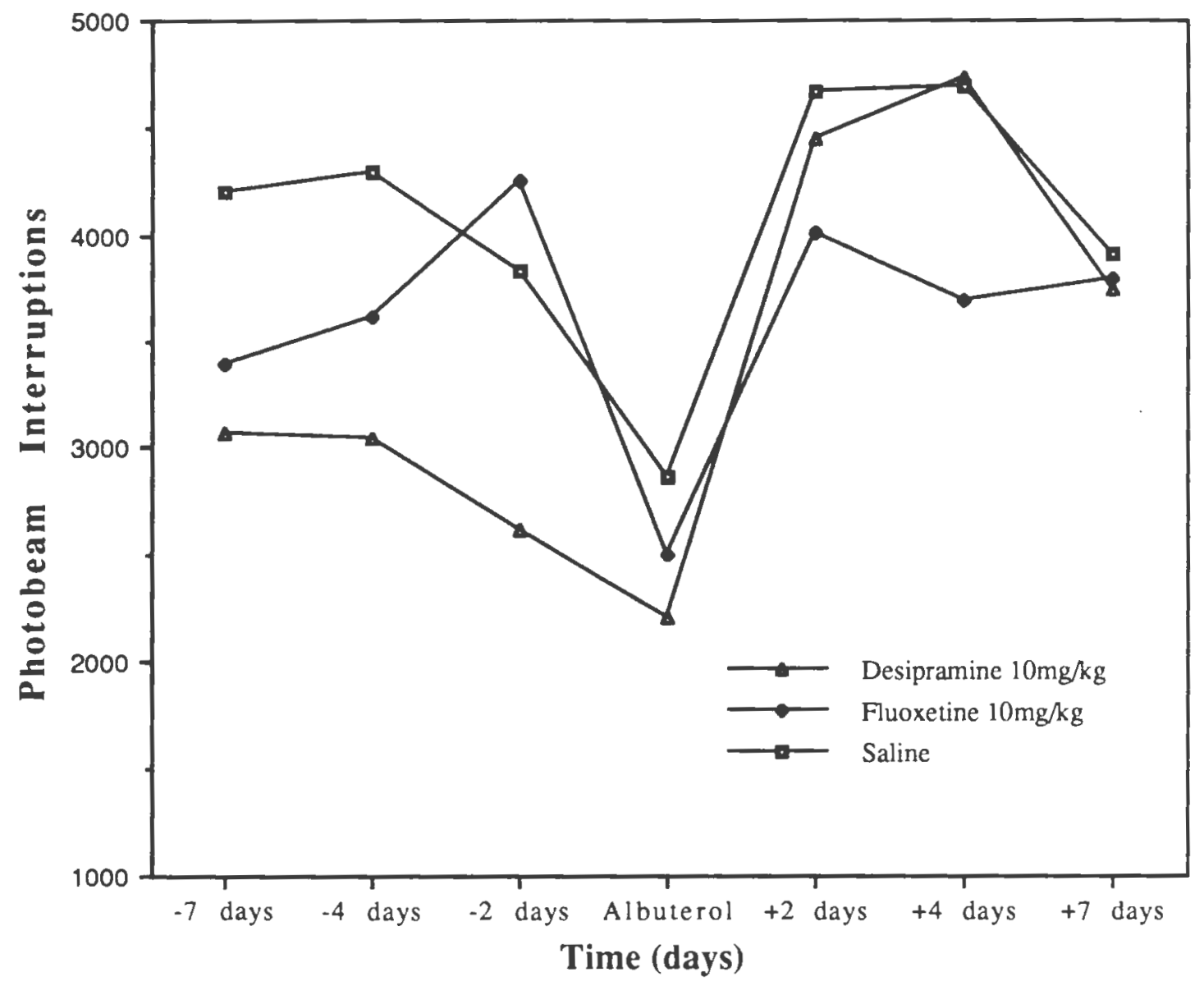

Fig. 11. The effects of albuterol in the first fifteen minutes of horizontal activity during the post antidepressant phase. Albuterol $(10 \mathrm{mg} / \mathrm{kg})$ given at time zero was associated with significantly $(p<.01)$ decreased activity for all drug groups. 


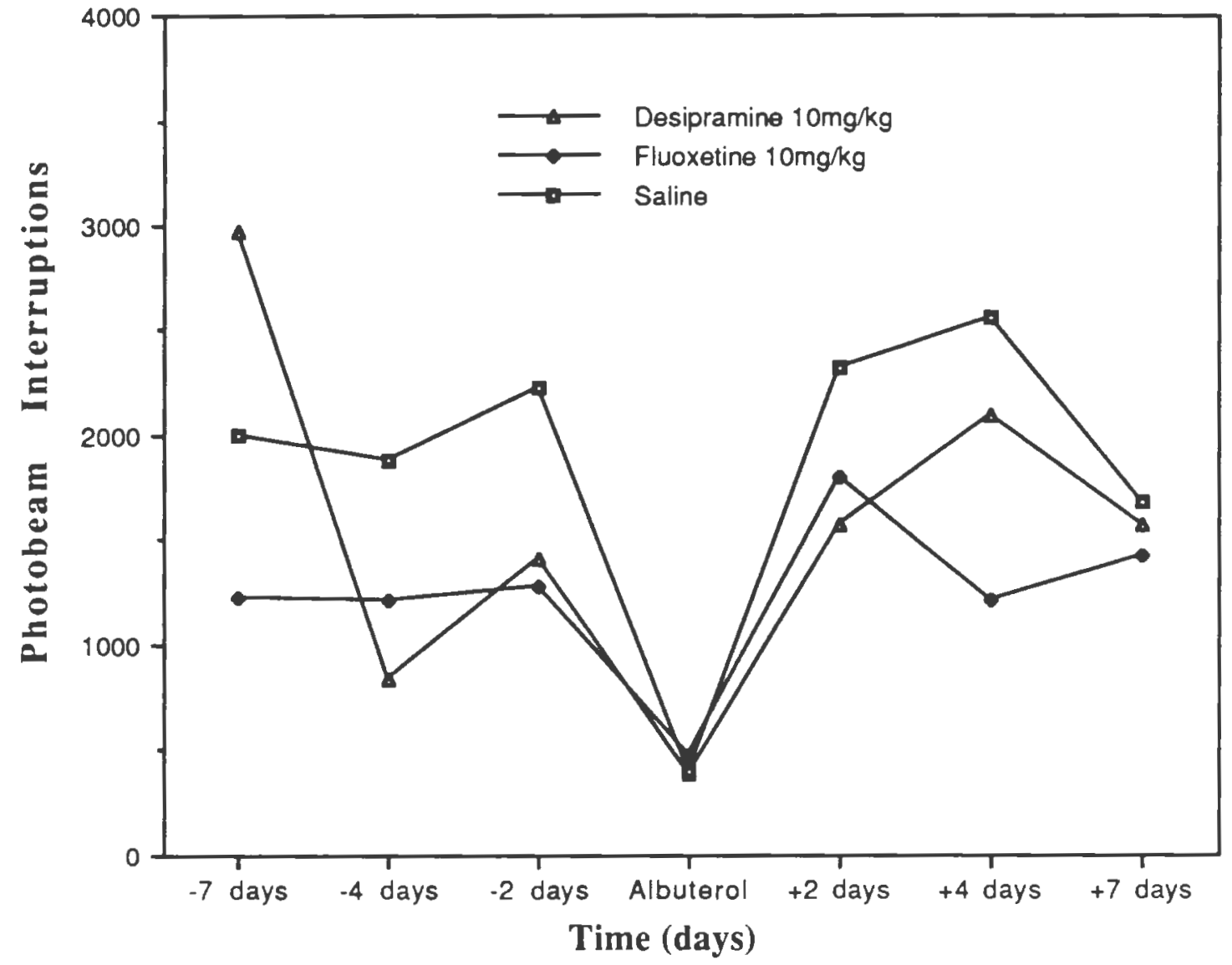

Fig. 12. The effects of albuterol on the second fifteen minutes of horizontal activity in the post antidepressant phase. Albuterol $(10 \mathrm{mg} / \mathrm{kg})$ given at time zero was associated with significant decreases in activity that did not differ between groups. 


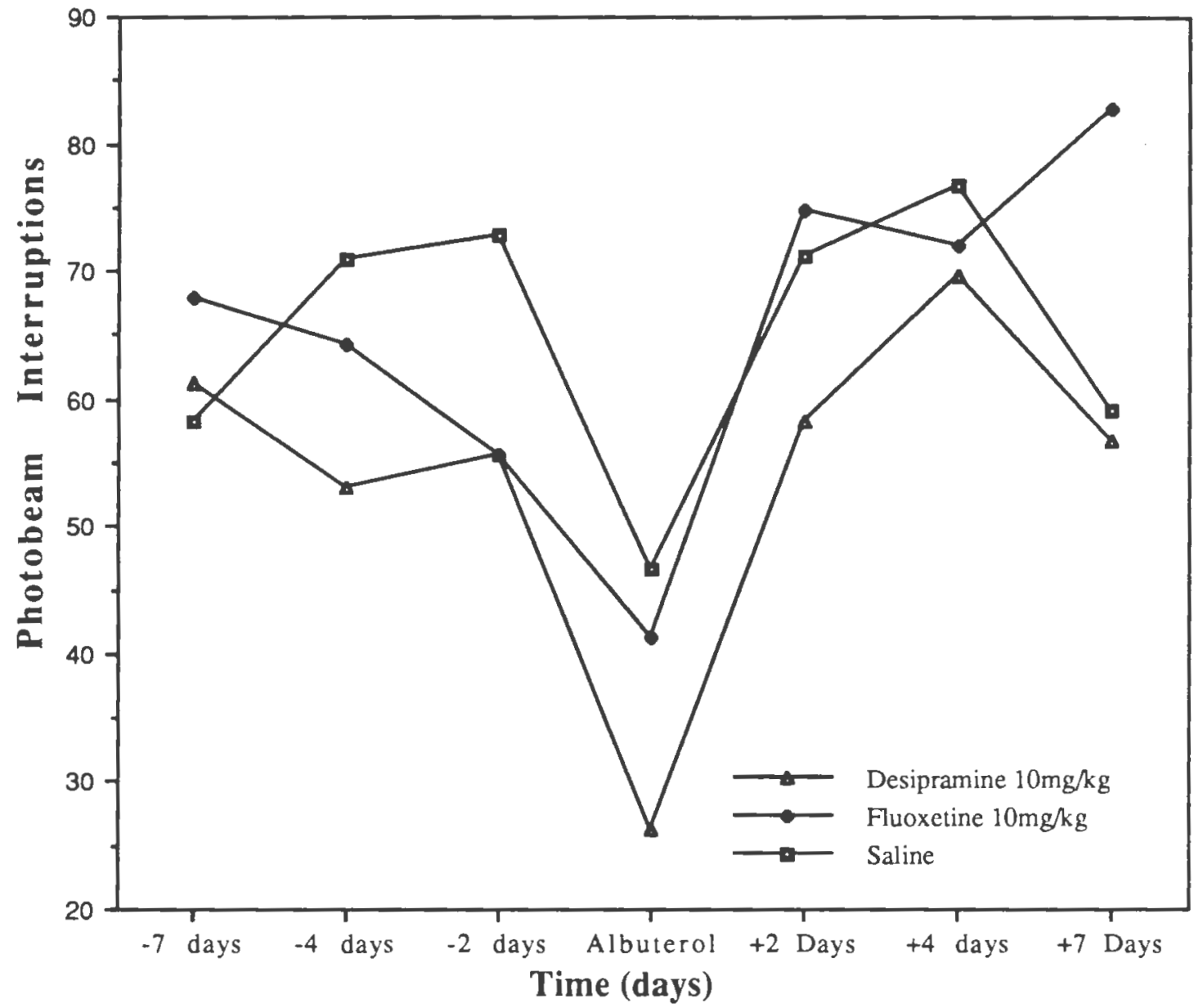

Fig. 13. The effects of albuterol on rearing in the first fifteen minute period in the post antidepressant phase. Albuterol at time zero was associated with a significant decrease $(p<.01)$ in rearing for all drug groups. 


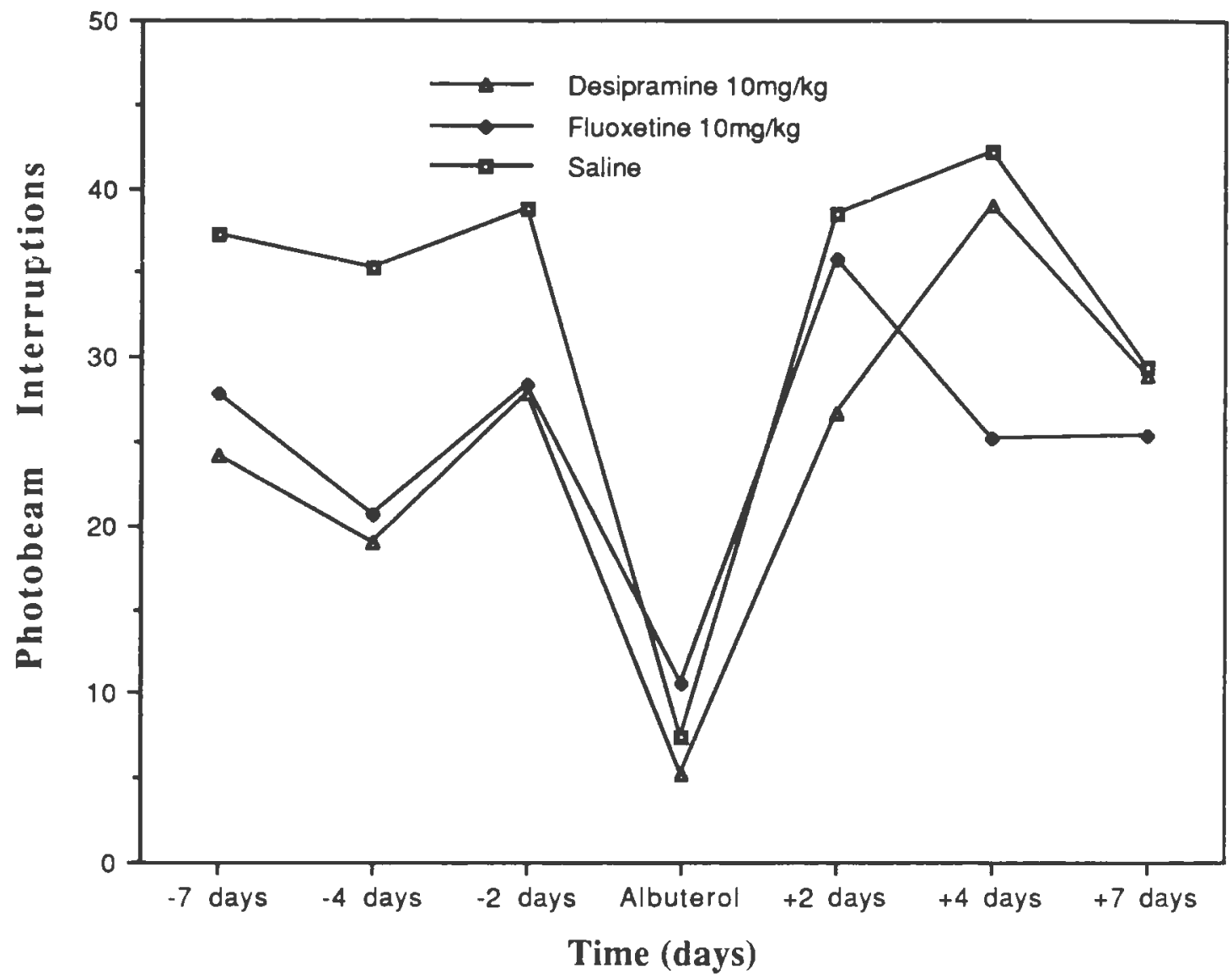

Fig. 14. The effects of albuterol on rearing in the second fifteen minute period during the post antidepressant phase. Albuterol (10 $\mathrm{mg} / \mathrm{kg})$ given at time zero was associated with a significant $(\mathrm{p}<.01)$ decrease in rearing for all drug groups. 


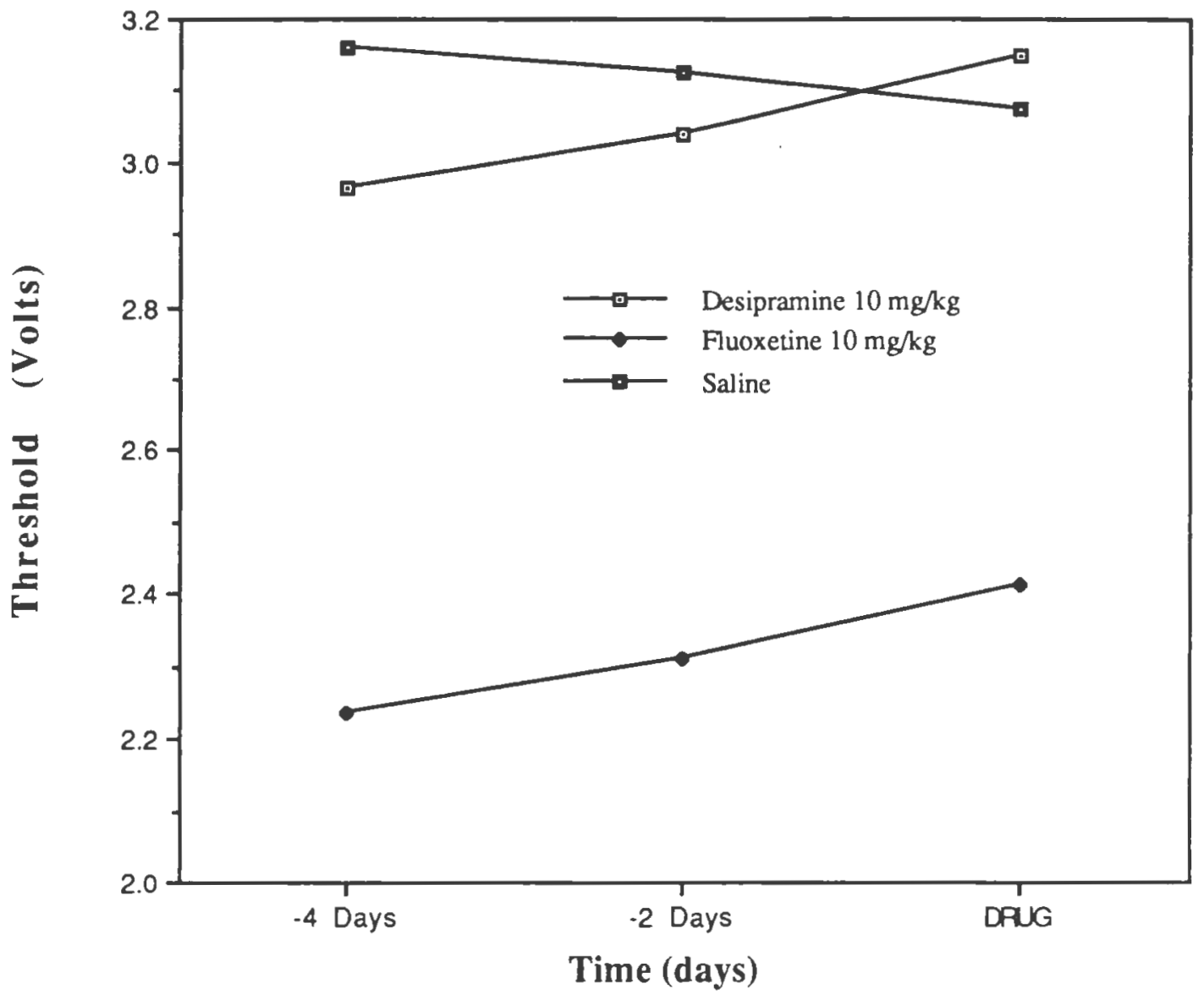

Fig. 15. The effects of acute administration of antidepressants vs. saline on mean thresholds. There were no changes over time or between groups. 


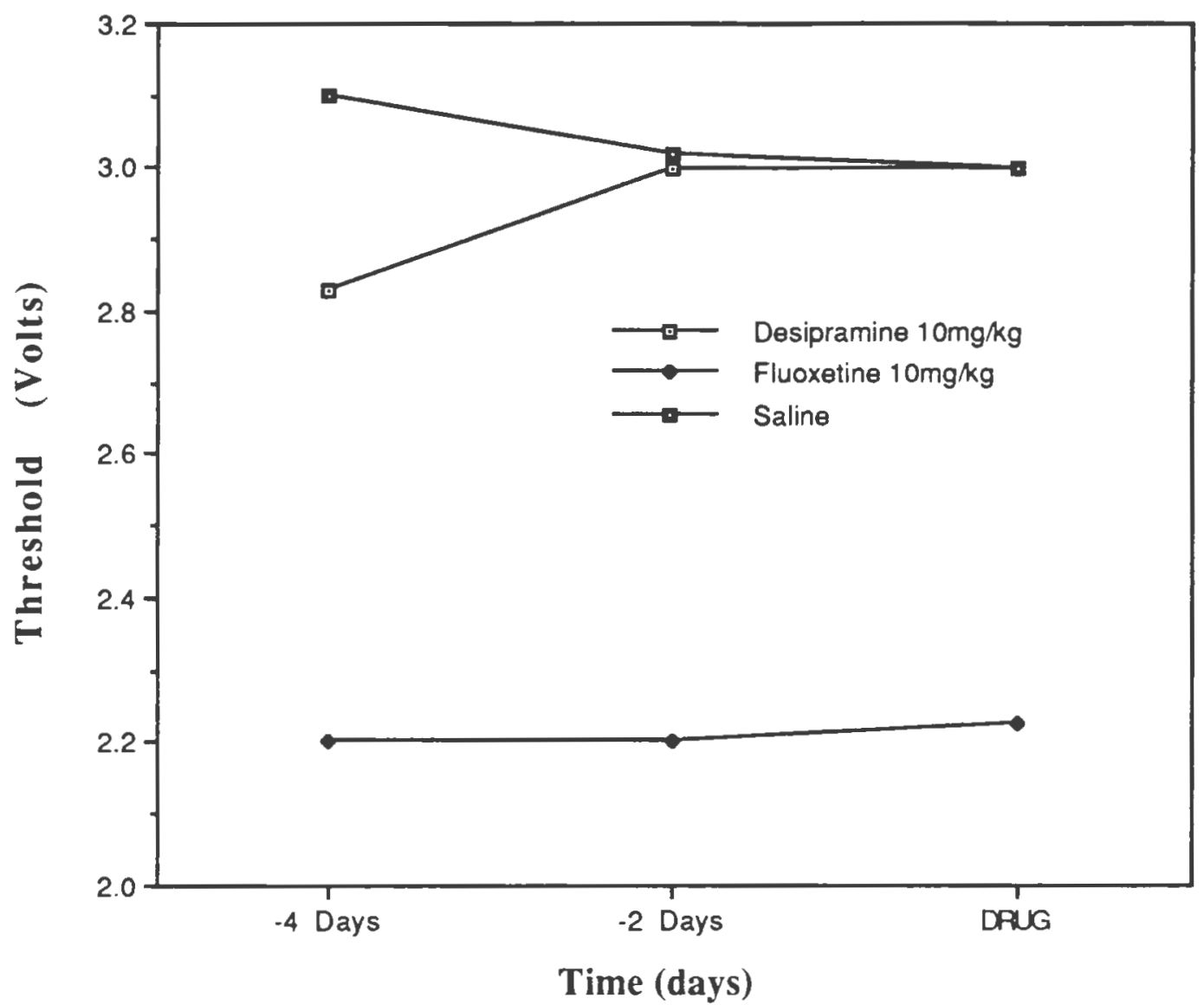

Fig. 16. The effects of acute administration of antidepressants vs. saline on descending thresholds. There were no differences between groups or over time. 


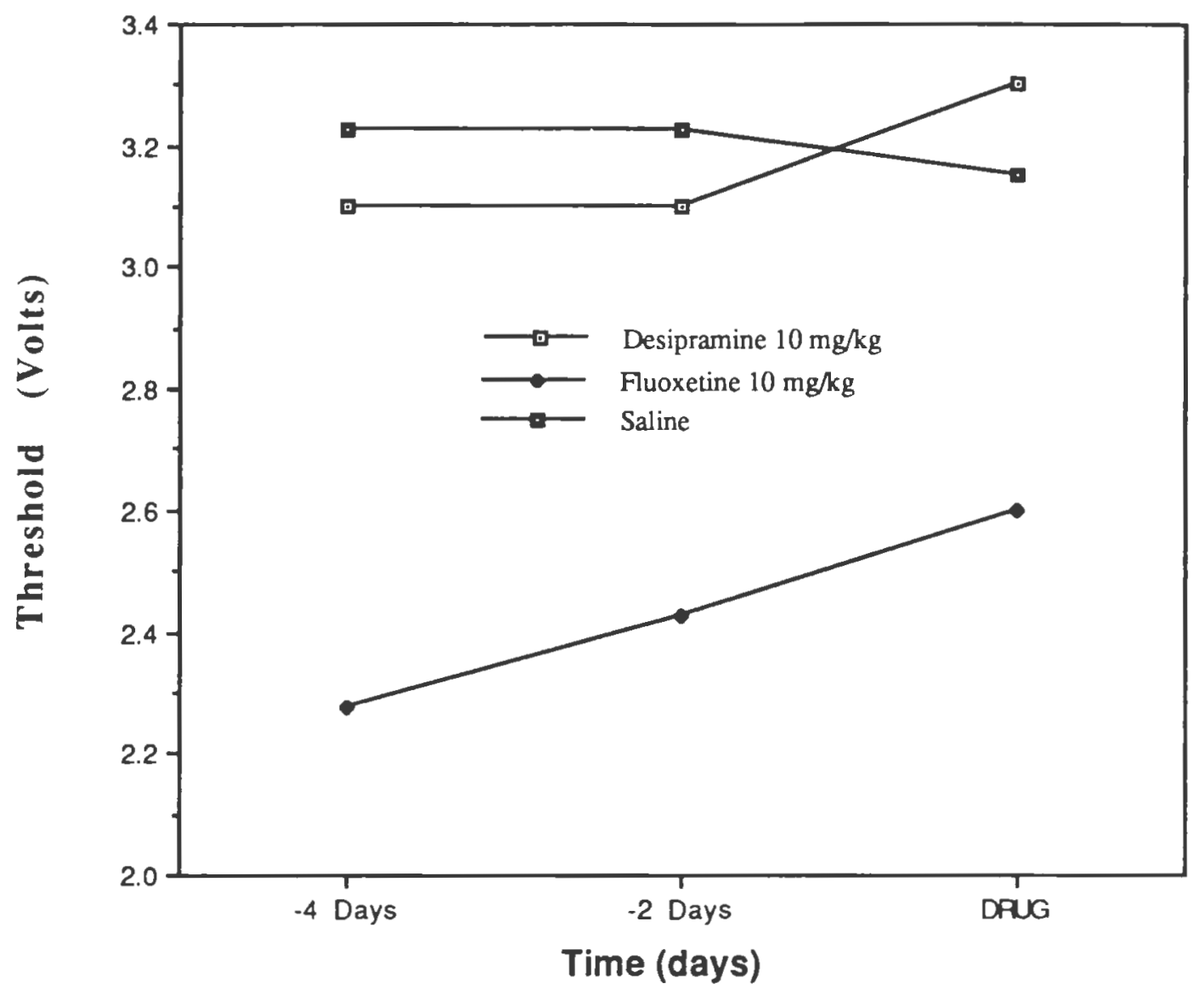

Fig. 17. The effects of acute administration of antidepressants vs. saline on ascending thresholds.

There were no differences between groups or over time. 


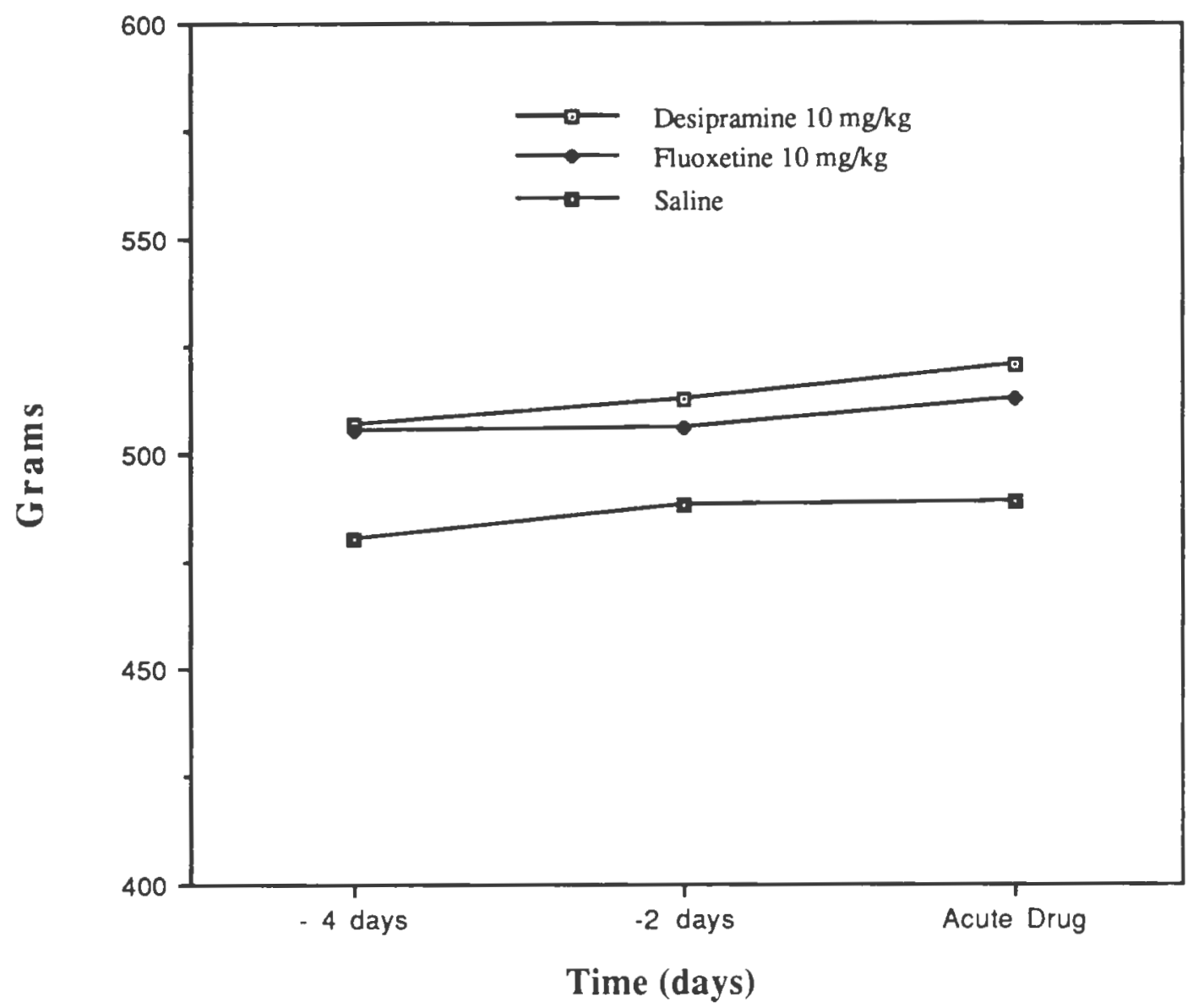

Fig. 18. The effects of acute administration of antidepressants vs. saline on weight. There were no differences between groups or over time. 


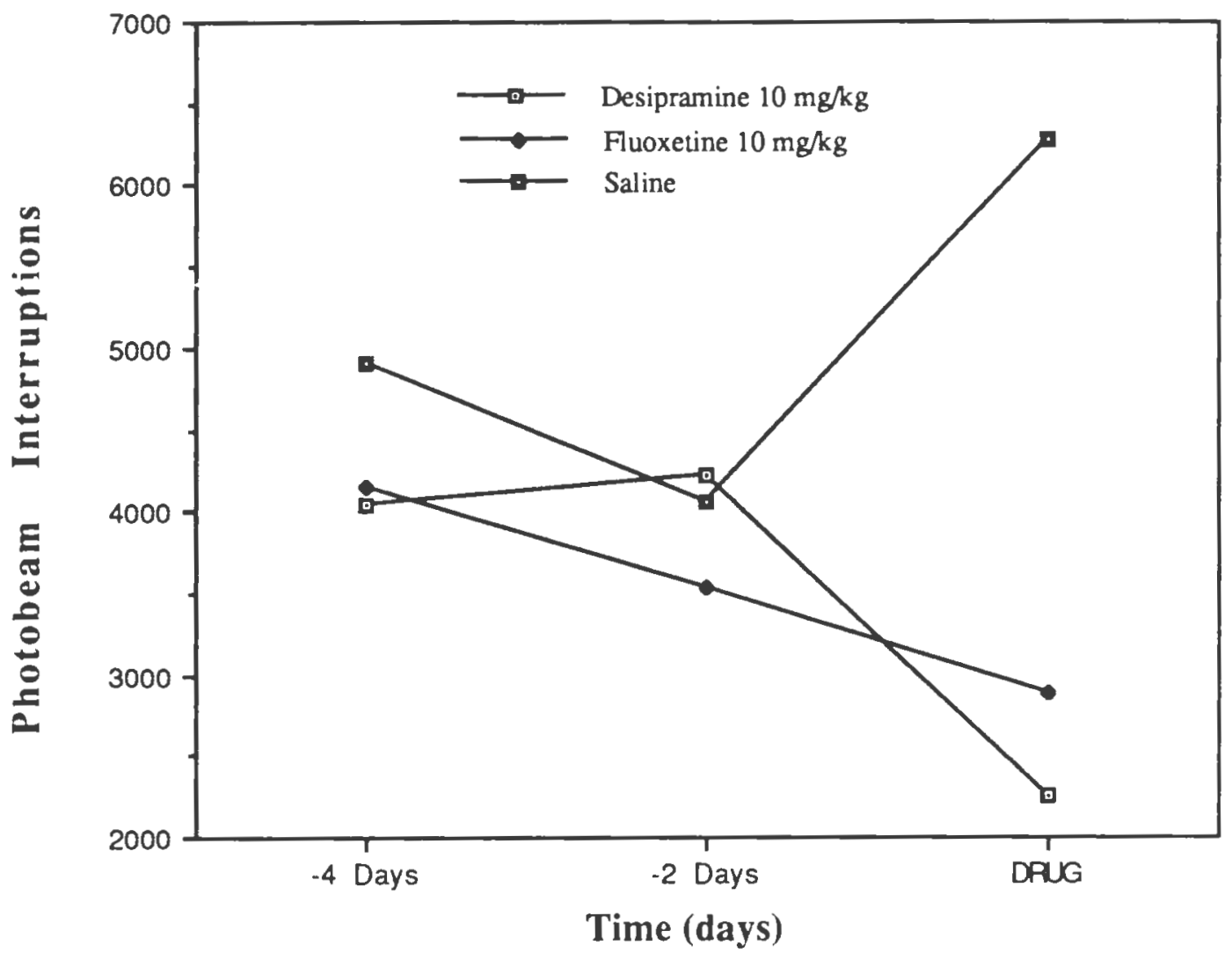

Fig. 19. The effects of acute administration of antidepressant vs. saline on the first fifteen minutes of horizontal activity. Animals given desipramine $(10 / \mathrm{mg} / \mathrm{kg})$ showed a significant decrease and saline a significant $(p<.05)$ increase in activity. 


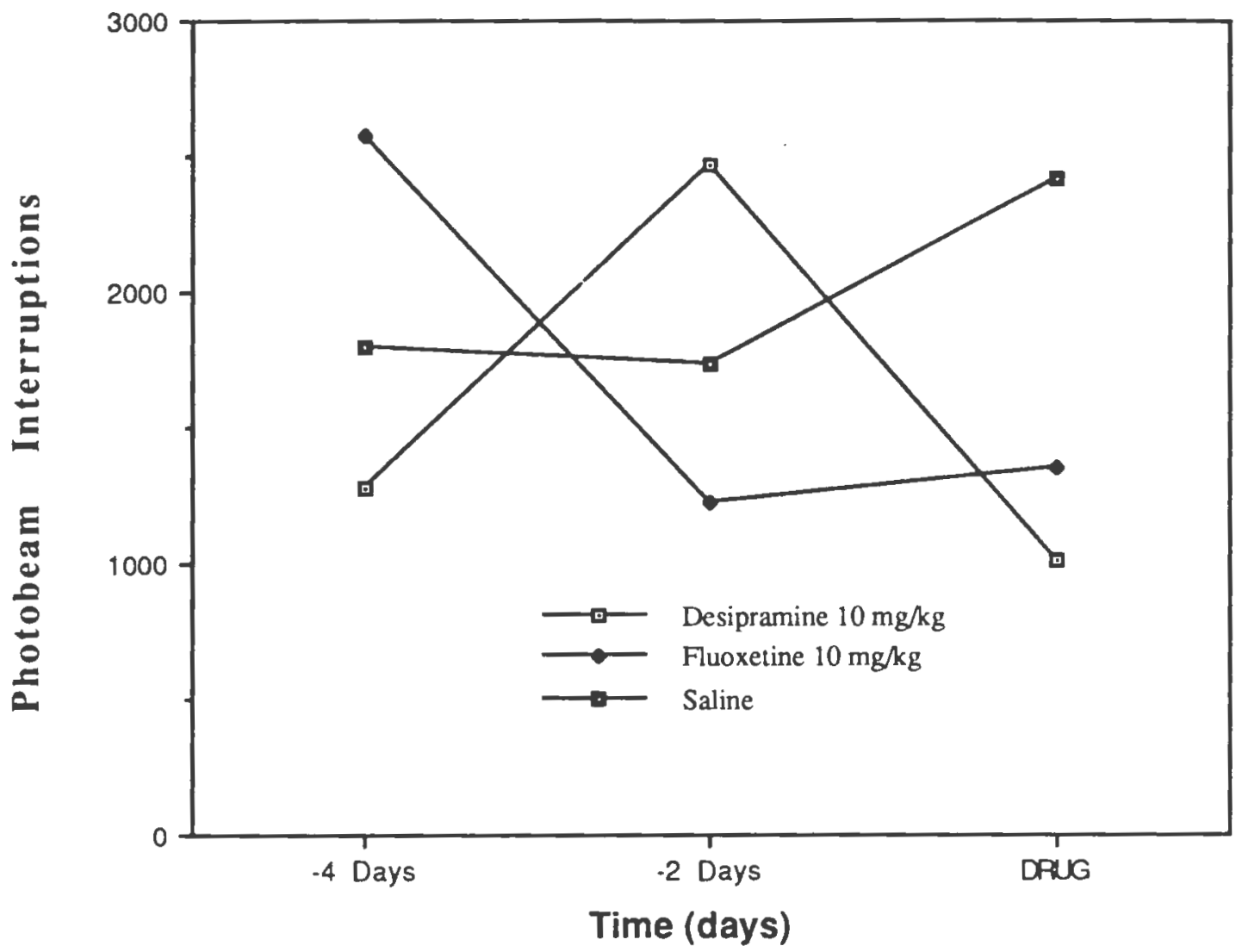

Fig. 20. The effects of acute administration of antidepressants vs. saline on the second fifteen minutes of horizontal activity. Desipramine and fluoxetine treated animals showed decreased $(p<.05)$ activity over time whereas the saline group did not. 


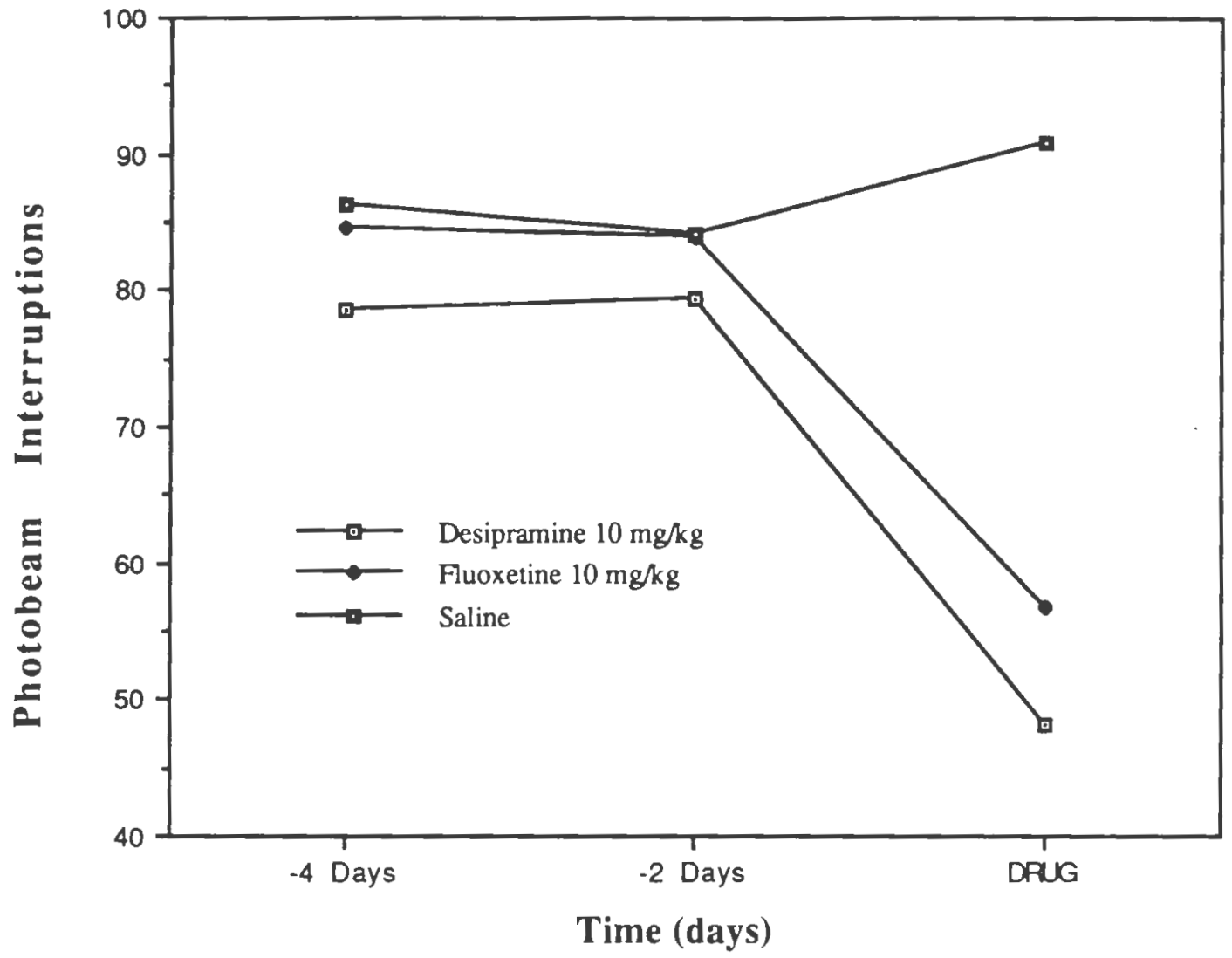

Fig. 21. The effects of acute administration of antidepressants vs. saline on the first fifteen minute period of rearing. Desipramine and fluoxetine treated animals showed significantly decreased $(p<.05)$ rearing while the saline animals did not. 


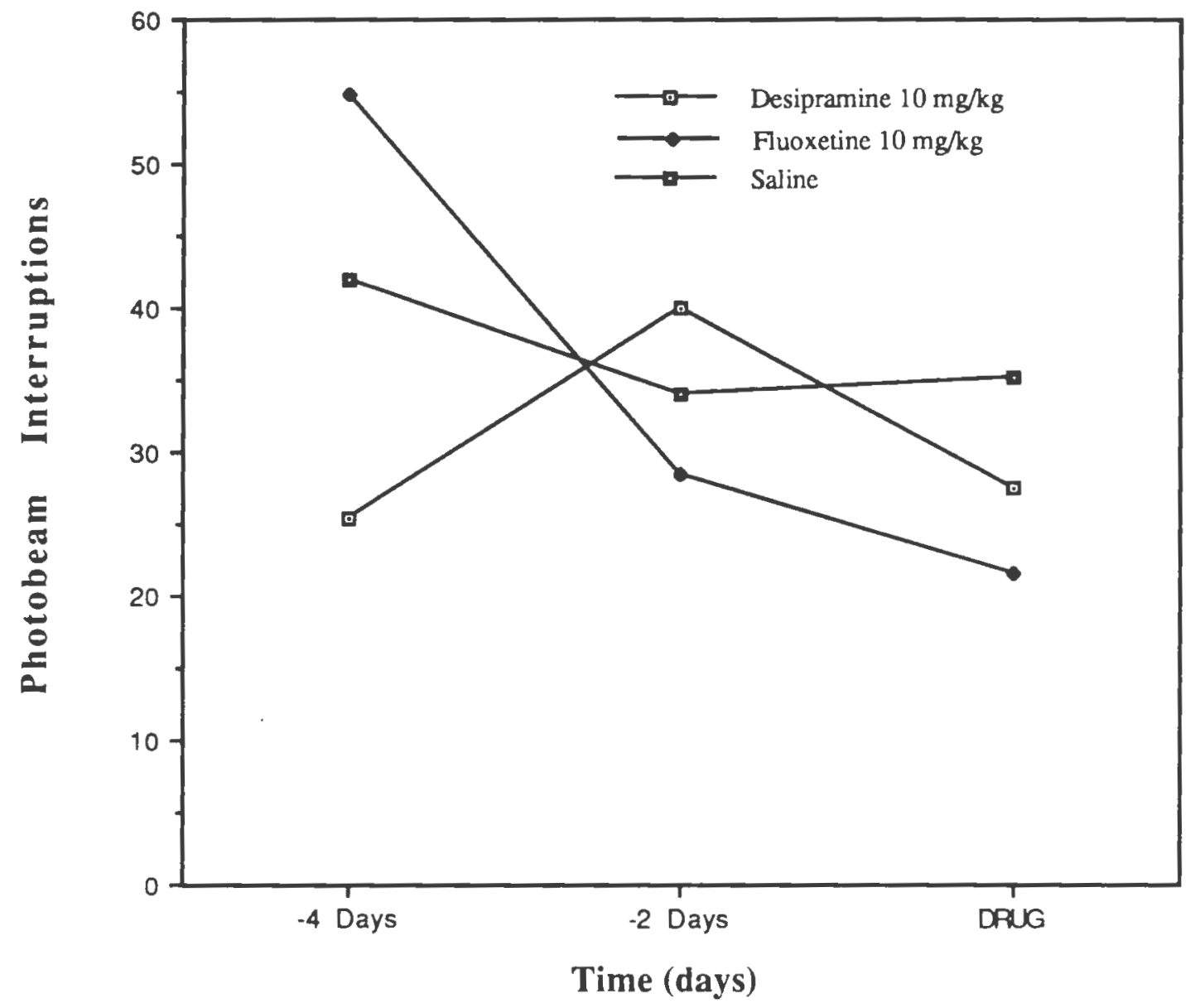

Fig. 22. The effects of acute administration of antidepressants vs. saline on aring during the second fifteen minute period. There were no differences between groups of over time. 


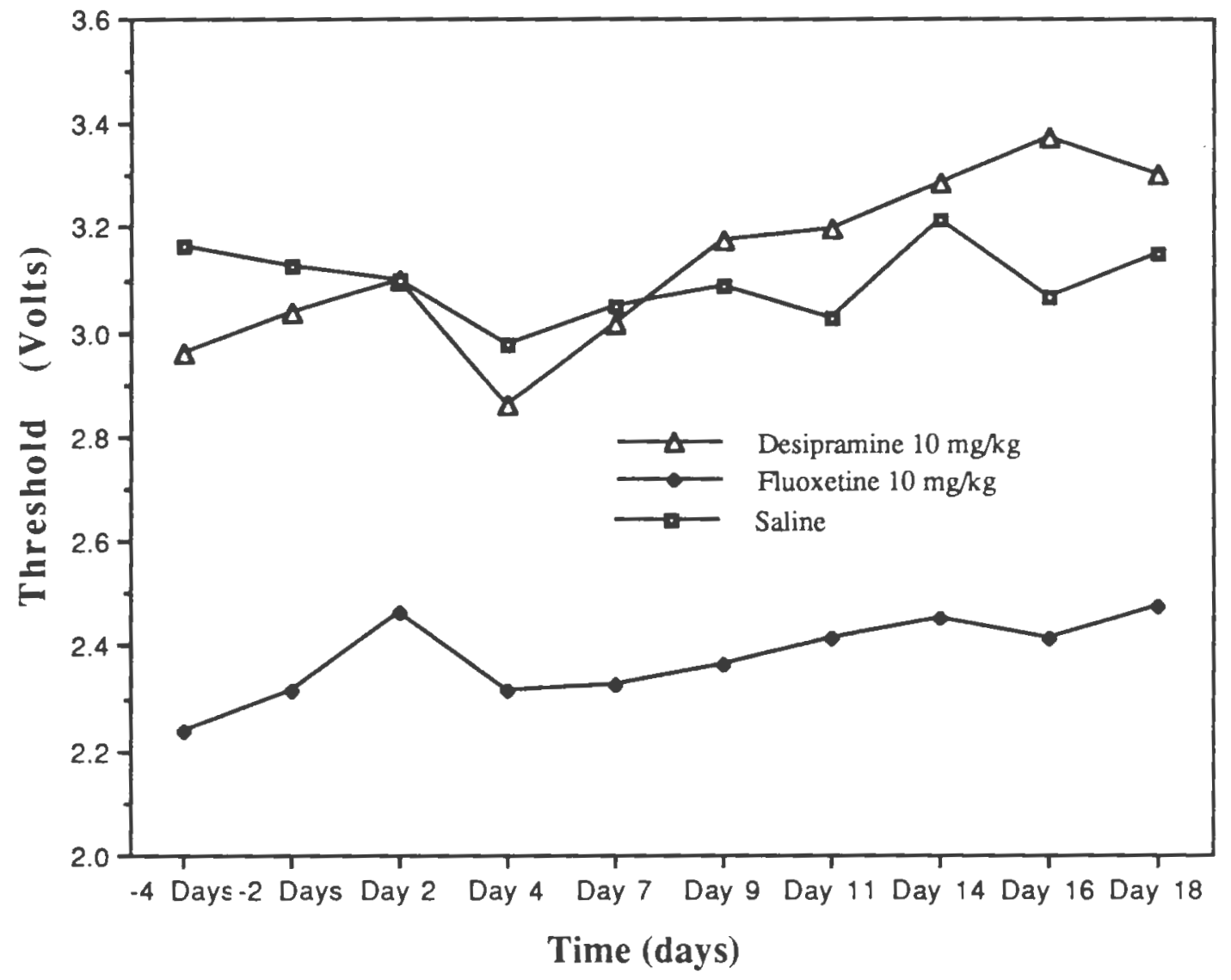

Fig. 23. The effects of chronic administration of antidepressants vs. saline on mean thresholds. There was a significant $(\mathrm{p}<.01)$ increase in thresholds over time that was not different between groups. 


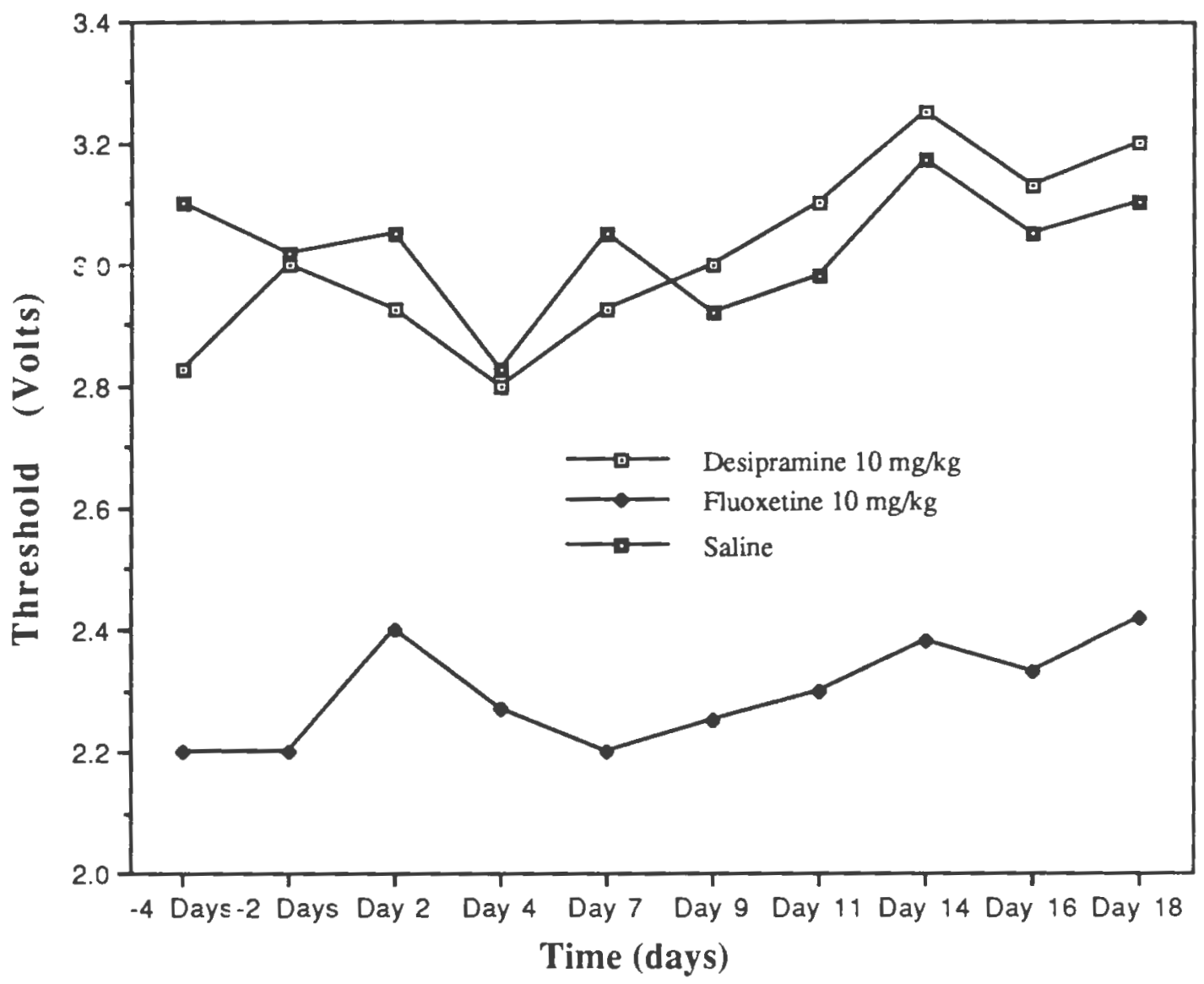

Fig. 24. The effects of chronic administration of antidepressants vs. saline on descending thresholds. There was a significant $(p<.01)$ increase in thresholds over time regardless of drug treatment group. 


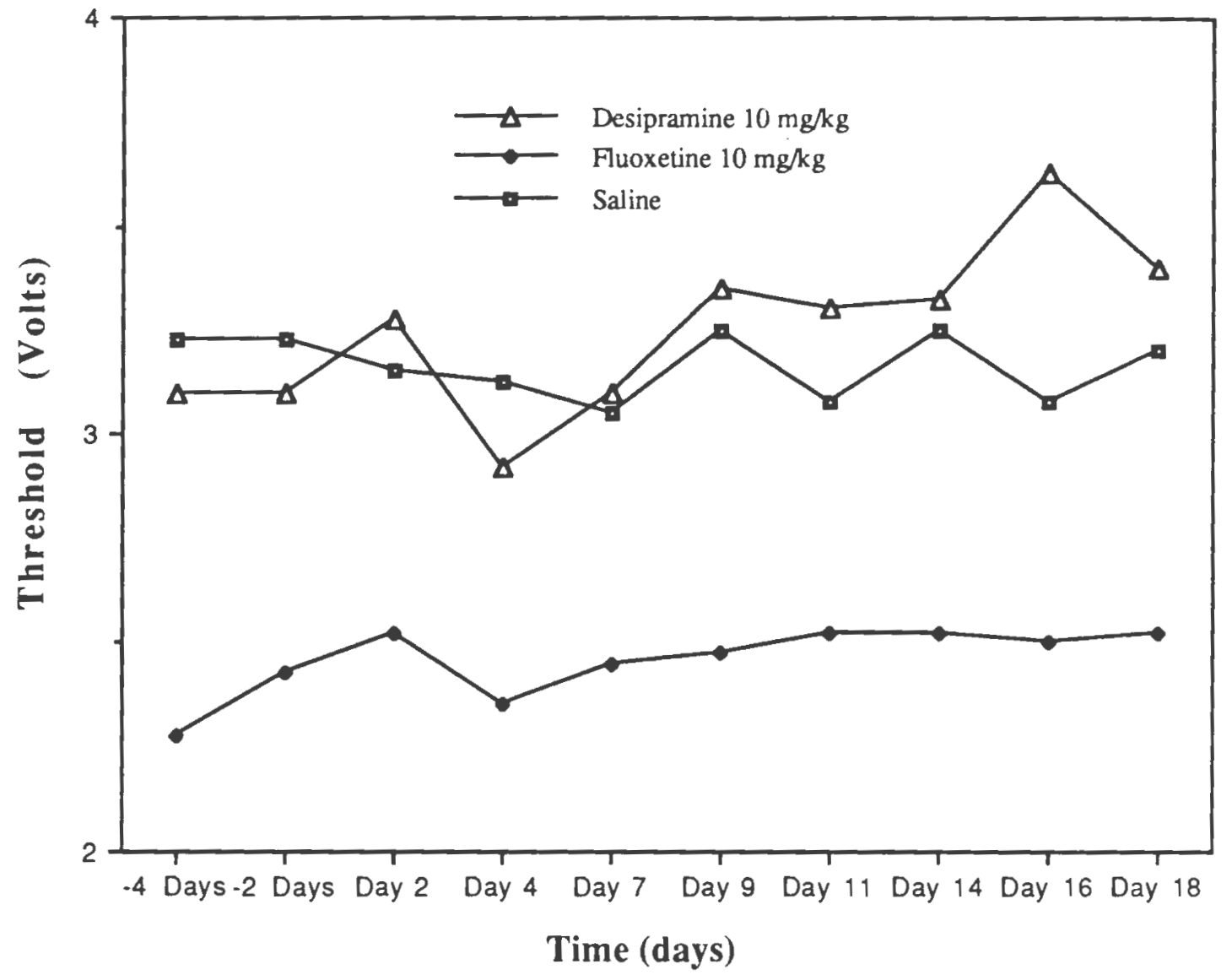

Fig. 25. The effects of chronic administration of antidepressants vs. saline on ascending thresholds. Thresholds increased significantly $(p<.01)$ over time regardless of drug treatment group. 


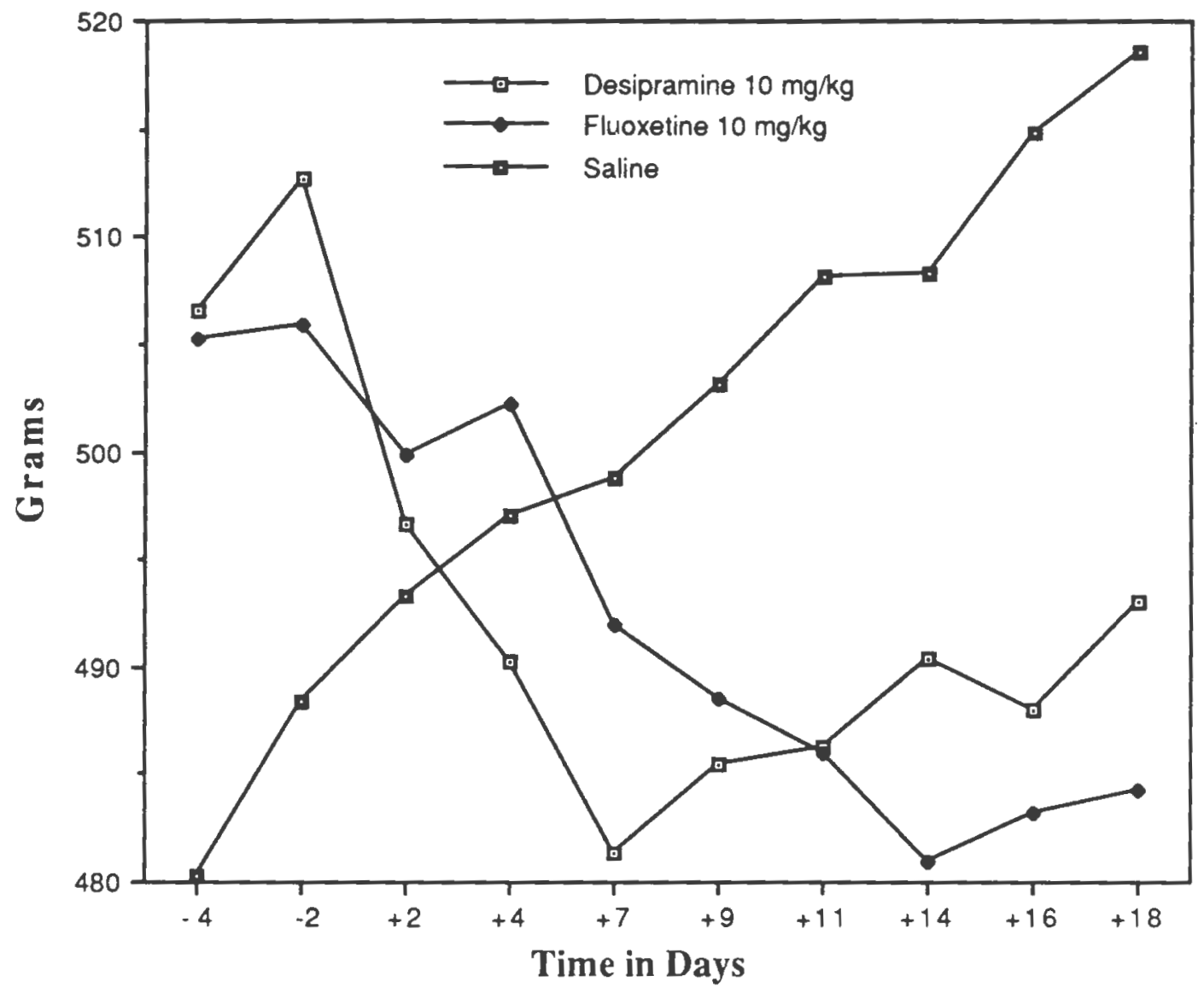

Fig. 26. The effects of chronic administration of antidepressants vs. saline on weight. Desipramine and fluoxetine treated animals lost while saline animals gained significant $(\mathrm{p}<.01)$ amounts of weight over the course of this study phase. 


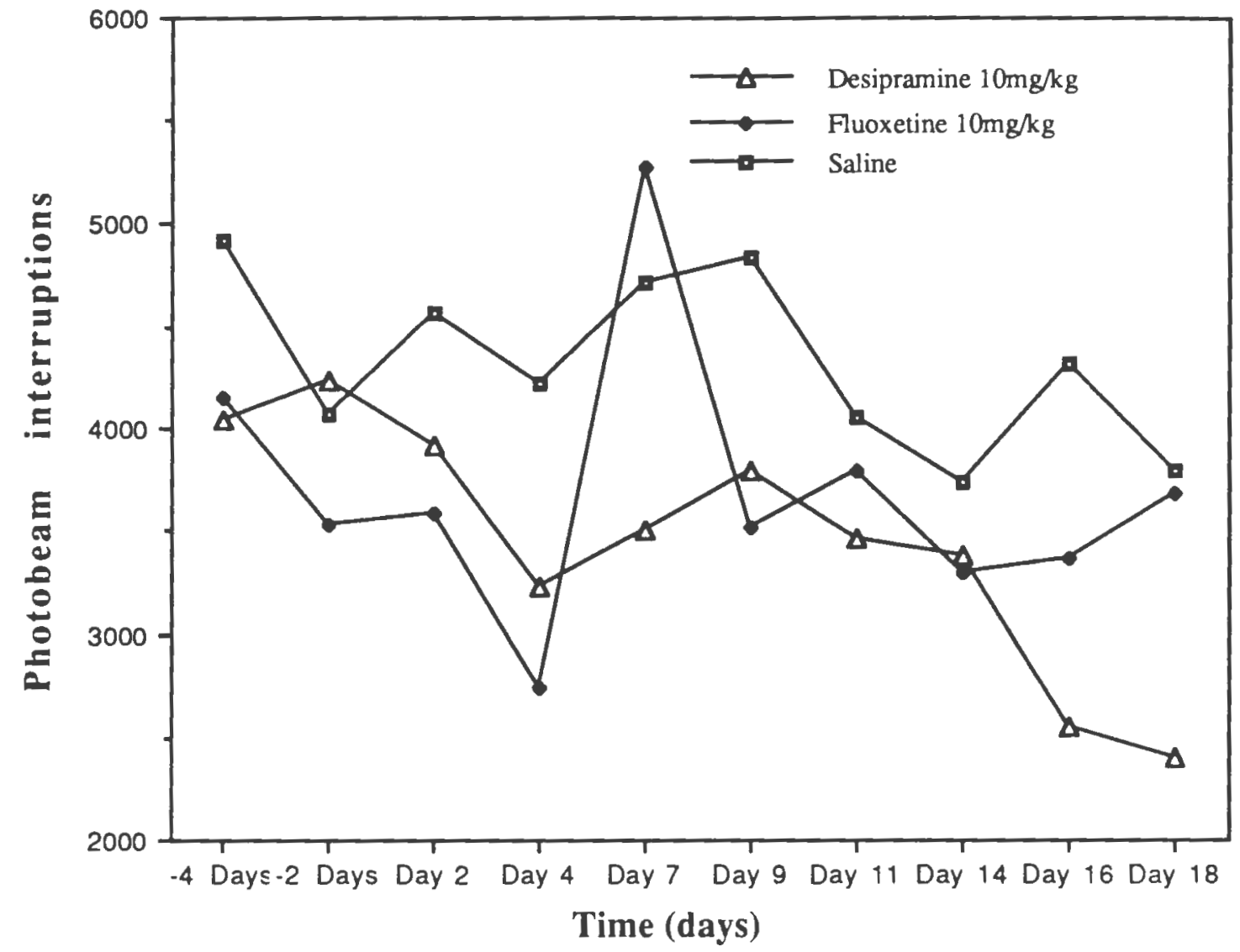

Fig. 27. The effects of chronic administration of antidepressants vs. saline on the first fifteen minutes of horizontal activity. A significant $(p<.01)$ decrease in activity was observed regardless of drug treatment group. 


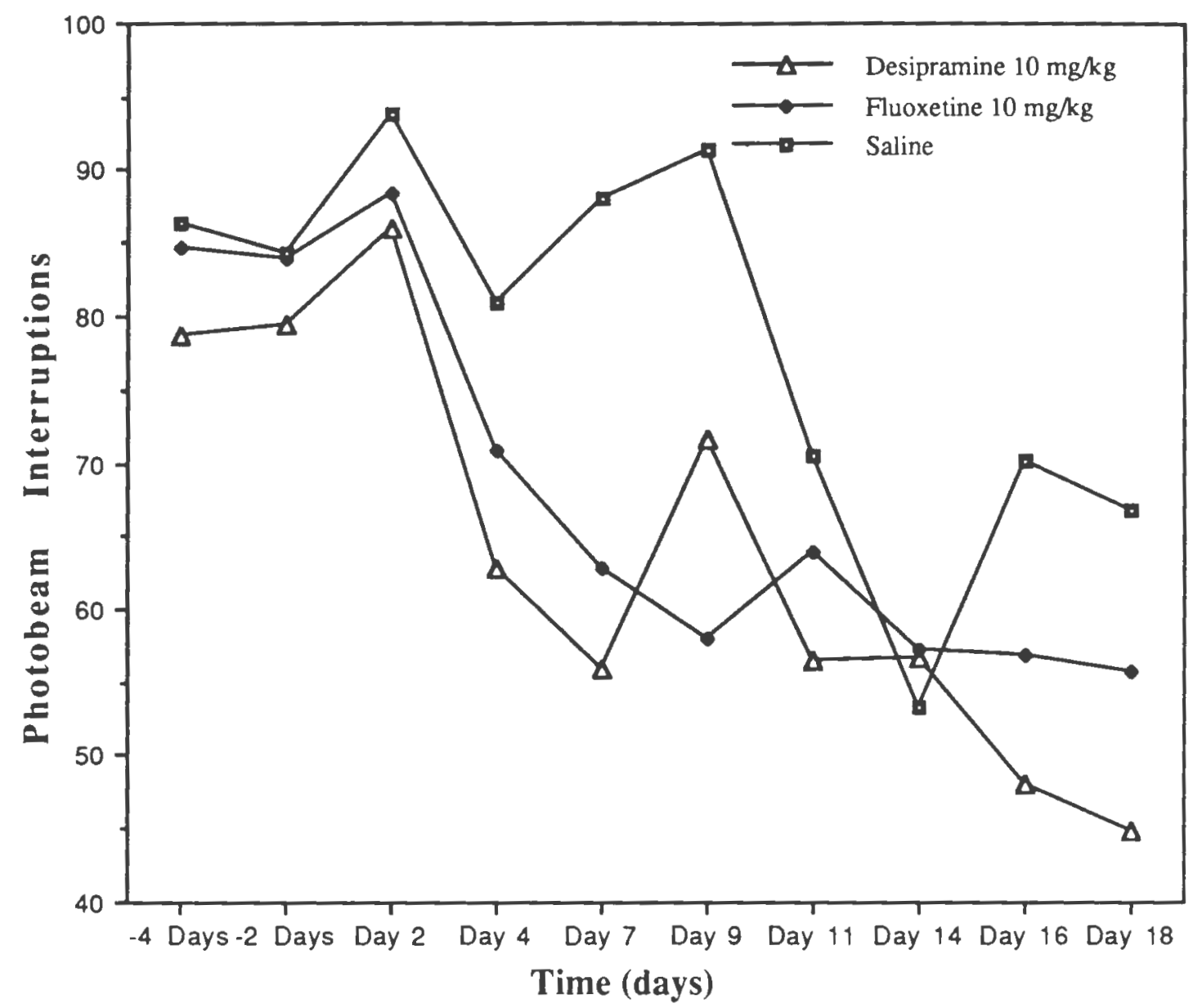

Fig. 28. The effects of chronic administration of antidepressants vs. saline on rearing in the first fifteen minutes. Thresholds decreased significantly $(p<.01)$ over time regardless of drug treatment group. 


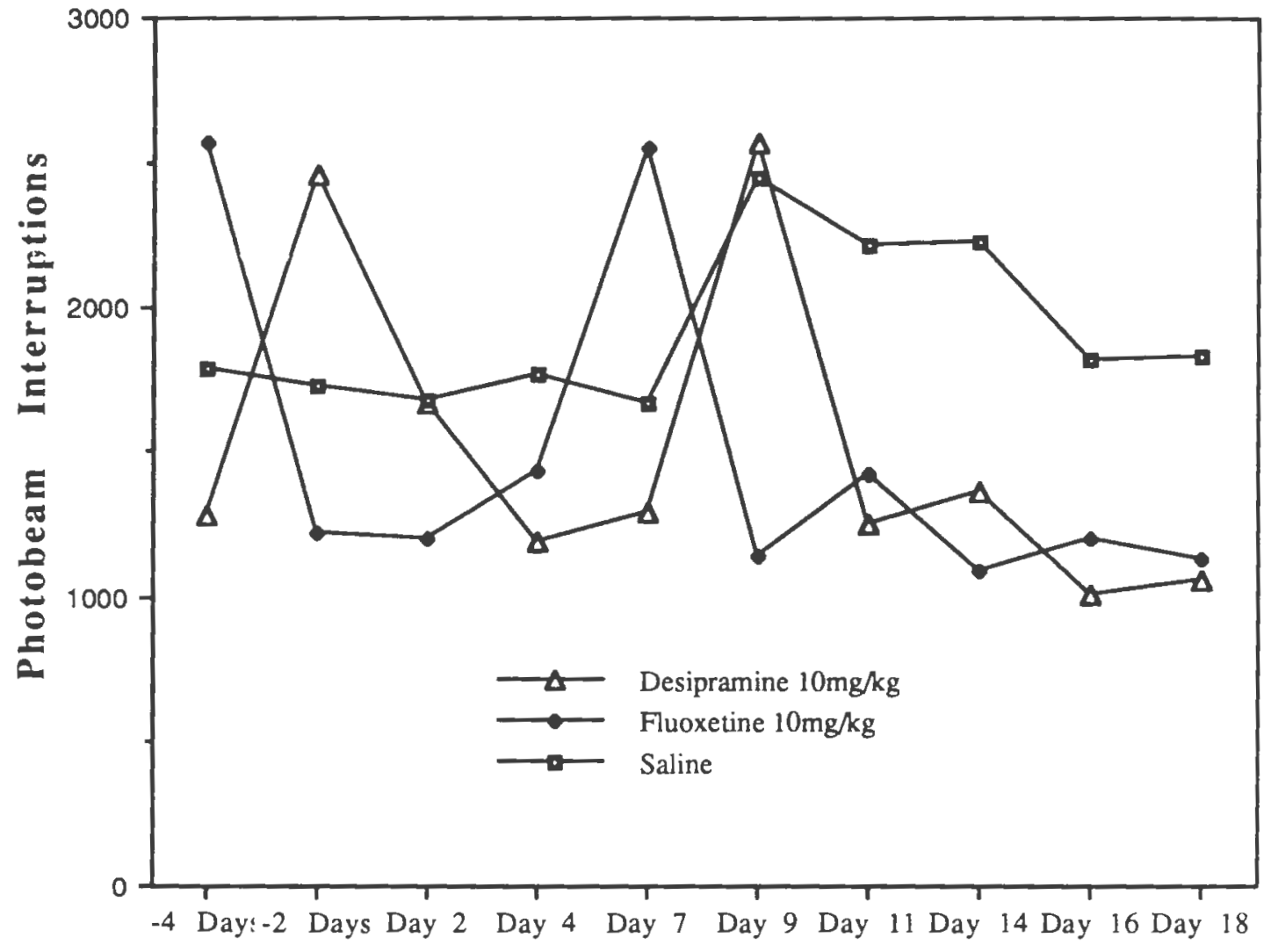

Time (days)

Fig. 29. The effects of chronic administration of antidepressant vs. saline on the second fifteen minute period of horizontal activity. Activity decreased significantly $(p<.01)$ over time for desipramine and fluoxetine but not for control animals. 


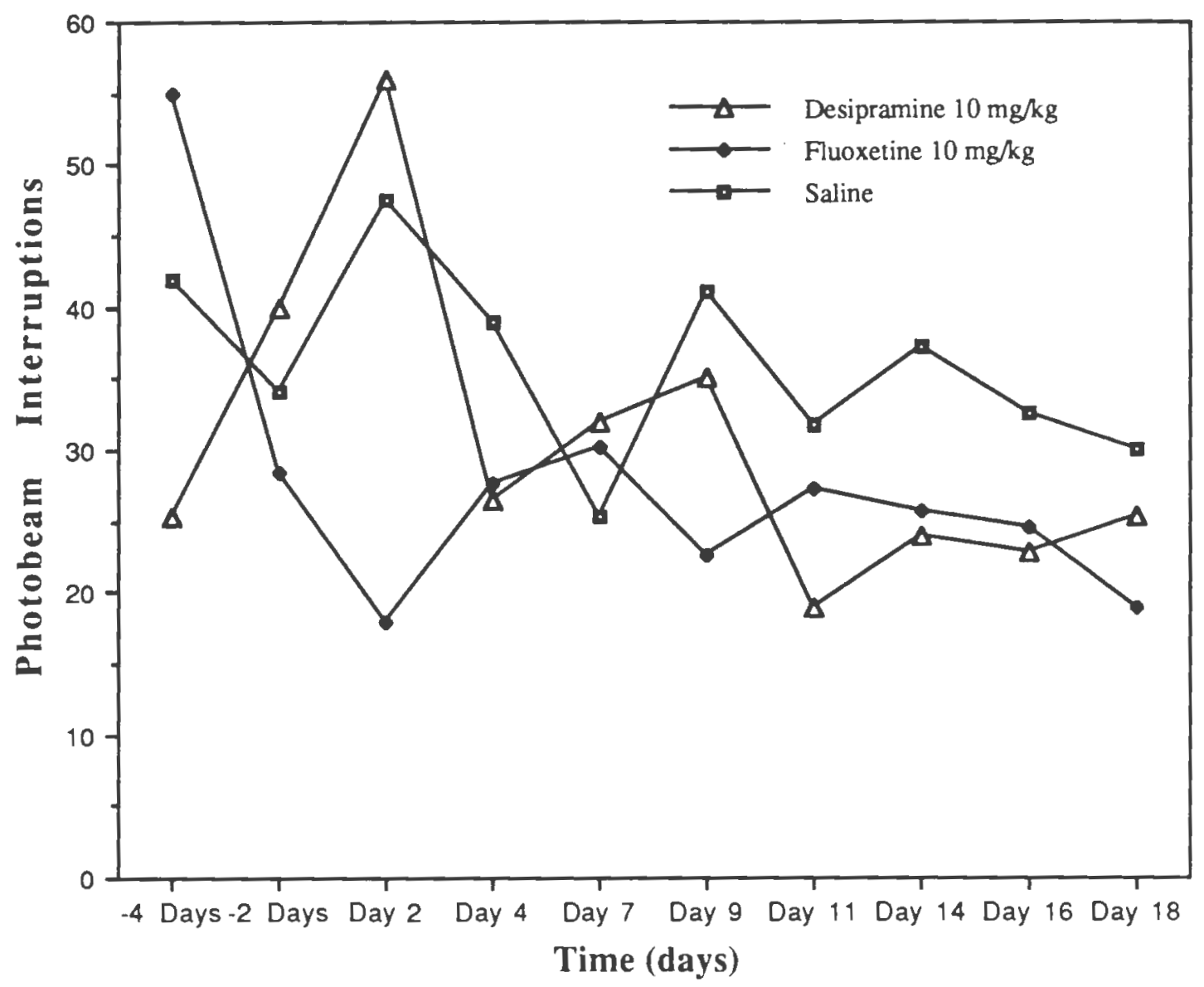

Fig. 30. The effects of chronic administration of antidepressants vs. saline on rearing during the second fifteen minutes. Desipramine and fluoxetine treated animals demonstrated significantly decreased rearing as compared to controls. 


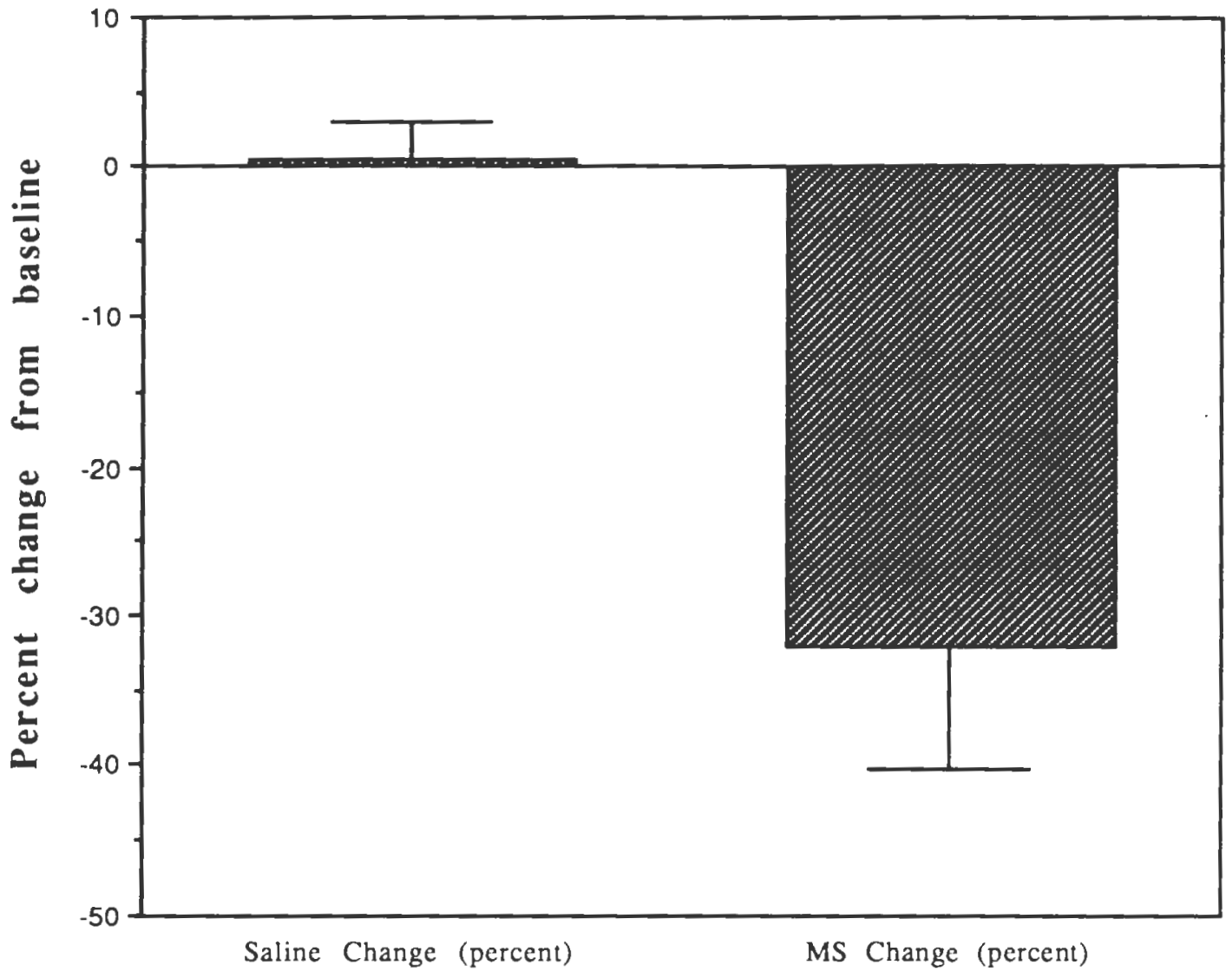

Fig. 31. Decrease in percent mean thresholds with Morphine Sulfate $6 \mathrm{mg} / \mathrm{kg}$ I.P. or saline as compared with control. 


\section{REFERENCES}

Abramson LY, Seligman MEP, and Teasdale JD. Learned helplessness in humans: critique and reformulation. Journal of Abnormal Psychology, 87(1), 49-74, 1978.

Adams, W.J., Lorens, S.A. and Mitchel, C.L. Morphine enhances lateral hypothalamus self-stimulation in the rat. Proceedings of Society for Experimental Biology, 140, 770-771, 1972.

Binks S.M., Murchie J.K., and Greenwood D.T. A reward reduction model of depression using self stimulating rats: an appraisal. Pharmacology, Biochemistry, and Behavior ,10(3), 441-443, 1979.

Carlson, N.R. Physiology of Behavior, Third Edition, Allyn and Bacon, Inc., Boston, 466-478, 1986.

Carpenter, M. B. and Suttin, J. Human Neuroanatomy. Eighth edition, Baltimore and London: Wilkins and Wilkins, 654-566, 1983.

Carr K.D. and Coons, E.E. Rats self administer nonrewarding brain stimulation to ameliorate aversion. Science, 215, 1516-1517, 1982.

Chaouloff, F., Danguir,J., and Elghozi, J.L. Dextrofenfluramine, bot not 8-OH-DPAT affects the decrease in food consumed by rats submitted 
to physical excercise. Pharmacology, Biochemistry, \& Behavior, 32, $573-576,1989$.

Clarke, A. and File S.E. Effects of ACTH, benzodiazepines and 5-HT antagonists on escape from periaqueductal grey stimulation in the rat. Prog. Neuro-Psychopharmacol \& Biol. Psychiatry, 6, 27-35, 1982.

Cooper, R.M., and Taylor, L.H. Thalamic reticular system and central grey: self stimulation. Science, 156, 102-103, 1967.

Cooper, B.R., Howard, J.L. and Soroko, F.E. Animal models used in prediction of antidepressant effects in man. $J$ Clin Psychiatry 44(5), $63-66,1983$.

Cooper J.R., Bllom, F.E. and Roth, R.H. The Biochemical Basis of Pharmacology, Oxford University Press, New York, Fifth edition, 1986.

Costa, E., Garattini, S., and Valzelli, L. Interactions between reserpine, chlorpromazine, and imipramine. Experientia,16, 461-463, 1960.

Cowen, P.J., Grahame-Smith, D.G., Green, A.R., and Heal D.J. Badrenoceptor agonists enhance 5-hydroxytryptamine-mediated behavioral responses. British Journal of Pharmacology, 76, 265-270, 1982. 
Crews F.T, and Smith, C.B. Presynaptic alpha-receptor subsensitivity after long term antidepressant treatment. Science, 202, 322-324, 1978.

Davidson, M. and Toporek, J. BMDP 4V - General univariate and multivariate analysis of variance. BMDP Technical Report No. 67, BMDP Statistical Software, Los Angeles, 1986.

Doogan, D.P. Fluvoxamine as an antidepressant drug. Neuropharmacology, 19, 1215-1216, 1980.

Drago, F., Caccamo, G., Continella, G., and Scapagnini, U. Amphetamine induced analgesia does not involve brain opioids. European Journal of Pharmacology, 101, 267-269, 1984.

Dufresne, R.L., Weber SS, and Becker, R.E. Bupropion hydrochloride: new drug evaluation. Drug Intelligence and Clinical Pharmacy, 18, 957-964, 1984.

Dumbrille-Ross, A., and Tang, S.W. Noradrenergic and serotonergic input necessary for imipramine-induced changes in beta but not $\mathrm{S}_{2}$ receptor densities. Psychiatry Research, 9, 207-215, 1983.

Enna, S.J., Mann, E., Kendall, D., Stancel, G.M. Effect of chronic antidepressant administration on brain neurotransmitter receptor binding. In Antidepressants: Neurochemical, Biochemical, and 
Clinical Perspectives, S.J. Enna, Malick, J.B., and Richelson, E. (eds), Raven Press, New York, 91-105, 1981.

Esposito, R. and Kornetsky, C. Morphine Insering of self stimulation thresholds: lack of tolerance with long-term administration. Science, 195, 189-191, 1977.

Fibinger H.C., and Phillips, A.G. Increased intracranial self stimulation in rats after long term administration of desipramine. Science, 214, 683-5, 1981.

Fibiger, H.C. and Phillips, A.G. Mesocortical Dopamine systems and reward. In The Mesocorticolimbic Dopamine System, P.W. Kalivas and C.B. Nemeroff (eds), The New York Academy of Sciences, New York, 206-215, 1988.

File S.E. and Tucker, J.C. Behavioral consequences of antidepressant treatment in rodents. Neuroscience and Behavioral Reviews, 10, 123-134, 1986.

Fuller, R.W. Pharmacological properties of seratonergic and antidepressant drugs. Journal of Clinical Psychiatry, 48(S-3),5-11, 1987.

Gandolfi O., Barbaccia, M.L., Chuang, D.M. and Costa, E. Daily bupropion injections for 3 weeks attenuate the NE stimulation of 
adenylate recognition sites in rat frontal coretx. Neuropharmacology, 22, 927-9, 1983.

Gonturkun, O., Grothues, A. Hautkappe, A., Vise, F., Wawrzyniak, N., and Zwilling, U. Serotonergic modulation of ingestive behavior in the pigeon. Pharmacology, Biochemistry, \& Behavior, 32, 415-420, 1989.

Goodwin F.K., Ebert M.H., and Bunney W.E. Mental effects of reserpine in man. A review. In: Shader R.I. (ed) Psychiatric Complications of Medical Drugs. Raven Press, New York, 73-101, 1972.

Green, A.R., Cowen, P.J., Nimgaonkar, V.L., and Graham-Smith, D.G. Effect of $B_{2}$-adrenoceptor agonists on serotonin biochemistry and function. In E.Usdin (ed) Frontiers in Biochemical and Pharmacological Research in Depression, Raven Press, N.Y., 1984.

Green, A.R., Hall, J.E., and Rees, A.R. A behavioral and biochemical study in rats of 5-hydroxytryptamine receptor agonists and antagonists, with observation of structure-activity requirements for the agonists. British Journal of Pharmacology, 73, 703-719, 1981.

Grob, G., Hante, K., and Gothert, M. Effect of antidepressant and neuroleptic drugs on the electrically evoked release of serotonin from rat cerebral cortex. Psychopharmacology, 91, 175-181, 1987. 
Harrison-Read, P.E., and Steinberg, H. Tricyclic antidepressant drugs and individual differences in the exploratory activity of rats: Contrasting effects of tertiary and secondary amine compounds. Psychopharmacology, 69, 85-91, 1980 .

Hoebel BG, Teitlebaum, P. Hypothalamic control of feeding and self stimulation. Science, 135, 357-377, 1962.

Horovitz Z.P., M. Chow and Carlton, P.L. Self stimulation of the brain by cats; technique and preliminary drug effects. Psychopharmacologia, 3:449-454, 1962.

Howard J.L., Sorpko, F.E. and Cooper, B.R. Empirical Behavioral Models of Depression, with Emphasis on Tetrabenazine Antagonism. In Antidepressants: Neurochemical, Behavioral, and Clinical Perspectives, S.J. Enna, Malick, J.B., and Richelson, E. (eds), Raven Press, New York, 107-120, 1981.

Hubner C.B., Bain G.T., and Kornetsky C. : The combined effect of morphine and $\mathrm{D}$-amphetamine on the threshold forbrain stimulation reward. Pharmacology, Biochemistry, and Behavior, 28(2), 311-315, 1987.

Izenwasser S.E. and Kornetsky, C. Pharmacological effects of morphine on brain reward. Psychopharmacology, 93, 136-137, 1987. 
Katz, R.J. and Carroll, B.J. Intracranial reward after Lilly 110140 (Fluoxetine HCL): Evidence for an inhibitory role for serotonin. Psychopharmacology, 51, 189-193, 1977.

Kelley, A.E. and Cador, M. Behavioral evidence for differential neuropeptide modulation of the mesolimbic dopamine system. In The Mesocorticolimbic Dopamine System, P.W. Kalivas and C.B. Nemeroff (eds), The New York Academy of Sciences, New York, 415$444,1988$.

Kokkinidis, L. and Zacharko, RM. Response sensitization and depression following long term amphetamine tretament in a self stimulation paradigm. Psychopharmacology, 68, 73-76, 1980.

Koop, G.F. Incentive shifts in intracranial self-stimulation produced by a different series of stimulus intensity presentations. Physiol. Behav. 18, 131-135, 1977.

Kornetsky, C., Esposito, R.U., McLean, S., and Jacobson, J.O. Intracranial self-stimulation thresholds: a model for hedonic effects of drugs of abuse. Archives of General Psychiatry, 36, 289-292, 1979.

Kornetsky C., Bain G. : Biobehavioral basis of the reinforcing properties of opiate drugs. Ann NY Acad Sci, 398, 241-59, 1982.

Kornetsky, C. Brain-stimulation reward: A model for the neuronal bases for drug-induced euphoria. In Brown, R.M., Friedman, D.P., and 
Nimit, Y., (eds.) Neuroscience Methods in Drug Abuse Research. National Institute on Drug Abuse Research Monograph 62, DHSS Publication No. (ADM) 85-1415, Washington, D.C.: Superintendent of Documents, U.S. Government Printing Office. 30-50, 1985.

Kostowski, W., Plaznik, A., and Danysz, W. The role of the locus coeruleus-limbic noradrenergic transmission in the action of antidepressant drugs. Psychopharmacology Bulletin, 22(2), 512-522, 1986.

Kulkarni, S.K. and Dandiya, P.C. Effects of antidepressant agents on open field behavior in rats. Psychopharmacologia, 33, 333-338, 1973.

Lecubier Y., Peuch A., Jouvent, A.J., Simon, P. and Widlocher, D. A beta-adrenergic stimulant (salbutamol) versus clomipramine in depression: a controlled study. British Journal of Psychiatry, 136, 354-358.

Liebman J.M. Discriminating between reward and performance, a critical review of intracranial self stimulation methodology. Neuroscience and Biobehavioral Reviews, 7,45-72, 1983.

Liebman, J.F., Hall, N.R., Prowse, J., Gerhardt, S., Noreila, L., and Fenton, H.M. Comparitive effetcs of $B_{2}$-adrenoceptor agonists on intracranial self-stimulation, Sidman avoidance, and motor activity in rats. Psychopharmacology, 84, 336-341, 1984. 
Leibowitz, S.F. Hypothalamic paraventricular nucleus: interaction between $\alpha_{2}$-noradrenergic system and circulating hormones and nutrients in relation to energy balance. Neuroscience \& Biobehavioral Reviews, 12, 101-109, 1988.

Leith N.J. and Barrett R.J.: Amphetamine and the reward system: evidence for tolerance and post drug depression. Psychopharmacology, 46,19-25, 1976.

Leith N.J. and Barrett R.J. Effects of chronic amphetamine or reserpine on self stimulation: animal model of depression? Psychopharmacology ,72,9-15, 1980.

Leith N.J. and Barrett R.J. Self-stimulation and amphetamine: Tolerance to $d$ and $l$ isomers and cross tolerance to cocaine and methylphendidate. Psychopharmacology,74,23-28, 1981.

Leshner, A., Remier, H., Biegnon, A., and Samuel D. Desmethylimipramine (DMI) counteracts learned helplessness in rats. Psychopharmacology, 66, 207-208, 1979.

Lorens, S.A., Mitchel, C.L. Influence of morphine on lateral hypothalamic self-stimulation in the rat. Psychopharmacologia, 32, $271-277,1973$. 
Lorens, S.A. Comparison of the effects of morphine on hypothalamic and medial frontal cortex self-stimulation in the rat. Psychopharmacology, 48, 217-224, 1976.

Maciewicz, R. and Martin, J.B. Pain: pathophysiology and management. In Harrison's Principles of Internal Medicine, Eds. Braunwald, E., Isselbacher, K.J., Petersdorf, R.G., Wilson, J.D., Martin, J.B., and Fauci, A.S. Eleventh edition, 13-17, 1987.

Malick, J.B. Yohimbine potentiation as a predictor of antidepressant action. In Antidepressants: Neurochemical, Biochemical, and Clinical Perspectives, S.J. Enna et al. (eds), Raven Press, New York, 141-155, 1981.

Marcus $R$ and Kornetsky C. Negative and positive intracranial reinforcement thresholds: effects of morphine. Psychopharmacologia, 38:1-13, 1974.

McClelland, R.C., Sarfaty, T., Hernandez, L., and Hoebel, B.G. The appetite suppressant, d-Fenfluramine, decreases self-stimulation at a feeding site in the lateral hypothalamus. Pharmacology, Biochemistry, \& Behavior, 32, 411-414, 1989.

McMillen, B.A., Warmack, W., German,D.C., and Shore, P.A. Effects of chronic desipramine treatment on rat brain noradrenergic responses to $\alpha$-adrenergic drugs. European Journal of Pharmacology, 61, 239246, 1980. 
Mendels, J. Clinical experience with serotonin reuptake inhibiting antidepressants. Journal of Clinical Psychiatry, 48(3S), 26-30, 1987.

Miller WR, Rosellini RA, and Seligman MEP. Learned helplessness and depression. In Psychopathology: Experimental Models, Eds. Maser JD and Seligman, MEP, W.H. Freeman and Company, San Francisco, pp 104-130, 1977.

Minneman, K.P., Dibner, M.D., Wolfe, B.B., and Molinoff, P.B. $B_{1^{-}}$and $B_{2}$-adrenergic receptors in rat cerebral cortex are independently regulated. Science, 204, 866-868, 1979.

Minneman, K.P., Pittman, R.N., and Molinoff, P.B. B-adrenergic receptor subtypes: Properties, distribution, and regulation. Annual Review of Neurosciences, 4, 419-461, 1981.

Mishra, R., Janowsky, A., and Sulser, F. Subsensitivity of the Norepinephrine (NE) receptor coupled adenylate cyclase system in brain: Effects of nisoxetine vs fluoxetine. European Journal of Pharmacology, 60, 379-382.

Mobley, P.L. and Sulser, F. Down-regulation of the central noradrenergic receptor system by antidepressant therapies: Biochemical and clinical aspects. In Antidepressants: Neurochemical, Biochemical, and Clinical Perspectives, S.J. Enna et al. (eds), Raven Press, New York, 31-47, 1981. 
Mogilnicka, E. The effects of acute and repeated treatments with salbutamol, a B-adrenoceptor agonist, on clondine induced hypoactivity in rats. Journal of Neural Transmission, 53, 117-126, 1982

Morato de Carvalho, S., Aguiar, J.C., and Graeff, F.G. Effects of minor tranqilizers, tryptamine antagonists, and amphetamine on behavior punished by brain stimulation. Pharmacology, Biochemistry, \& Behavior, 15, 351-356, 1981.

Nielsen, J.A., Shannon, N.J., Bero, L. and Moore, K.E. Effects of acute and chronic bupropion on locomotor activity and dopaminergic neurons. Pharmacology, Biochemistry, \& Behavior, 24,795-799, 1986

Olds J. Effects of hunger and male sex hormone on self stimulation of the brain. Journal of Comparitive Physiological Psychology, 51, 320$324,1958$.

Olds J. and Travis, R.: The effects of chlorpromazine, meprobamate, pentobarbital, and morphine on self-stimulation. Journal of Pharmacology and Experimental Therapeutics,128, 397-404, 1959.

Olds, J. Hypothalamic substrates of reward. Physiology Review, 42, $554-604,1962$. 
Olds M. E., and Olds J. Pharmacological patterns in subcortical reinforcement behavior. International Journal of Neuropharmacology, 2, 309-325, 1964.

O'Neill, K. A. Acute and chronic effects of antidepressants on opiate systems. Doctor of Philosophy Dissertation, University of Rhode Island, 1983.

O'Rourke, D.A., Wurtman, J.J., Brezezinski, A., Nader, T.A., and Chew, B. Serotonin implicated in etiology of seasonal affective disorder. Psychopharmacology Bulletin, 23(2), 358-359, 1987.

Pert, A. and Hulsebus, R. Effect of morphine on intracranial selfstimulation behavior following brain amine depletion. Life Sciences, 17, 19-20, 1975.

Przegalinski, E., Baran, L. and Siwanowicz, J. The effect of chronic treatment with antidepressant drugs on salbutamol induced hypoactivity in rats. Psychopharmacology (Berlin), 80, 355-359, 1983.

Quetsch, R.M., Anchor, R.W., Litin, E.M. Depressive reactions in hypertensive patients. A comparison of those treated with Rawolfia and those receiving no specific antihypertensive treatment. Circulation, 19, 366-375, 1959. 
Riccitelli A., Valentino, D., and Dufresne R.L. Effects of Chronic Desmethylimipramine Treatment on Brain Stimulation Reward Thresholds in the rat. Presented at the eighteenth annual meeting of New England Pharmacologists, Omni-Parker Hotel, Boston, Massachusetts, on February 4, 1989.

Routenberg, A. The reward system of the brain. Scientific American, 239, 154-164, 1975.

Sasson, S., Unterwald, E.M., and Kornetsky, C. Potentiation of morphine analgesia by d-amphetamine. Psychopharmacology, 90, $163-165,1986$.

Schmidt, M.J. and Thornberry, J.F. Norepinephrine-stimulated cyclic AMP accumulation in brain slices in vitro after serotonin depletion or chronic administration of selective amine reuptake inhibitors. Archives of International Pharmacodynamics, 229, 42-51, 1977.

Sellinger-Barnette, MM, Mendels J, and Frazer, A. The effect of Psychoactive drugs on beta adrenergic receptor binding sites in rat brain. Neuropharmacology, 19, 447-454, 1980.

Shillito, E.E. A method for investigating the effects of drugs on the exploratory behavior of mice. British Journal of Pharmacology, 40, $113-123,1970$. 
Shopsin B, Cassano, G.B., and Conti, L. An overview of new "second generation" antidepressant compounds, research and treatment implications. In, Antidepressants, Neurochemical, Behavioral, and Clinical Perspectives, Eds. S.J. Enna et al., Raven Press, New York, 1981.

Stahl, S.M., Beer, M.S., Hacker, S.A., Poat, J.A., and Iversen, L.L. Beta1and Beta2-Adrenoceptor regulation in rat nervous system by chronic treatment with desipramine and beta adrenoceptor agonists. Psychopharmacology Bulletin, 23(3), 473-475, 1987.

Stark, P., Fuller, R.W., and Wong, D.T. The pharmacological profile of fluoxetine. Journal of Clinical Psychiatry, 46(3) 7-13, 1985.

Stein, L. Effects and Interactions of Imipramine, Chlorpromazine, Reserpine, and Amphetamine on Self-Stimulation: Possible neurophysiological basis of depression. Recent Advances in Biological Psychiatry, 4, 288-308, 1962.

Sulser, F., Owens, M.L., and Dingell, J.V. On the mechanism of amphetamine potentiation of amphteamine by desipramine. Life Science, 5, 2005-2010, 1966.

Sulser, F. Serotonin-norepinephrine receptor interactions in the brain: Implications for the pharmacology and pathophysiology of affective disorders. Journal of Clinical Psychiatry, 48(S3), 12-18, 1987. 
Tucker, J.C. and File, S.E. The effects of tricyclic and 'atypical' antidepressants on spontaneous locomotor activity in rodents. Neuroscience and Biobehavioral Reviews, 10, 115-121, 1986.

Unterwald E.M., and Kornetsky C. Effects of nalbuphine alone and in combination with tripelennamine on rewarding brain stimulation thresholds in the rat. Pharmacology, Biochemistry, and Behavior, 25,629-632, 1986.

Wamsley JK, Byerley WF, McCabe T, McConnell, E.J., Dawson, T.M., and Grosser, B.I. Receptor alterations with serotonergic agents. Journal of Clinical Psychiatry, 48(S3), 19-25, 1987.

Wilner, P. The validity of animal models of depression. Psychopharmacology, 83,1-16, 1984.

Winer, BJ. Statistical Principles in Experimental Design. McGraw-Hill, Inc., New York, 1971.

Zacharko, R.M., Bowkers, W.J., Kelley, M.S., and Anisman, H. Prevention of stressor induced disturbances of self-stimulation by desmethylimipramine. Brain Research, 321, 175-179, 1984.

Zebrowska-Lupina, I. Presynaptic alpha-adrenoceptors and the action of tricyclic antidepressant drugs in behavioral despair in rats. Psychopharmacology, 71,169-172, 1980. 


\section{APPENDIX A}

Example of a Trial to Obtain an Intracranial Self-Stimulation

Threshold

FILE FOR PROJECT: RL23 4-18-88

DATE IS: $04-19-88$

ID\# GROUP +TRIALS NEGSEG FALSEP VOLTSEG

$\begin{array}{lcclll}23 & 5 & 8 & 0 & 1 & 6.2 \\ 23 & 5 & 10 & 0 & 0 & 6 \\ 23 & 5 & 10 & 0 & 0 & 5.8 \\ 23 & 5 & 10 & 0 & 4 & 5.6 \\ 23 & 5 & 10 & 0 & 0 & 5.4 \\ 23 & 5 & 10 & 0 & 1 & 5.2 \\ 23 & 5 & 9 & 0 & 1 & 5.0 \\ 23 & 5 & 10 & 0 & 1 & 4.8 \\ 23 & 5 & 10 & 0 & 0 & 4.6 \\ 23 & 5 & 6 & 0 & 0 & 4.4 \\ 23 & 5 & 5 & 0 & 2 & 4.2 \\ 23 & 5 & 6 & 0 & 0 & 4.0\end{array}$

Decending threshold

$\begin{array}{rrrrrr}23 & 5 & 1 & 0 & 0 & 3.8 \\ 23 & 5 & 1 & 2 & 0 & 3.4 \\ 23 & 5 & 1 & 3 & 0 & 3.6 \\ 23 & 5 & 5 & 3 & 0 & 3.8 \\ 23 & 5 & 3 & 2 & 0 & 4.0 \\ & & & & & \text { Ascending threshold } \\ 23 & 5 & 8 & 3 & 0 & 4.2\end{array}$


$\begin{array}{llllll}23 & 5 & 10 & 2 & 1 & 4.4\end{array}$

Legend: ID\# is animal identification, Group is study condition designation, +TRIAL is the number of responses out of 10 times when the rewarding electrical stimulation is available, NEGSEGS is the number of times an animal fails to respond at least 5 of ten times, FALSEP is the number of pressess when current is not available, and VOLTSEG is the voltage available for the segment. For this run, the descending threshold is 3.9 volts, the ascending threshold is 4.1 volts, and the mean threshold is 4.0 volts. 


\section{APPENDIX B}

Three stable baseline readings

Thresholds do not differ

by mare than 0.4 volts

Saline daily

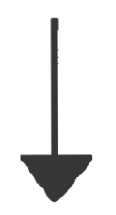

Rats are given $10 \mathrm{mg} / \mathrm{kg}$ of

albuterol via gastric lavage.

Saline given until

there are three stable

baselines.

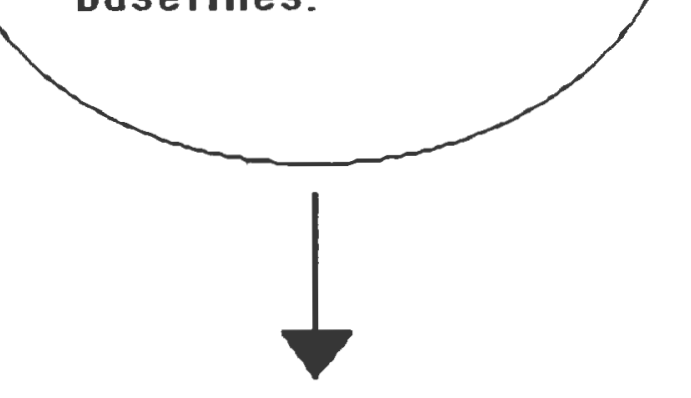


Rats are given acute dose of fluoxetine, desipramine, or saline 30 minutes prior to testing.

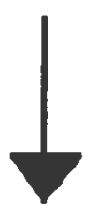

Rats are given desipramine, fluoxetine, or saline via gastric lavage for 19 days at 6 p.m. at a dose of $10 \mathrm{mg} / \mathrm{kg}$ daily.

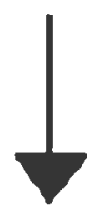

All animals are washed out for 48 hours;

Then all are given albuterol $10 \mathrm{mg} / \mathrm{kg}$ via gastric lavage.

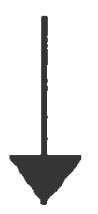

Three soline test periods. 


\section{BIBLIOGRAPHY}

Abramson LY, Seligman MEP, and Teasdale JD. Learned helplessness in humans: critique and reformulation. Journal of Abnormal Psychology, 87(1), 49-74, 1978.

Adams, W.J., Lorens, S.A. and Mitchel, C.L. Morphine enhances lateral hypothalamus self-stimulation in the rat. Proceedings of Society for Experimental Biology, 140, 770-771, 1972.

Binks S.M., Murchie J.K., and Greenwood D.T. A reward reduction model of depression using self stimulating rats: an appraisal. Pharmacology, Biochemistry, and Behavior ,10(3), 441-443, 1979.

Carlson, N.R. Physiology of Behavior, Third Edition, Allyn and Bacon, Inc., Boston, 466-478, 1986.

Carlsson, A. Current theories on the mode of action of antidepressant drugs. In Frontiers in Biochemical and Pharmacological Research in Depression, E. Usdin (ed), Raven Press, New York, 213-221, 1984.

Carpenter, M. B. and Suttin, J. Human Neuroanatomy. Eighth edition, Baltimore and London: Wilkins and Wilkins, 654-566, 1983.

Carr K.D. and Coons, E.E. Rats self administer nonrewarding brain stimulation to ameliorate aversion. Science, 215, 1516-1517, 1982. 
Chaouloff, F., Danguir,J., and Elghozi, J.L. Dextrofenfluramine, bot not 8-OH-DPAT affects the decrease in food consumed by rats submitted to physica! excercise. Pharmacology, Biochemistry, \& Behavior, 32, $573-576,1989$.

Clarke, A. and File S.E. Effects of ACTH, benzodiazepines and 5-HT antagonists on escape from periaqueductal grey stimulation in the rat. Prog. Neuro-Psychopharmacol \& Biol. Psychiatry, 6, 27-35, 1982.

Cooper, R.M., and Taylor, L.H. Thalamic reticular system and central grey: self stimulation. Science, 156, 102-103, 1967.

Cooper, B.R., Howard, J.L. and Soroko, F.E. Animal models used in prediction of antidepressant effects in man. $J$ Clin Psychiatry 44(5), 63-66, 1983.

Cooper J.R., Bllom, F.E. and Roth, R.H. The Biochemical Basis of Pharmacology, Oxford University Press, New York, Fifth edition, 1986.

Costa, E., Garattini, S., and Valzelli, L. Interactions between reserpine, chlorpromazine, and imipramine. Experientia,16, 461-463, 1960.

Cowen, P.J., Grahame-Smith, D.G., Green, A.R., and Heal D.J. Badrenoceptor agonists enhance 5-hydroxytryptamine-mediated 
behavioral responses. British Journal of Pharmacology, 76, 265-270, 1982.

Crews F.T, and Smith, C.B. Presynantir: ITha-receptor subsensitivity after long term antidepressant treatment. Science, 202, 322-324, 1978.

Davidson, M. and Toporek, J. BMDP 4V - General univariate and multivariate analysis of variance. BMDP Technical Report No. 67, BMDP Statistical Software, Los Angeles, 1986.

Doogan, D.P. Fluvoxamine as an antidepressant drug. Neuropharmacology, 19, 1215-1216, 1980.

Drago, F., Caccamo, G., Continella, G., and Scapagnini, U. Amphetamine induced analgesia does not involve brain opioids. European Journal of Pharmacology, 101, 267-269, 1984.

Dufresne, R.L., Weber SS, and Becker, R.E. Bupropion hydrochloride: new drug evaluation. Drug Intelligence and Clinical Pharmacy, 18, 957-964, 1984.

Dumbrille-Ross, A., and Tang, S.W. Noradrenergic and serotonergic input necessary for imipramine-induced changes in beta but not $\mathrm{S}_{2}$ receptor densities. Psychiatry Research, 9, 207-215, 1983. 
Enna, S.J., Mann, E., Kendall, D., Stancel, G.M. Effect of chronic antidepressant administration on brain neurotransmitter receptc binding. In Antidepressants: Neurochemical, Biochemical, and Clinical Perspectives, S.J. Enna , Malick, J.B., and Richelson, E. (eds), Raven Press, New York, 91-105, 1981.

Esposito, R. and Kornetsky, C. Morphine lowering of self stimulation thresholds: lack of tolerance with long-term administration. Science, 195, 189-191, 1977.

Fallon, J.H. Topographic organization of ascending dopaminergic projections. In The Mesocorticolimbic Dopamine System, P.W. Kalivas and C.B. Nemeroff (eds), The New York Academy of Sciences, New York, 1-9,1988.

Fibinger H.C., and Phillips, A.G. Increased intracranial self stimulation in rats after long term administration of desipramine. Science, 214, 683-5, 1981.

Fibiger, H.C. and Phillips, A.G. Mesocortical dopamine systems and reward. In The Mesocorticolimbic Dopamine System, P.W. Kalivas and C.B. Nemeroff (eds), The New York Academy of Sciences, New York, 206-215, 1988.

File S.E. and Tucker, J.C. Behavioral consequences of antidepressant treatment in rodents. Neuroscience and Behavioral Reviews, 10, $123-134,1986$. 
Frazer, A., Ordway, G., O'Donnell, J., Vos, P., and Wolfe, B. Effects of repeated administration of clenbuterol on the regulation of $B$ adrenoceptors in the central nervous system of the rat. In Antidepressants and Receptor Function, Ciba Foundation Symposium 123, Wiley, Chichester, 170-190, 1986.

Fuller, R.W. Pharmacological properties of seratonergic and antidepressant drugs. Journal of Clinical Psychiatry, 48(S-3),5-11, 1987.

Fuller, R.W. Enhancement of monoaminergic neurotransmission by antidepressant drugs. In Antidepressants, Neurochemical, Behavioral, and Clinical Perspectives, S.J. Enna, Malick, J.B., and Richelson, E. (Eds)., Raven Press, New York, 1-12, 1981.

Gandolfi O., Barbaccia, M.L., Chuang, D.M. and Costa, E. Daily bupropion injections for 3 weeks attenuate the NE stimulation of adenylate recognition sites in rat frontal coretx. Neuropharmacology, 22, 927-9, 1983.

Gonturkun, O., Grothues, A. Hautkappe, A., Vise, F., Wawrzyniak, N., and Zwilling, U. Serotonergic modulation of ingestive behavior in the pigeon. Pharmacology, Biochemistry, \& Behavior, 32, 415-420, 1989.

Goodwin F.K., Ebert M.H., and Bunney W.E. Mental effects of reserpine in man. A review. In: Shader R.I. (ed) Psychiatric 
Complications of Medical Drugs. Raven Press, New York, 73-101, 1972.

Goodwin, F.K. The biology of depression: conceptual issues. In Frontiers in Biochemical and Pharmacological Research in Depression, E. Usdin (ed), Raven Press, New York, 11-26, 1984.

Green, A.R., Cowen, P.J., Nimgaonkar, V.L., and Graham-Smith, D.G. Effect of $B_{2}$-adrenoceptor agonists on serotonin biochemistry and function. In E.Usdin (ed) Frontiers in Biochemical and Pharmacological Research in Depression, Raven Press, N.Y., 1984.

Green, A.R., Hall, J.E., and Rees, A.R. A behavioral and biochemical study in rats of 5-hydroxytryptamine receptor agonists and antagonists, with observation of structure-activity requirements for the agonists. British Journal of Pharmacology, 73, 703-719, 1981.

Grob, G., Hante, K., and Gothert, M. Effect of antidepressant and neuroleptic drugs on the electrically evoked release of serotonin from rat cerebral cortex. Psychopharmacology, 91, 175-181, 1987.

Harrison-Read, P.E., and Steinberg, H. Tricyclic antidepressant drugs and individual differences in the exploratory activity of rats: Contrasting effects of tertiary and secondary amine compounds. Psychopharmacology, 69, 85-91, 1980 . 
Hoebel BG, Teitlebaum, P. Hypothalamic control of feeding and self stimulation. Science, 135, 357-377, 1962.

Horovitz 7.P., M. Chow and Carlton, P.L. Self stimulation of the brain by cats; technique and preliminary drug effects. Psychopharmacologia, 3:449-454, 1962.

Howard J.L., Sorpko, F.E. and Cooper, B.R. Empirical Behavioral Models of Depression, with Emphasis on Tetrabenazine Antagonism. In Antidepressants: Neurochemical, Behavioral, and Clinical Perspectives, S.J. Enna, Malick, J.B., and Richelson, E. (eds), Raven Press, New York, 107-120, 1981.

Hubner C.B., Bain G.T., and Kornetsky C. : The combined effect of morphine and $\mathrm{D}$-amphetamine on the threshold forbrain stimulation reward. Pharmacology, Biochemistry, and Behavior, 28(2), 311-315, 1987.

Izenwasser S.E. and Kornetsky, C. Pharmacological effects of morphine on brain reward. Psychopharmacology, 93, 136-137, 1987.

Katz, R.J. and Carroll, B.J. Intracranial reward after Lilly 110140 (Fluoxetine HCL): Evidence for an inhibitory role for serotonin. Psychopharmacology, 51, 189-193, 1977. 
Katz, R.J. Animal model of depression: pharmacological sensitivity of a hedonic deficit. Pharmacology, Biochemistry, and Behavior, 16, 965-968, 1982.

Kelley, A.E. and Cador, M. Behavioral evidence for differential neuropeptide modulation of the mesolimbic dopamine system. In The Mesocorticolimbic Dopamine System, P.W. Kalivas and C.B. Nemeroff (eds), The New York Academy of Sciences, New York, 415444, 1988.

Kokkinidis, L. and Zacharko, RM. Response sensitization and depression following long term amphetamine tretament in a self stimulation paradigm. Psychopharmacology, 68, 73-76, 1980.

Koop, G.F. Incentive shifts in intracranial self-stimulation produced by a different series of stimulus intensity presentations. Physiology and Behavior, 18, 131-135, 1977.

Kornetsky, C., Esposito, R.U., McLean, S., and Jacobson, J.O. Intracranial self-stimulation thresholds: a model for hedonic effects of drugs of abuse. Archives of General Psychiatry, 36, 289-292, 1979.

Kornetsky C., Bain G. : Biobehavioral basis of the reinforcing properties of opiate drugs. Ann NY Acad Sci, 398, 241-59, 1982.

Kornetsky, C. Brain-stimulation reward: A model for the neuronal bases for drug-induced euphoria. In Brown, R.M., Friedman, D.P., and 
Nimit, Y., (eds.) Neuroscience Methods in Drug Abuse Research. National Institute on Drug Abuse Research Monograph 62, DHSS Publication No. (ADM) 85-1415, Washington, D.C.: Superintendent of Documents, U.S. Government Printing Office, 30-50, 1985.

Kostowski, W., Plaznik, A., and Danysz, W. The role of the locus coeruleus-limbic noradrenergic transmission in the action of antidepressant drugs. Psychopharmacology Bulletin, 22(2), 512-522, 1986.

Kulkarni, S.K. and Dandiya, P.C. Effects of antidepressant agents on open field behavior in rats. Psychopharmacologia, 33, 333-338, 1973.

Lecubier Y., Peuch A., Jouvent, A.J., Simon, P. and Widlocher, D: A beta-adrenergic stimulant (salbutamol) versus clomipramine in depression: a controlled study. British Journal of Psychiatry, 136 $354-358$.

Liebman J.M. Discriminating between reward and performance, a critical review of intracranial self stimulatiion methodology. Neuroscience and Biobehavioral Reviews, 7,45-72, 1983.

Liebman, J.F., Hall, N.R., Prowse, J., Gerhardt, S., Noreila, L., and Fenton, H.M. Comparitive effetcs of $B_{2}$-adrenoceptor agonists on intracranial self-stimulation, Sidman avoidance, and motor activity in rats. Psychopharmacology, 84, 336-341, 1984. 
Leibowitz, S.F. Hypothalamic paraventricular nucleus: interaction between a2-noradrenergic system and circulating hormones and nutrients in relation to energy balance. Neuroscience \& Biobehavioral Reviews, 12, 101-109, 1988.

Leith N.J. and Barrett R.J.: Amphetamine and the reward system: evidence for tolerance and post drug depression. Psychopharmacology, 46,19-25, 1976.

Leith N.J. and Barrett R.J. Effects of chronic amphetamine or reserpine on self stimulation: animal model of depression? Psychopharmacology,72,9-15, 1980.

Leith N.J. and Barrett R.J. Self-stimulation and amphetamine: Tolerance to $d$ and $l$ isomers and cross tolerance to cocaine and methylphendidate. Psychopharmacology,74,23-28, 1981.

Leshner, A., Remier, H., Biegnon, A., and Samuel D. Desmethylimipramine (DMI) counteracts learned helplessness in rats. Psychopharmacology, 66, 207-208, 1979.

Linnoila, M., Karoum, F., and Potter, W.Z. Phenylethylamine and tyramine outputs in parients with affective disorders: behavioral and biochemical correlates. In Frontiers in Biochemical and Pharmacological Research in Depression, E. Usdin (ed), Raven Press, New York, 153-157, 1984. 
Lorens, S.A., Mitchel, C.L. Influence of morphine on lateral hypothalamic self-stimulation in the rat. Psychopharmacologia, 32, $271-277,1973$.

Lorens, S.A. Comparison of the effects of morphine on hypothalamic and medial frontal cortex self-stimulation in the rat. Psychopharmacology, 48, 217-224, 1976.

Maciewicz, R. and Martin, J.B. Pain: pathophysiology and management. In Harrison's Principles of Internal Medicine, Eds. Braunwald, E., Isselbacher, K.J., Petersdorf, R.G., Wilson, J.D., Martin, J.B., and Fauci, A.S. Eleventh edition, 13-17, 1987.

Malick, J.B. Yohimbine potentiation as a predictor of antidepressant action. In Antidepressants: Neurochemical, Biochemical, and Clinical Perspectives, S.J. Enna, Malick, J.B., and Richelson, E. (eds), Raven Press, New York, 141-155, 1981.

Marcus $\mathrm{R}$ and Kornetsky $\mathrm{C}$. Negative and positive intracranial reinforcement thresholds: effects of morphine. Psychopharmacologia, 38:1-13, 1974.

McClelland, R.C., Sarfaty, T., Hernandez, L., and Hoebel, B.G. The appetite suppressant, d-Fenfluramine, decreases self-stimulation at a feeding site in the lateral hypothalamus. Pharmacology, Biochemistry, \& Behavior, 32, 411-414, 1989. 
McMillen, B.A., Warmack, W., German,D.C., and Shore, P.A. Effects of chronic desipramine treatment on rat brain noradrenergic responses to a-adrenzrgic drugs. European Journal of Pharmacology, 61, 239246, 1980.

Mendels, J. Clinical experience with serotonin reuptake inhibiting antidepressants. Journal of Clinical Psychiatry, 48(3S), 26-30, 1987.

Miller WR, Rosellini RA, and Seligman MEP. Learned helplessness and depression. In Psychopathology: Experimental Models, Eds. Maser JD and Seligman, MEP, W.H. Freeman and Company, San Francisco, pp 104-130, 1977.

Minneman, K.P., Dibner, M.D., Wolfe, B.B., and Molinoff, P.B. B1- and B2-adrenergic receptors in rat cerebral cortex are independently regulated. Science, 204, 866-868, 1979.

Minneman, K.P., Pittman, R.N., and Molinoff, P.B. B-adrenergic receptor subtypes: Properties, distribution, and regulation. Annual Review of Neurosciences, 4, 419-461, 1981.

Mishra, R., Janowsky, A., and Sulser, F. Subsensitivity of the Norepinephrine (NE) receptor coupled adenylate cyclase system in brain: Effects of nisoxetine vs fluoxetine. European Journal of Pharmacology, 60, 379-382. 
Mobley, P.L. and Sulser, F. Down-regulation of the central noradrenergic receptor system by antidepressant therapies:

Biochemical and clinical aspects. In Antidepressants: Neurochemical, Biochemical, and Clinical Perspectives, S.J. Enna, Malick, J.B., and Richelson, E. (eds), Raven Press, New York, 31-47, 1981.

Mogenson, G.J., Jones, D.L., and Yu, C.Y. From motivation to action: functional interface between the limbic system and the motor system. Progress in Neurobiology, 14, 69-97, 1980.

Mogilnicka, E. The effects of acute and repeated treatments with salbutamol, a B-adrenoceptor agonist, on clondine induced hypoactivity in rats. Journal of Neural Transmission, 53, 117-126, 1982.

Morato de Carvalho, S., Aguiar, J.C., and Graeff, F.G. Effects of minor tranqilizers, tryptamine antagonists, and amphetamine on behavior punished by brain stimulation. Pharmacology, Biochemistry, \& Behavior, 15, 351-356, 1981.

Nielsen, J.A., Shannon, N.J., Bero, L. and Moore, K.E. Effects of acute and chronic bupropion on locomotor activity and dopaminergic neurons. Pharmacology, Biochemistry, \& Behavior, 24,795-799, 1986 
Olds J. Effects of hunger and male sex hormone on self stimulation of the brain. Journal of Comparitive Physiological Psychology, 51, 320$324,1958$.

Olds J. and Travis, R.: The effects of chlorpromazine, meprobamate, pentobarbital, and morphine on self-stimulation. Journal of Pharmacology and Experimental Therapeutics,128, 397-404, 1959.

Olds, J. Hypothalamic substrates of reward. Physiology Review, 42, $554-604,1962$.

Olds, J., Yuwiler, A., Olds, M.E., and Yun, C. Neurohumors in hypothalamic substrates of reward. American Journal of Physiology, 207(1), 242-254, 1964.

Olds, M. E. Inhibitory evoked unit activity in the medial forebrain bundle in the rat and self-stimulation behavior. Neuropharmacology, $17,515-523,1978$.

Olds M.E., and Olds J. Pharmacological patterns in subcortical reinforcement behavior. International Journal of Neuropharmacology, 2, 309-325, 1964.

Olds, M.E. The central basis of motivation: intracranial selfstimulation studies. Annual Review of Psychology, 32, 523-574, 1981 . 
O'Neill, K. A. Acute and chronic effects of antidepressants on opiate systems. Doctor of Philosophy Dissertation, University of Rhode Island, 1983.

O'Rourke, D.A., Wurtman, J.J., Brezezinski, A., Nader, T.A., and Chew, B. Serotonin implicated in etiology of seasonal affective disorder. Psychopharmacology Bulletin, 23(2), 358-359, 1987.

Peroutka, S.J., and Snyder, S.H. Interactions of antidepressants with neurotransmitter receptor sites. In, Antidepressants, Neurochemical, Behavioral, and Clinical Perspectives, S.J. Enna, Malick, J.B., and Richelson, E. (Eds)., Raven Press, New York, 75-89, 1981.

Pert, A. and Hulsebus, R. Effect of morphine on intracranial selfstimulation behavior following brain amine depletion. Life Sciences, 17, 19-20, 1975.

Porsolt, R.D. Behavioral despair. In Antidepressants: Neurochemical, Biochemical, and Clinical Perspectives, S.J. Enna, Malick, J.B., and Richelson, E. (eds), Raven Press, New York, 121-139, 1981.

Prado-Alcala, R.A., Kent, E.W., and Reid, L.D. Intracranial selfstimulation effects along the route of the nigrostriatal bundle. Brain Research, 84, 531-540, 1975.

Przegalinski, E., Baran, L. and Siwanowicz, J. The effect of chronic treatment with antidepressant drugs on salbutamol induced 
hypoactivity in rats. Psychopharmacology (Berlin), 80, 355-359, 1983.

Quetsch, R.M., Anchor, R.W., Litin, E.M. Depressive reactions in hypertensive patients. A comparison of those treated with Rawolfia and those receiving no specific antihypertensive treatment. Circulation, 19, 366-375, 1959.

Riccitelli A., Valentino, D., and Dufresne R.L. Effects of Chronic Desmethylimipramine Treatment on Brain Stimulation Reward Thresholds in the rat. Presented at the eighteenth annual meeting of New England Pharmacologists, Omni-Parker Hotel, Boston, Massachusetts, on February 4, 1989.

Routenberg, A. The reward system of the brain. Scientific American, 239, 154-164, 1975.

Sasson, S., Unterwald, E.M., and Kornetsky, C. Potentiation of morphine analgesia by d-amphetamine. Psychopharmacology, 90, $163-165,1986$.

Schmidt, M.J. and Thornberry, J.F. Norepinephrine-stimulated cyclic AMP accumulation in brain slices in vitro after serotonin depletion or chronic administration of selective amine reuptake inhibitors. Archives of International Pharmacodynamics, 229, 42-51, 1977. 
Sellinger-Barnette, MM, Mendels J, and Frazer, A. The effect of Psychoactive drugs on beta adrenergic receptor binding sites in rat brain. Neuropharmacology, 19, 447-454, 1980.

Seymour, P.A. The effects of desipramine, mianserin, and yohimbine on alpha2-adrenoceptor functional sensitivity in the rat: a behavioral analysis. Doctoral of Philosophy Dissertation, University of Rhode Island, 1984.

Shillito, E.E. A method $r$ investigating the effects of drugs on the exploratory behavior of ce. British Journal of Pharmacology, 40, $113-123,1970$.

Shopsin B, Cassano, G.B., and Conti, L. An overview of new "second generation" antidepressant compounds, research and treatment implications. In, Antidepressants, Neurochemical, Behavioral, and Clinical Perspectives, Eds. S.J. Enna et al., Raven Press, New York, 1981.

Stahl, S.M., Beer, M.S., Hacker, S.A., Poat, J.A., and Iversen, L.L. Beta1and Beta2-Adrenoceptor regulation in rat nervous system by chronic treatment with desipramine and beta adrenoceptor agonists. Psychopharmacology Bulletin, 23(3), 473-475, 1987.

Stark, P., Fuller, R.W., and Wong, D.T. The pharmacological profile of fluoxetine. Journal of Clinical Psychiatry, 46(3) 7-13, 1985. 
Sulser, F., Owens, M.L., and Dingell, J.V. On the mechanism of amphetamine potentiation of amphteamine by desipramine. Life Science, 5, 2005-2010, 1966.

Sulser, F., Vetulani, J., and Mobley, P.L. Mode of action of antidepressant drugs. Biochemical Pharmacology, 27, 257-261, 1978.

Stein, L. : Effects and Interactions of Imipramine, Chlorpromazine, Reserpine, and Amphetamine on Self-Stimulation: Possible neurophysiological basis of depression. Recent Advances in Biological Psychiatry, 4, 288-308, 1962.

Sulser, F. Serotonin-norepinephrine receptor interactions in the brain: Implications for the pharmacology and pathophysiology of affective disorders. Journal of Clinical Psychiatry, 48(S3), 12-18, 1987.

Tucker, J.C. and File, S.E. The effects of tricyclic and 'atypical' antidepressants on spontaneous locomotor activity in rodents. Neuroscience and Biobehavioral Reviews, 10, 115-121, 1986.

Unterwald E.M., and Kornetsky C. Effects of nalbuphine alone and in combination with tripelennamine on rewarding brain stimulation thresholds in the rat. Pharmacology, Biochemistry, and Behavior, 25,629-632, 1986 . 
Wamsley JK, Byerley WF, McCabe T, McConnell, E.J., Dawson. T.M., and Grosser, B.I. Receptor alterations with serotonergic agents. ournal of Clinical Psychiatry, 48(S3), 19-25, 1987.

Wessinger, W.D. Approaches to the study of drug interactions in behavioral pharmacology. Neuroscience \& Biobehavioral Reviews, 10, 103-113, 1986.

Wilner, P. The validity of animal models of depression. Psychopharmacology, 83,1-16, 1984.

Winer, BJ. Statistical Principles in Experimental Design. McGraw-Hill, Inc., New York, 1971.

Wise, R.A. Psychomotor stimulant properties of addictive drugs. In The Mesocorticolimbic Dopamine System, P.W. Kalivas and C.B. Nemeroff (eds), The New York Academy of Sciences, New York, 228$234,1988$.

Zacharko, R.M., Bowkers, W.J., Kelley, M.S., and Anisman, H. Prevention of stressor induced disturbances of self-stimulation by desmethylimipramine. Brain Research, 321, 175-179, 1984.

Zarevics, P., and Setler, P.E. Effects of gabaergic drugs on brain stimulation reward as assessed by a threshold method. Brain Research, 215, 201-209, 1981. 
Zebrowska-Lupina, I. Presynaptic alpha-adrenoceptors and the action of tricyclic antidepressant drugs in behavioral despair in rats. Psychopharmacology, 71,169-172, 1980. 